STUDY ABROAD FOR STUDENTS OF COLOR:

A THIRD SPACE FOR NEGOTIATING AGENCY AND IDENTITY

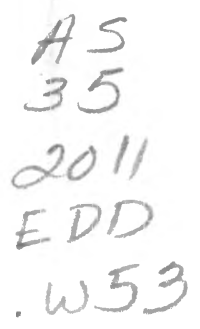

A dissertation submitted to the faculty of

San Francisco State University

in partial fulfillment of

the Requirements for

the Degree

Doctor of Education

in

Educational Leadership

by

David John Wick

San Francisco, California

May 2011 


\section{Copyright by}

David John Wick

2011 


\section{CERTIFICATION OF APPROVAL}

I certify that I have read Study Abroad For Students Of Color: A Third Space For Negotiating Agency And Identity by David John Wick, and that in my opinion this work meets the criteria for approving a dissertation submitted in partial fulfillment of the requirements for the degree: Doctor of Education in Educational Leadership at San Francisco State University.

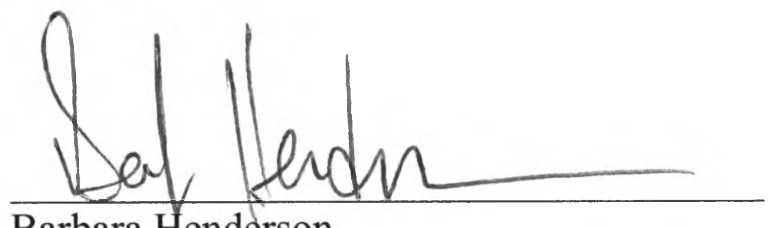

Barbara Henderson

Professor

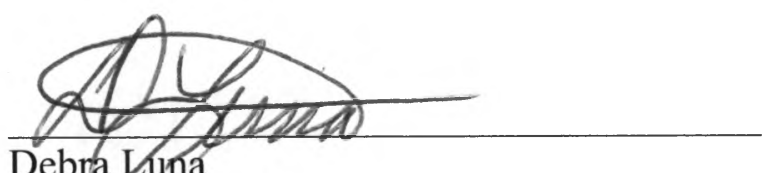

Debra buna

Associate Professor

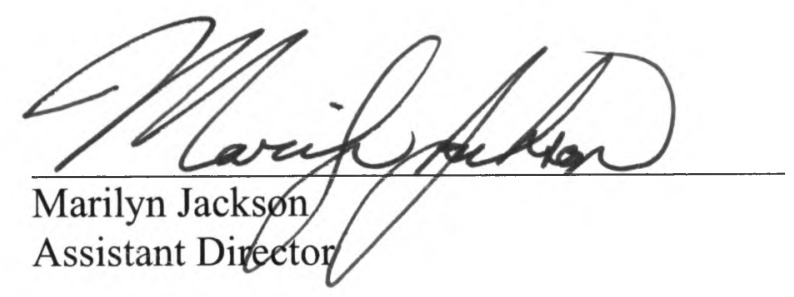




\title{
STUDY ABROAD FOR STUDENTS OF COLOR: A THIRD SPACE FOR NEGOTIATING AGENCY AND IDENTITY
}

\author{
David John Wick \\ San Francisco State University \\ 2011
}

Consistently low levels of study abroad participation by students of color have fueled extensive anecdotal advice literature and a few empirical studies that examined perceived barriers to access. Literature that explores the experiences of students of color who studied abroad remains extremely limited. The primary goal of this research was to add the narratives of study abroad of students of color to the literature. Documenting these experiences allowed me to investigate the role of identity in the study abroad process and to develop a conceptual framework of the study abroad experience for students of color from a Critical Race Theory perspective. This longitudinal qualitative research included 47 study abroad returnees who participated in six interviews and five focus groups that took place 3-6 and 12-18 months after return. Participants had studied abroad for a semester or year in cross-cultural immersion programs in 16 countries. The findings indicated that study abroad was a unique context for leveraging and building social and cultural capital, critically negotiating intersecting identities, and developing agency. These results helped to re-conceptualize study abroad as a transformative process that begins when students first believe that it is possible and continues well beyond return. Additionally, these findings suggested that study abroad acts as a Third Space for students of color in which they can freely reconsider their social locations and the impact that they want to have on the world. The student narratives in this study lent support to arguments that study abroad can promote citizenship, democratization, and humanization for participants and their host communities.

I certify that the Abstract is a correct representation of the content of this dissertation.

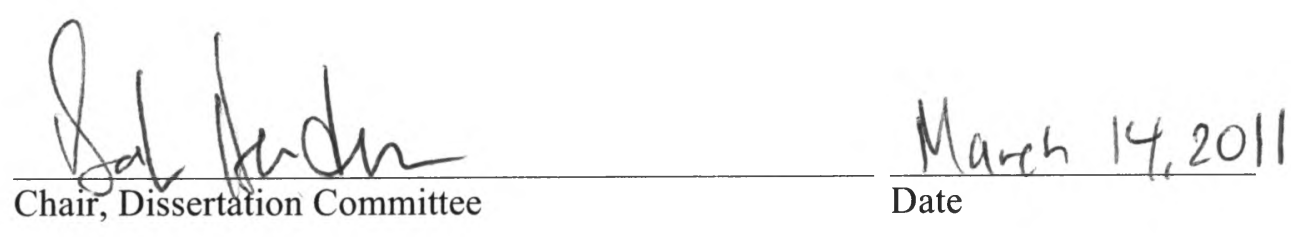




\section{ACKNOWLEDGEMENTS}

When I began writing this dissertation I had no idea how many others would be an integral part of my process. Over the last two years I was:

- humbled by the generosity of the 47 participants,

- challenged by critical colleagues to see my research in a larger context,

- honored by the research assistants who volunteered their time,

- inspired by the committed educators in Ed.D. Cohort 2008,

- guided by my advisor and committee,

- motivated by the passion of my colleagues in international education,

- encouraged by friends,

- $\quad$ soothed by my mother, who had done this before,

- and loved by my wife.

I deeply appreciate these contributions to this work. It would not have been possible without them. 


\section{TABLE OF CONTENTS}

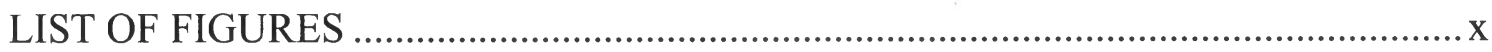

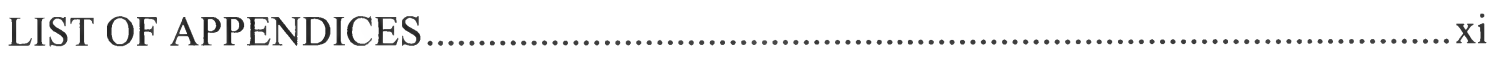

Chapter One: Purpose of the Study ...................................................................... 1

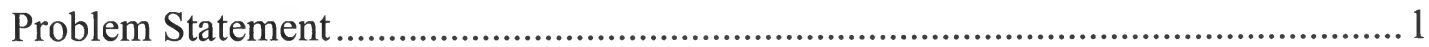

Purpose of the Study ................................................................................... 3

Research Question and Propositions.................................................................. 4

Research Propositions .......................................................................... 5

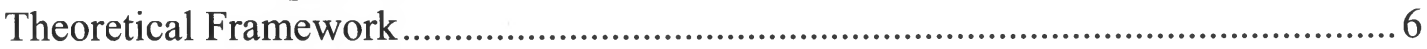

Critical Race Theory ........................................................................... 7

Social and Cultural Capital ..................................................................... 7

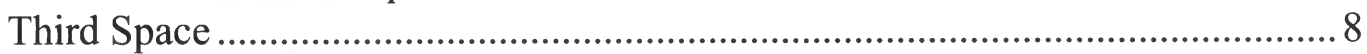

From identity development to identity negotiation......................................... 9

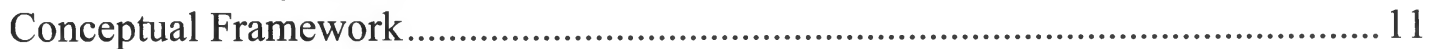

Operational Definitions of Key Terms ................................................................ 13

Statement of Delimitations and Scope of Study .................................................... 14

Significance of the Study ............................................................................... 15

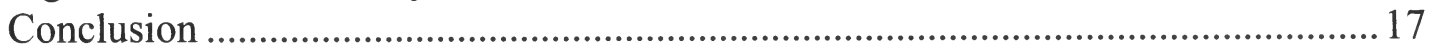

Chapter Two: Review of Literature on Study Abroad Students of Color...................... 19

Background on Study Abroad Students of Color ................................................ 19

Problem Statement: Narratives Missing, Inequitable Context Unexamined ......23

Scope of the Review ................................................................................... 24

Databases Accessed and Keywords Searched ................................................ 24

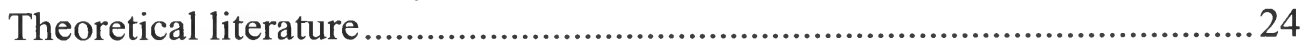

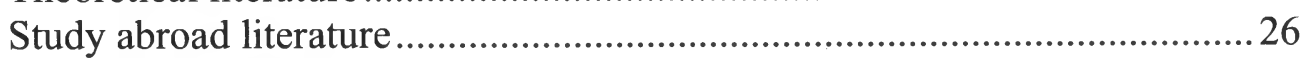

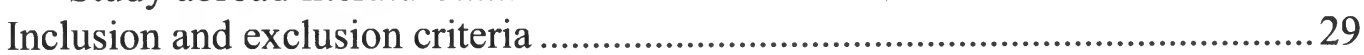

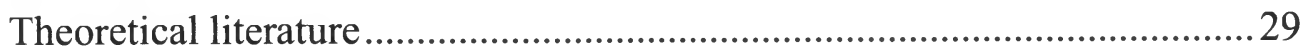

Study abroad literature .......................................................................29

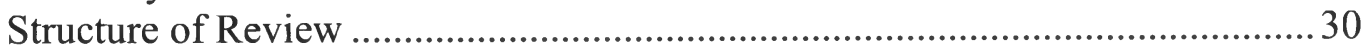

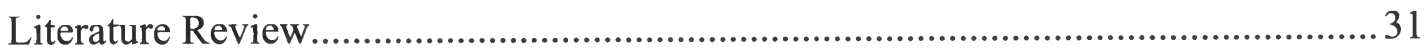

Why should students of color study abroad? ............................................. 31 


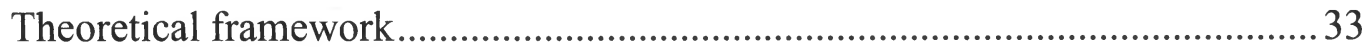

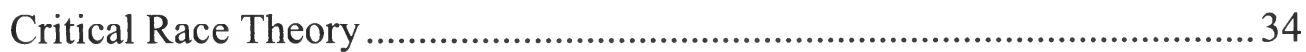

From social and cultural capital to community cultural wealth......................37

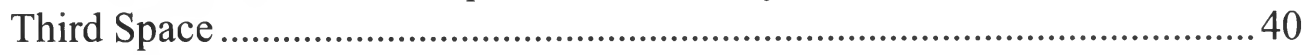

From identity development to negotiating identity........................................ 41

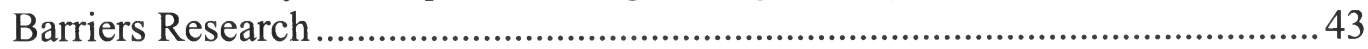

Study abroad not relevant, not for me......................................................... 44

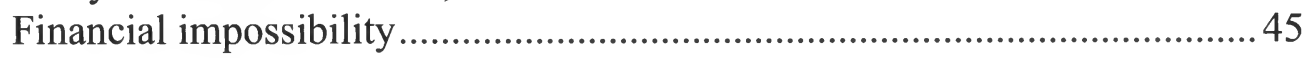

Family concerns and closeness ................................................................... 47

Fear of racism abroad and safety concerns ..................................................... 47

Academic concerns: time to graduation, relevance, and more ....................... 48

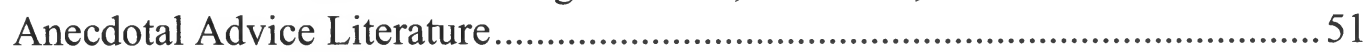

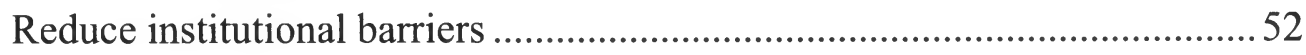

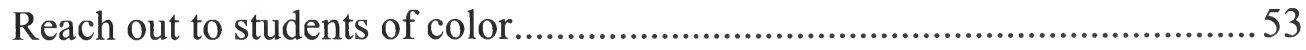

Heritage seeking programs of short duration..................................................5 53

Address race and build capital ......................................................................54

When Students of Color Study Abroad: Outcomes and Experiences...................55

The state of study abroad outcomes research ..................................................55

Limited research on study abroad students of color .......................................57

Heritage sought but not found.......................................................................5

Rethinking identity through study abroad.......................................................66 61

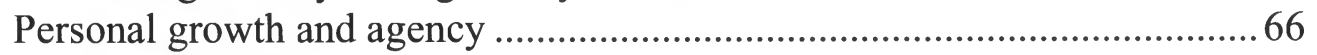

Conclusions and Implications ...............................................................................66

Chapter Three: Methodology …………………………................................................ 70

Research Question and Guiding Propositions.......................................................... 72

Research Propositions ....................................................................................... 73

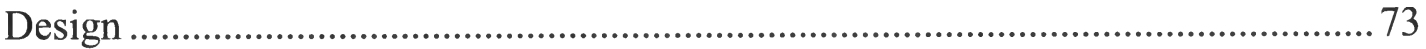

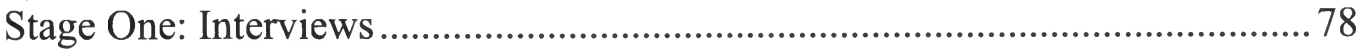

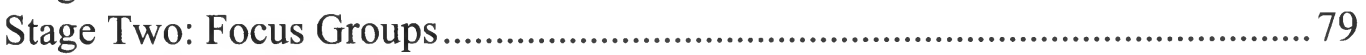

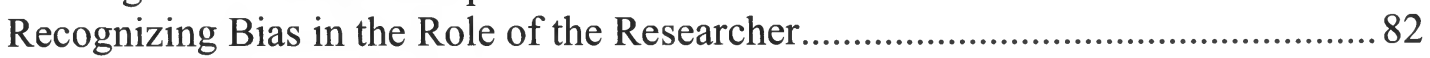

My Relationship to Participants and Institution.................................................. 83

Relationships in Participatory Research ........................................................ 84

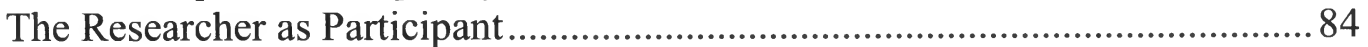

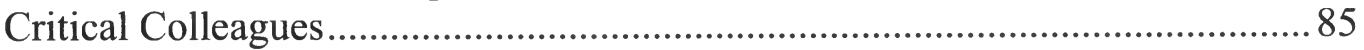

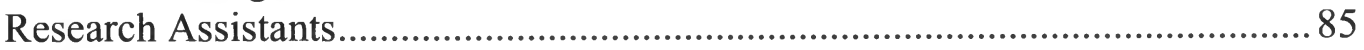

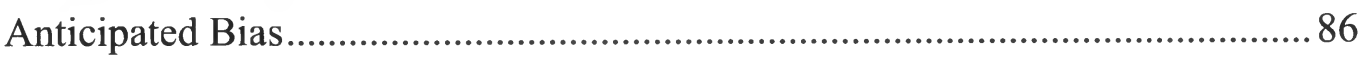

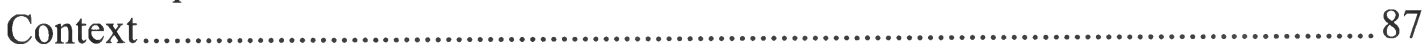

Participant Selection .............................................................................................. 89 
Interview Participants ...................................................................................... 90

Focus Group Participants................................................................................ 91

Ethics and Protection of Human Subjects................................................................99

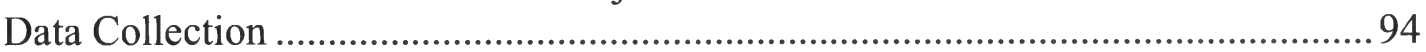

Validity and Transferability ................................................................................99

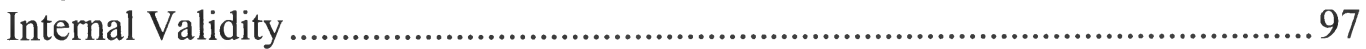

External Validity and Transferability ................................................................98

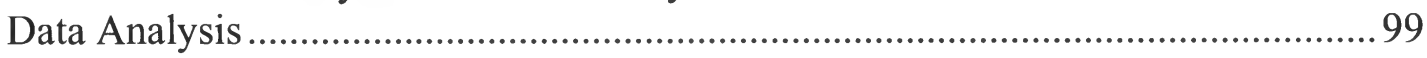

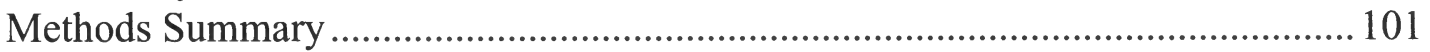

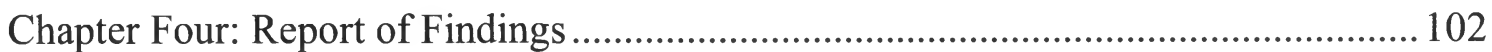

The Findings: Study Abroad as a Process and Third Space Abroad ....................... 103

Capital: Leveraging Capital and Wealth........................................................... 107

Capital: Focal participant Christine ............................................................ 108

Social capital from family in the U.S....................................................... 111

Social capital from family abroad............................................................. 114

Cultural capital from past travel experiences................................................117

Social capital from peers and mentors .......................................................... 121

Social and cultural capital from the study abroad office ............................. 122

Global capital from global networks and experiences .................................. 124

Identity: Negotiating Intersecting Identities Abroad .......................................... 126

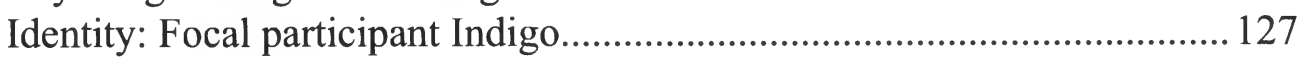

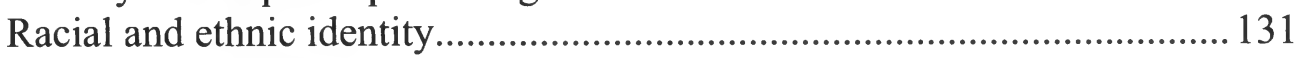

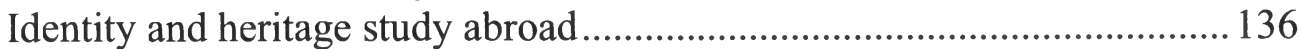

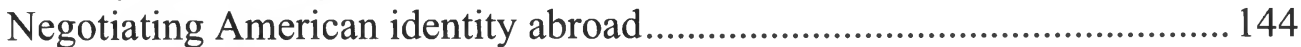

Obama's impact on American identities abroad ............................................ 150

Negotiating a global identity.................................................................... 152

Agency: Confidence, Commitment, and Engagement........................................ 154

Agency: Focal participant Jackie ................................................................. 155

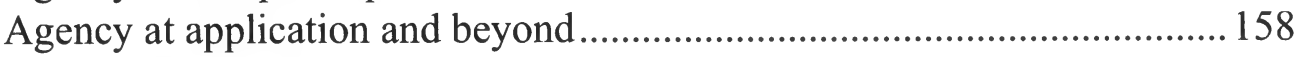

Agency through new experiences ................................................................. 159

Agency through a critical lens ..................................................................... 162

Agency as global citizenship ..................................................................... 163

Summary and Synthesis ....................................................................................... 165

Chapter Five: Discussion and Recommendations...................................................... 167

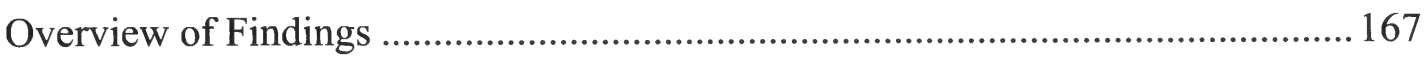

Interpretation of Findings .................................................................................... 170

Study abroad as a process ......................................................................... 171 
Third Space while abroad ............................................................................ 173

Importance of racial and ethnic heritage.................................................... 173

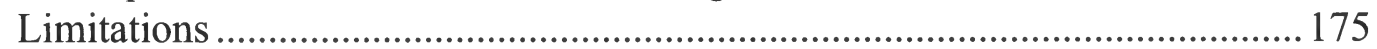

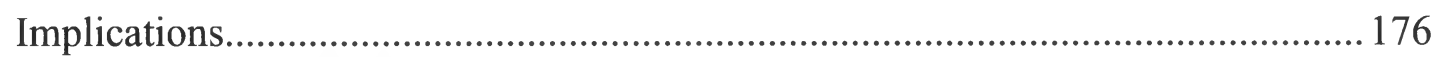

Implications for leadership .................................................................... 177

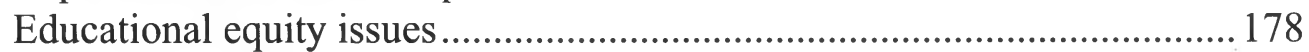

Study abroad policy issues...................................................................... 179

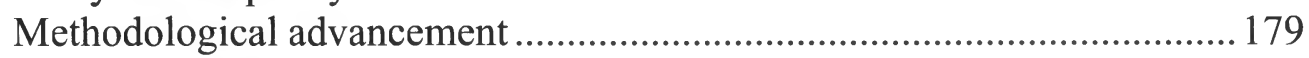

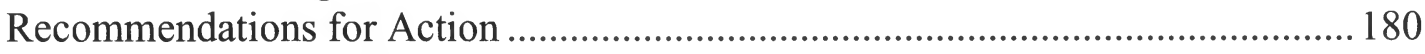

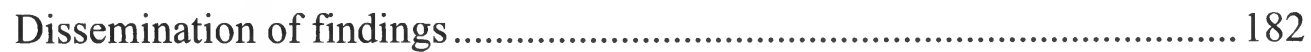

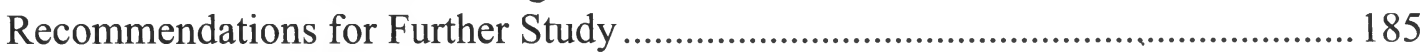

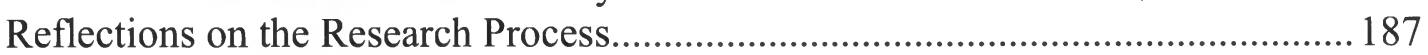

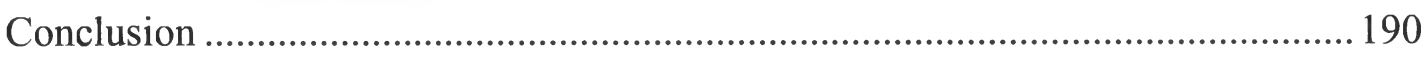

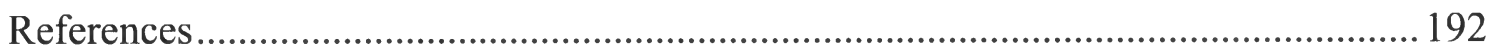




\section{LIST OF FIGURES}

Figure

Page

1. Theoretical Framework ............................................................................... 6

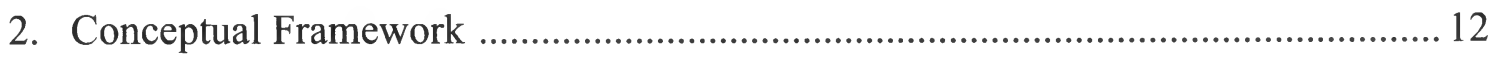

3. Students of Color in Higher Education and Study Abroad ................................... 22

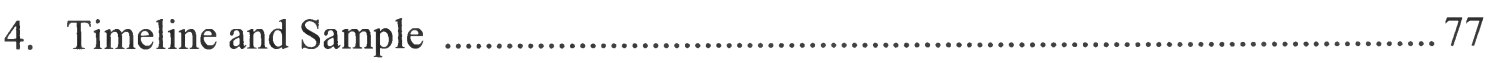

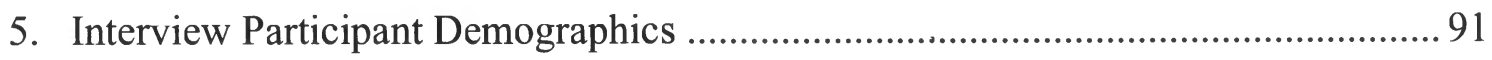

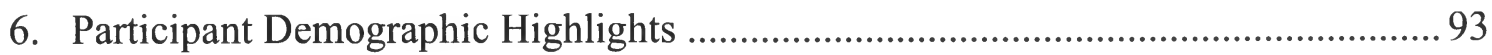

7. Diagram of Relationships in Findings ......................................................... 107

8. Heritage-Seeking Participants by Country ...................................................... 138 


\section{LIST OF APPENDICES}

Appendix Page

A. Participant Demographics with Study Locations....................................................... 203

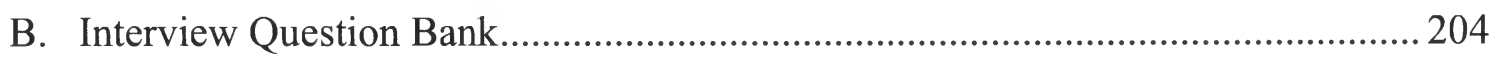

C. Focus Group Question Bank .................................................................................. 205

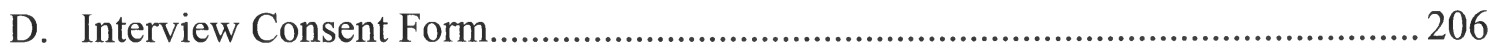

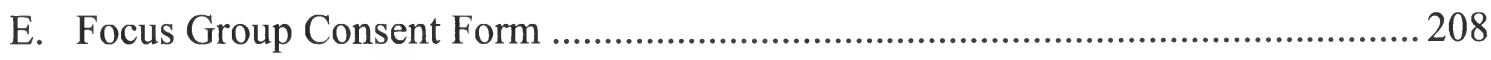

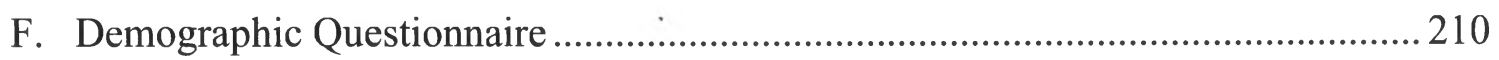


Chapter One: Purpose of the Study

I began this research by examining persistent underrepresentation of students of color on study abroad as an issue of inequitable access. As a study abroad advisor, I believed that this underrepresentation was a problem because of my view that study abroad is an essential component of higher education. From what I had seen, students make academic progress, increase intercultural sensitivity, and gain global competence by studying abroad. Current rhetoric about globalization suggests that these skills are necessary for success in today's world. Thus, denying students of color this experience creates a new achievement gap in global competency, which would hinder them in the job market. To me, these factors made access to study abroad an equity issue.

As I continued to read about the educational experiences of people of color in the U.S. and in higher education I came to recognize underrepresentation in study abroad as a symptom of systemic inequity. I also recognized that access alone was not enough to ensure equity. Finally, I came to question the assumption that study abroad has the same benefits for all students. These three realizations led me to the current research on the study abroad experiences of students of color.

\section{Problem Statement}

Persistent underrepresentation of students of color in study abroad programs has driven decades of debate on how to effectively reach this student group (Chow \& Bhandari, 2010; Comp, 2008). This debate has centered around increasing access based 
on the assumption that study abroad is good for all students and therefore should be equally accessible (Commission on the Abraham Lincoln Study Abroad Fellowship Program, 2005; Martinez, Ranjeet, \& Marx, 2009; Murray Brux \& Fry, 2010; Obst, Bhandari, \& Witherell, 2007; Raby, 2008). There is room to question the good that study abroad produces. Despite decades of research on the academic, personal, and professional benefits of study abroad there is no broad agreement in the empirical research on its effects as noted by (Guerrero, 2006; McClure, Szelenyi, Niehaus, Anderson, \& Reed, 2010). Empirical research on study abroad students of color is extremely limited, as documented in two recent dissertations (Guerrero, 2006; Jackson, 2006), making it impossible to ascertain its impact on this group of students.

Most of the rationales for study abroad emphasize its role in preparing students to compete in the global economy. This rationale for study abroad as development of human capital is rooted in neoliberal ideas of education as described by (Coleman, 1988; Gradstein, Justman, \& Meier, 2005). Critical Race Theorists (CRT) have challenged neoliberal agendas for education and proposed broader goals related to equity and social justice (Duncan-Andrade \& Morrell, 2008; Giroux, 1997; LadsonBillings \& Tate, 1995; Yosso, 2005). Even the limited research on study abroad experiences of students of color suggests that the unique nature of study abroad and its transformative impact may contribute to Critical Race Theory's (CRT) goals of reducing inequity (Day-Vines, Barker, \& Exum, 1998; Guerrero, 2006; Jackson, 2006; 
Landau \& Moore, 2001; Morgan, Mwegelo, \& Turner, 2002; Talburt \& Stewart, 1999). Therefore, using a CRT framework to examine how study abroad facilitates identity negotiation and relates to social and cultural capital for students of color may suggest benefits of participation that lead to increased equity in the U.S. and abroad. Purpose of the Study

The primary purpose of this study was to amplify the perspectives of study abroad students of color by adding their narratives to the literature. These narratives provided a lens to critically reexamine the study abroad literature on students of color that includes anecdotal advice literature, barriers research, and outcomes research. This research focuses on the role of study abroad in relationship to identity negotiation because of the power that perceptions of racial, ethnic, and national identity can have in disrupting social and cultural reproduction of inequity. It also emphasizes social and cultural capital because of their importance in educational success for students of color. Gaining the perspectives of study abroad students of color through narratives facilitated my examination of the process of negotiating the intersections of race, ethnicity, and other social locations through study abroad. Through this literature review and research I developed a conceptual framework that documents the nature of the study abroad process for students of color. This conceptual framework suggests that participation in study abroad may have an emancipatory effect. 
Concerns about access to study abroad for students of color coupled with calls for broader participation are based on a belief that study abroad is an essential part of higher education for all students. Yet so little is known about the study abroad experiences of students of color that it is difficult to defend this assertion. Empirical studies published to date include a total of 26 study abroad students of color; all participants in these studies are African-American and studied in either Ghana or Spain (Day-Vines, et al., 1998; Landau \& Moore, 2001; Morgan, et al., 2002; Talburt \& Stewart, 1999). These empirical studies are supplemented by four recent dissertations that contain analyses of the study abroad experiences of students of color (Guerrero, 2006; Jackson, 2006; Souders, 2009; Young, 2009). The diversity of program type and duration in this empirical and dissertation research make it difficult to generalize the findings across the studies. By focusing on the study abroad experiences of students of color participating in one type of program the results of this study may provide more transferable insights that lead professionals to design systems that focus on increasing equity from access to outcomes.

\section{Research Question and Propositions}

The guiding question for my research was: How does the study abroad experience shape the identity and goals of college students of color? I approached this question from a qualitative perspective. This perspective emphasizes inductive reasoning, allows the findings to emerge from the data, and facilitates development of 
new theoretical frameworks (Bogdan \& Biklen, 2008). This research approach was well suited for examining identity negotiation during study abroad for students of color since the topic has not been fully defined in the literature.

I based my methodology on Critical Race Theory (Ladson-Billings \& Tate, 1995; Solorzano \& Yosso, 2001; Yosso, 2005). This theoretical perspective has been absent from the study abroad literature and is essential to understanding the experiences of people of color in the U.S. Using this framework guided my emphasis on student narratives and supports my focus on identity negotiation and the role of social and cultural capital in the study abroad process.

\section{Research Propositions}

These research propositions guided my research process.

- Study abroad should not be accepted as an unquestioned good for all students. Its benefits must be examined and may not be the same for all populations.

- Participation in study abroad requires social and cultural capital.

- Race and identity are central to the study abroad experiences of students of color.

- Study abroad creates opportunities for students of color to renegotiate their identity because intersectionality of race, class, and gender play out differently in a new cultural context.

- The process of identity development while abroad may augment the social and cultural capital that study abroad students of color leverage throughout the study abroad process. 
- The narratives of students of color will reveal strategies and skills that help these students benefit from study abroad.

\section{Theoretical Framework}

My theoretical framework consists of four interrelated constructs. These are Critical Race Theory (CRT), social and cultural capital, Third Space, and identity theories. CRT guided this investigation and informed my reading of the other three theories. I kept CRT central to my investigation by focusing on the intersections of CRT with social and cultural capital theories, Third Space, and identity theories as shown in Figure 1.

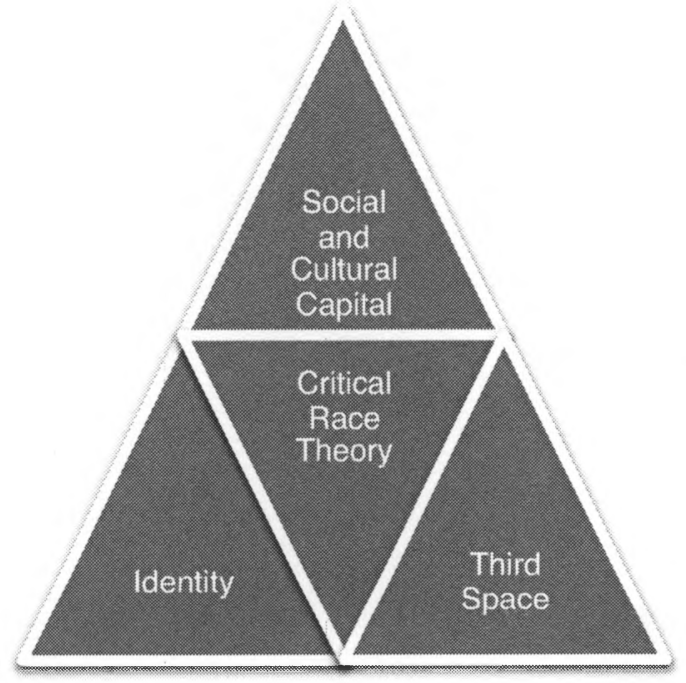

Figure 1.Theoretical framework demonstrating the relationship of the four theories. The theoretical focus of this research is on the intersections between Critical Race Theory and the three supporting theories. 


\section{Critical Race Theory}

Critical Race Theory proposes that race is an analytic tool for understanding the role of race in the U.S. (Ladson-Billings \& Tate, 1995; Solorzano \& Yosso, 2001; Yosso, 2005). Critical Race Theory (CRT) is often described with five guiding tenets, (a) centrality of race, (b) challenge to dominant ideology, (c) commitment to social justice, (d) centrality of experiential knowledge, and (e) an interdisciplinary perspective (Ladson-Billings \& Tate, 1995; Yosso, 2005). The primary argument in CRT is that race and racism are central to understanding the systems and structures that oppress people of color and maintain hegemony (Ladson-Billings \& Tate, 1995; Solorzano \& Yosso, 2001; Yosso, 2005). The intersections between race and other aspects of identity such as socioeconomic status, age, gender, and sexuality are also included in this critical perspective.

\section{Social and Cultural Capital}

The concept of social and cultural capital frames the ways that students of color interact with educational institutions. Bourdieu (1986) describes social capital as material and immaterial aggregated resources that individuals can access through their social ties. Cultural capital includes the educational or intellectual assets that individuals can leverage to access institutions (Bourdieu, 1986). These concepts provided a lens for reading the study abroad literature and guided data analysis. 
CRT researchers have challenged the role of social and cultural capital. Their concern is that these constructs do not lead to change because they fail to acknowledge the unrecognized capital that people of color possess (Yosso, 2005). To address this concern Yosso (2005) proposed a new approach to capital that recognized what she called community cultural wealth. Six types of capital make up this wealth. These are aspirational capital, familial capital, social capital, linguistic capital, resistant capital, and navigational capital. This CRT reframing of capital affirms the wealth, total accumulated assets, that communities of color possess rather than reinforcing the capital that they lack. Yosso (2005) argues that educational institutions must recognize the strengths that people of color bring and redefine systems to value this wealth. I used this study in part to determine if study abroad students of color have opportunities to leverage their community cultural wealth through the study abroad process.

\section{Third Space}

Bhabha's (2004) construct of Third Space explains the importance of a mediating space in creating meaning from interpersonal interactions. This Third Space leads to personal and social transformation and to changes in the dominant systems that reproduce inequity. As a critical postcolonial theory Third Space challenges the systems that maintain inequity worldwide (Moje, et al., 2004). It emphasizes the interpretation that occurs in communication between people who communicate from different perspectives, or places. Bhabha argues that meaning is always mediated by cultural 
systems and social locations, or places, of those attempting to communicate. The Third Space is the intersection of these places where meaning is created. He argues that the greater the social or cultural distance between those communicating, the lesser the meaning that can be co-created in the Third Space -- unless there is a mediating factor. For individuals from marginalized communities this Third Space is essential to leveraging the community cultural wealth Yosso (2005) described, or to changing inequitable systems. This study proposes that study abroad examines the relevance of this construct in the context of study abroad.

From identity development to identity negotiation

One key element in Critical Race Theory is the importance of identity negotiation. Identity theories explain the interplay between various aspects of self and further develop an important goal of education (Torres, Jones, \& Renn, 2009). Identity development connects to one major element of the learning that occurs on study abroad, personal development (Day-Vines, et al., 1998; Landau \& Moore, 2001; Talburt \& Stewart, 1999). Recent dissertation research has suggested that cross-cultural adaptation, as part of the study abroad experience, creates a site for identity negotiation and identity development (Angulo, 2008; Guerrero, 2006; Jackson, 2006; Souders, 2009; Young, 2009). As detailed in chapter two, very little of this research has addressed the experiences of study abroad students of color. Thus their negotiation of identity during the study abroad process has not been fully theorized. 
Identity development is seen as an essential part of human development that is particularly important during typical college years (Chickering \& Braskamp, 2009).

Overall, identity comprises the personally held beliefs about the self in relation to groups around concepts of race, ethnicity, gender, age, and others (Torres, et al., 2009). Current student development theory suggests that identity development is a unique and complex process for people of color, which is heavily influenced by intersections of class, gender, sexuality, and other factors (Schachter, 2005; Tatum, 1992, 1997; Torres, et al., 2009). These approaches point to an understanding of identity as a negotiation among social locations that does not have a set path and is never fixed.

The salience of race in U.S. society also amplifies the importance of identity development for students of color (Ladson-Billings \& Tate, 1995; Tatum, 1997; Torres, et al., 2009). For students of color identity development has been seen to play an important role in achieving equity in education (Chickering \& Braskamp, 2009; Torres, et al., 2009). Creating a context for this type of identity negotiation in an institution can be difficult due to the relative stability of identity and the length of time that is usually required for major changes (Angulo, 2008). Emerging research on study abroad suggests that it fosters negotiation of identity over a short period of time such as a semester or year (Angulo, 2008). My research proposes that study abroad creates a unique context for examining identity negotiation. Existing studies such as Angulo's (2008) have not fully explored the relationship between study abroad and identity 
development for students of color. Most of these current studies focus on stage-based models of identity development. Using a CRT framework suggests that stage-based models are reductionist. For this reason CRT scholars focus on examinations of negotiation of multiple identities.

\section{Conceptual Framework}

For students of color study abroad appears to be a process of negotiating multiple identities to establish a global identity. Based on my research this negotiation begins when students decide to pursue study abroad -- a decision that requires social and cultural capital. This, this is the beginning of the transformation that occurs through study abroad. As students move through the application process they leverage their social and cultural capital. Defining goals for study abroad gives students an opportunity to negotiate identity. After selection into study abroad, students continue to build social and cultural capital through orientation programming and other events. They also continue to examine their multiple identities related to study abroad as they prepare to go abroad. Based on the literature and my research it appears that, significant opportunities to negotiate identity and build capital occur while students are abroad because their status in this new environment creates a Third Space in which students are able to negotiate meaning outside of the context of U.S. race relations. While abroad the students are no longer part of a marginalized community. Instead, they are received as privileged guests in another country who are seen as ambassadors for their nation, 
institution, and community. This experience allows them to leverage their community cultural wealth in ways that may not have been recognized in the U.S. Upon return students appear to have greater social and cultural capital through new networks and knowledge gained abroad and recognize how they can use their community cultural wealth and help others understand its value. This additional capital appears to provide agency that allows study abroad students of color to make independent decisions about the impact that they want to have on their world and what they can do with their lives. This process is outlined in Figure 2.

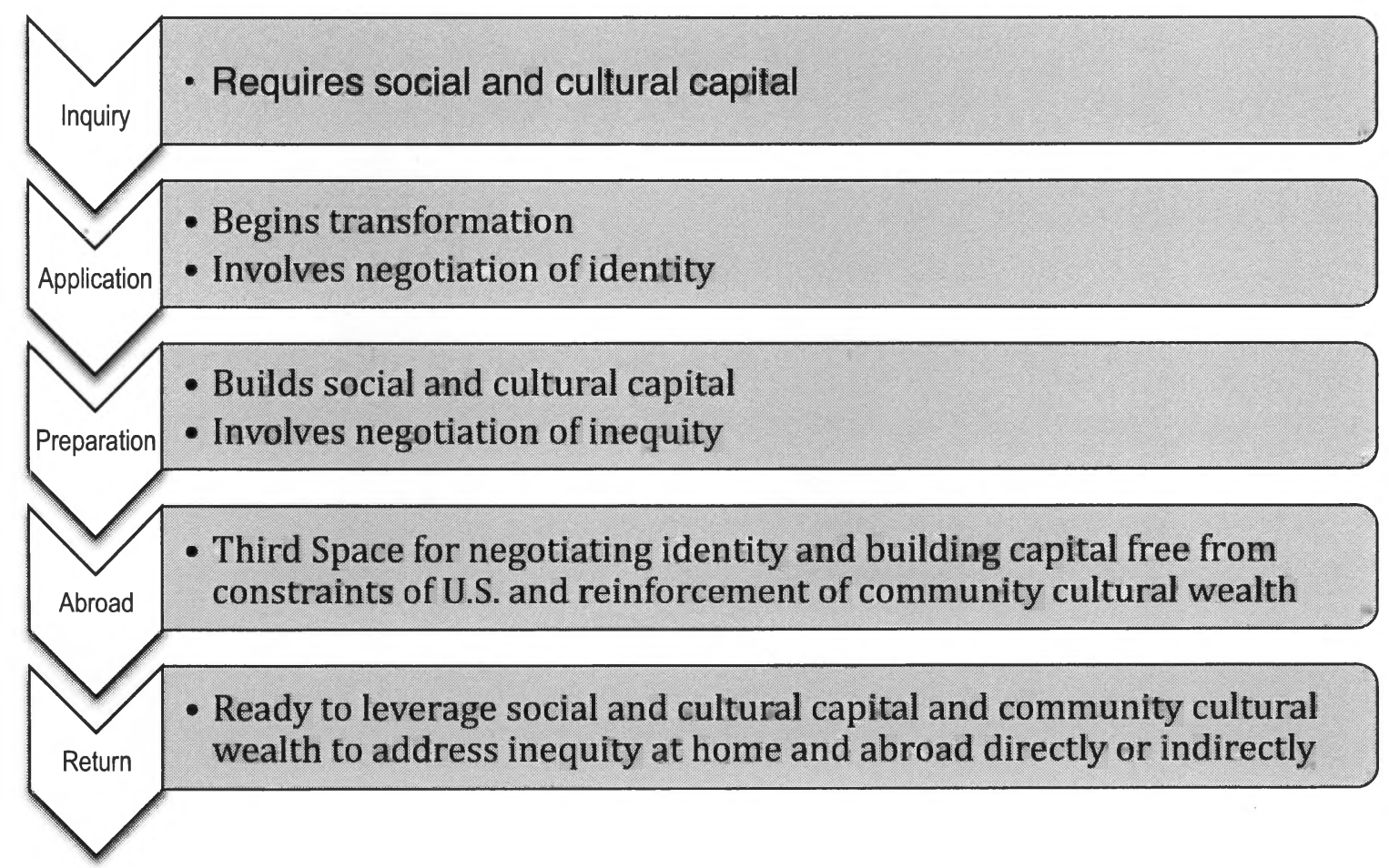

Figure 2. Conceptual framework illustrating the study abroad process for students of color. 


\section{Operational Definitions of Key Terms}

Many of the terms in this study have contested definitions. The following operational definitions provide a framework for understanding the key terms in this dissertation, research question, and propositions.

- Cultural capital comprises educational or intellectual assets that individuals can leverage to access institutions.

- Identity comprises the personally held beliefs about the self in relation to groups around concepts of race, ethnicity, gender, age, and others.

- Identity development describes how individuals come to understand who they are in relationship to others who are similar or different. In this case development has been used to describe stage-based models for development of various aspects of identity such as ethnicity or gender.

- Identity negotiation is the process of adjusting or adapting one's identity in order to function effectively in different contexts and with different groups. This construct recognizes the importance of intersections between various aspects of identity such as race, ethnicity, gender, sexuality, ability, education level, socioeconomic status and so on.

- Immersion is a type of study abroad in which students are placed in host institutions where they study alongside local students in the local language of instruction.

- Social Capital includes the material and immaterial aggregated resources that individuals can access through their social ties.

- Students of Color are students who do not identify as white. This term was chosen to include all students who share a common experience of racism in the U.S.

- Study Abroad is a credit-bearing educational experience that takes place outside of a student's home country. The credit from this experience helps the student complete a degree on his or her home campus in the U.S. For this research study abroad is seen as a process that comprises all 
of the experiences that a student has from initial interest through application, preparation, time abroad, and return.

- Third Space is a navigational space of cultural, social, and epistemological change that provides individuals with a way of crossing and succeeding in different communities, knowledges, and Discourses.

\section{Statement of Delimitations and Scope of Study}

This study was designed to develop a conceptual framework of the study abroad experiences of students of color. More specifically, it was designed to gain an understanding of how students of color negotiate identity through study abroad. It is not an evaluation of any single program or an assessment of specific learning outcomes. As the largest empirical study on study abroad students of color, the results of this study may have some transferability. The diversity of participants, global representation of study abroad sites, and uniform study abroad program type were chosen to enhance this transferability. However, this transferability may be limited by the fact that the research was conducted with students at one institution. Finally, my relationship to the participants as their advisor influenced the results in both positive and negative ways as is described more fully in chapter three. The institutional context and design of this study was essential given the paucity of research on study abroad students of color, the limited participation nationwide, and the absence of theoretical models of the study abroad experiences of students of color. 


\section{Significance of the Study}

The primary significance of this research is that it brings the experiences of study abroad students of color into the study abroad literature by amplifying their narratives. Introducing a CRT perspective into the study abroad literature frames the equity issues that, I believe, underlie underrepresentation of students of color in study abroad. This approach helped me develop a conceptual framework that explains the role of study abroad in the lives of students of color. Such a framework may make it possible to move beyond discussions about diversification of study abroad and initiate conversations about equity in study abroad. Focusing on the emancipatory effect of the study abroad process may lead to recommendations that dramatically increase equity in study abroad throughout the process and thus increase not only participation but also benefits to students and their home communities.

This research suggests that study abroad provided an environment for identity negotiation that increased the power of the social and cultural capital the participants possessed by creating a Third Space. This increase in social and cultural capital led to a valuing of their community cultural wealth and appeared to lead to agency after return. This agency may help address some of the difficulties students of color face in postsecondary education. Understanding the impact of study abroad on this student population could influence study abroad program design, promotion, support, admission processes, orientation structures, re-entry programming, and more as discussed below. 
The literature on barriers to study abroad examined in chapter two tended to approach underrepresentation from a deficit model that needs to be overcome through marketing. Advocates for increasing participation have focused on diversity rather than equity. This research on student experiences takes a critical approach to examining the study abroad process that allowed me to introduce an equity model that addresses access and outcomes for all students throughout the study abroad process (Espinoza, 2007).

As a practitioner researcher I have considered additional areas of potential significance beginning with my own practice and ending with significance to the international education community.

- Personal Significance: Understanding the experiences that study abroad students of color gave me insights that can lead to new advising approaches.

- Departmental Significance: The personal transformation that the participants experienced may suggest new approaches to promoting study abroad to students, departments, and colleges. Current study abroad advising and orientation sessions do not always address identity, race, or oppression. This research suggests that they should. CRT and the results of this study suggested that these are central aspects of the experiences of students of color in the U.S. and abroad. As such, curriculum and pedagogy changes at every stage of the study abroad process could make involvement with study abroad more common, meaningful, and equitable for this population.

- Institutional Significance: The context for this study, San Francisco State University, has strong philosophical support for study abroad, but does not always link it to other campus priorities such as equity and social justice. This new knowledge of how study abroad can serve the personal, academic, and professional needs of all students while helping them to build capital can connect the institution's support for study abroad to other aspects of its mission. 
- Significance to U.S. Study Abroad: This research may challenge the current grand narratives of study abroad as an unquestioned good for all students. The experience of critically negotiating intersecting identities while abroad appears to develop into new strengths when examined from a CRT perspective. Bringing race, oppression, and privilege into the discussions of study abroad could fundamentally shift the way the field thinks about equity and could broaden the impact of participation.

- Significance to International Education: Some researchers suggest that study abroad and international education can easily become educational colonialism due to the economic impacts and relationships between those involved (Caton \& Santos, 2009; Schroeder, Wood, Galiardi, \& Koehn, 2009). Examining student experiences with identity while abroad and challenging study abroad professionals to support their negotiation of identity and agency may lead to new ideas about how study abroad can sustain and empower individuals, communities, institutions, and nations in the U.S. and abroad. Such a dialog could influence policy and leadership for those committed to increasing diversity or reducing inequity in the international education community.

\section{Conclusion}

Profound concern about underrepresentation of students of color on study abroad drove extensive theorizing and some research on barriers to access for students of color. Very little empirical research on study abroad students of color has been conducted leaving a gap in knowledge about the importance of this activity in their lives. This study takes a qualitative approach to investigating the experiences of study abroad students of color. Through six interviews, five focus groups and a review of application essays for all 47 participants this research presents a CRT analysis of the study abroad process for students of color. This study represents the broadest investigation of this student population reported in the literature. Chapter two presents a 
review of the theoretical and study abroad literature that guided this investigation. The third chapter presents the methodology of this study. Chapter four focuses on the results of this study and presents the three major themes and their sub themes. The final chapter includes a discussion of the significance of these results, implications of the findings, and suggestions for future research. 
Chapter Two: Review of Literature on Study Abroad Students of Color

To provide background on study abroad this review begins with an introduction to the goals of study abroad and student interest levels. Persistent underrepresentation of students of color on study abroad is presented through analysis of study abroad trends and U.S. higher education trends. This introduction sets up the problem statement that outlines how the narratives of students of color are largely absent from the literature and how their participation in study abroad has not been connected to systemic inequity. The section on the scope of the review presents the methodology and limitations for this review of theoretical and study abroad literature.

\section{Background on Study Abroad Students of Color}

With globalization, calls for increasing participation in study abroad have come from associations, foundations, and government (American Council on Education, 2002; Association of American Colleges and Universities, 2007; Commission on the Abraham Lincoln Study Abroad Fellowship Program, 2005; Committee For Economic Development, 2006; IES Abroad, 2009; Obst, Bhandari, \& Witherell, 2007; Raby, 2008). These entities promoted study abroad as an essential means of developing the personal and professional knowledge, experience, and abilities students and nations will require in the globalized world. They suggested that those who lack these global skills will be unable to compete for jobs in the globalized workforce. They propose that study 
abroad is a key way to gain these essential global skills. Critical Race Theorists (e.g. Delgado Bernal, 2002; Duncan-Andrade \& Morrell, 2008) recognize that these goals are not neutral and all serve to reproduce inequity. One theoretical article from the study abroad literature challenged the neo liberal thinking behind these goals (Reilly \& Senders, 2009).

Student interest in study abroad has grown alongside these calls for increased participation. In 2008 college bound student interest in study abroad was reported as $55 \%$ from a sample of over 1,500 students who took the Scholastic Aptitude Test (American Council on Education, Art and Science Group, \& the College Board). In their study $27 \%$ of students indicated that they were absolutely certain they would study abroad, $28 \%$ were fairly certain that they would study abroad, another $26 \%$ hoped to study abroad, but believed that it would not be possible (American Council on Education, et al., 2008). In their study only $6 \%$ stated that they had absolutely no interest in study abroad and $13 \%$ felt that they did not have enough information to respond to the question. This level of interest is dramatically higher than the $1.36 \%$ of students in U.S. higher education who study abroad (Bhandari \& Chow, 2009; Chow \& Bhandari, 2010; National Center for Education Statistics, 2009, 2010). To date no research has accounted for this difference between interest and participation.

The authors of the study abroad interest survey suggested that interest in study abroad was similar for students from all racial and ethnic backgrounds (American 
Council on Education, et al., 2008). Similar rates of interest in study abroad across all racial and ethnic groups has been documented elsewhere (Salisbury, Umbach, Paulsen, \& Pascarella, 2009). Despite these high levels of interest, the personal, academic, and career benefits of study abroad reach only a small, albeit rapidly growing, proportion of the U.S. student population. Between 1996-97 and 2008-09 participation in study abroad grew from 99,488 to 260,327 (Chow \& Bhandari, 2010).

These high levels of interest have not led to proportional participation in study abroad by all students. Underrepresentation in study abroad has been broadly defined to include students of color, students with limited financial means, students with disabilities, older students, students at community colleges, transfer students, students in the STEM fields (science, technology, engineering, and mathematics), students with average or low academic performance, and students with dependents (Bhandari \& Chow, 2008; Hoffa, 2007; IES Abroad, 2009; Murray Brux \& Fry, 2010; Picard, Bernardino, \& Ehigator, 2009). Students of color make up the most commonly discussed underrepresented group in study abroad. This may be partially due to the ease of access to this data in the annual Open Doors publications on international educational exchange (Bhandari \& Chow, 2007, 2008, 2009). In addition, the social constraints for this group are unique due to the salience of race in U.S. society and structural inequity throughout all levels of education (Bernal, 2002; Ladson-Billings \& Tate, 1995; Solorzano \& Yosso, 2001; Yosso, 2005). 
Students of color have been consistently underrepresented in U.S. study abroad. Despite increases in the percentages of students of color enrolled in institutions of higher education, the percentage of students of color studying abroad has not increased proportionally. Data since 1996 show the proportion of students of color enrolled in higher education grew steadily from $27.2 \%$ in $1999-2000$ to $33.2 \%$ in $2008-09$ (National Center for Education Statistics, 2004, 2009, 2010). However, during the same period the proportion of students of color on study abroad increased only slightly from $16.3 \%$ to 19.5\% (Chow \& Bhandari, 2010). The increases in students of color on study abroad have not been as consistent or as rapid as those in higher education over all as demonstrated in Figure 3.

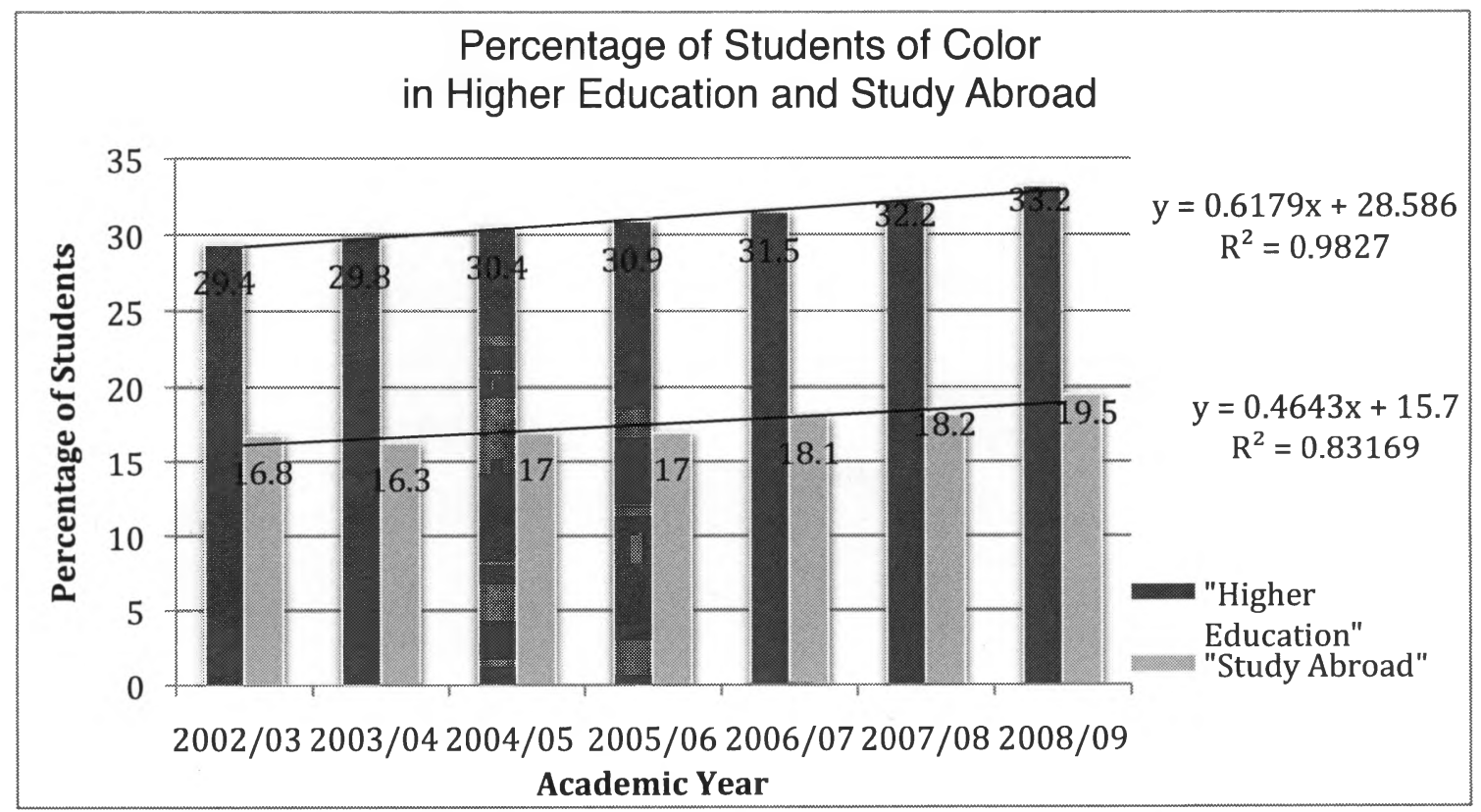

Figure 3. Percentage of students of color in higher education and percentage of students in study abroad from 2002-03 to 2008-09 by race/ethnicity (Chow \& Bhandari, 2010; National Center for Education Statistics, 2010). 
Problem Statement: Narratives Missing, Inequitable Context Unexamined

Given persistent disparity in study abroad participation among students of color (Chow \& Bhandari, 2010) its benefits are not reaching a part of the population that is already denied many educational opportunities (Anzaldúa, 2007; Delpit, 1995; DuncanAndrade, 2004; Kozol, 1992). Furthermore the lack of research on the experiences of study abroad students of color makes it impossible to know if these students receive the benefits commonly ascribed to study abroad. Understanding the impact of study abroad on this student population could influence study abroad program design, promotion, admission processes, advising, support, orientation structures, re-entry programming and more.

Overcoming underrepresentation in study abroad must consider the life experiences of students of color in the U.S.. As Orfield and Lee of the Harvard Civil Rights Project aptly noted, "if skin color were not systematically linked to other forms of inequality, it would, of course, be of little significance for educational policy" (2005, p. 5). The study abroad community has not considered the impact of race and structural inequity on differential participation in study abroad. Critical Race Theory presents a model for examining this impact that has not yet been considered in any of the study abroad literature. 
Scope of the Review

This section outlines the methodology, scope and structure of this literature review. I separated the literature in two sections. Theoretical literature that supports this investigation, and study abroad literature on students of color. Each body of literature required a different methodology, scope and structure.

\section{Databases Accessed and Keywords Searched}

The two bodies of literature I examined required different methodologies. For the theoretical literature I began with landmark articles or books and then searched for intersections between Critical Race Theory and the three supporting methods. For the study abroad literature I conducted database research that I supplemented with a review of key journals and public domain bibliographies.

\section{Theoretical literature}

For each of the key theoretical frameworks I began with a landmark article. This article helped to define the key concepts. Because of my focus on the experiences of students of color I chose to ground my theoretical literature in Critical Race Theory (CRT). This theory served as a foundation for examining the literature in the other three categories. CRT proposes that race is an analytic tool for understanding inequity and structural and cultural reproduction (Ladson-Billings \& Tate, 1995). I used this lens to guide my review and identify intersections between CRT and the other theoretical 
frameworks of social and cultural capital, identity, and Third Space as shown in chapter one Figure 1.

The examination of CRT began with Ladson-Billings and Tate's Toward a Critical Race Theory of Education (1995) because this article establishes CRT in the field of education. This guided a search for key articles that further defined the importance of CRT in education and in educational research. There were no articles linking CRT and study abroad.

Educational research on students of color often centers on the role of capital in educational success. Bourdieu (1986) developed the constructs of social, cultural, and economic capital to help explain differences in society and the power of capital in reproducing inequity. This foundational article guided database research, as described below, to identify articles that critiqued or challenge this theory. The search included articles that connected capital to CRT and study abroad.

The construct of Third Space appeared to be a promising explanation for what was happening for study abroad students of color. Bhabha's (2004) construct of Third Space suggests a type of environment that can lead to personal and social transformation and to changes in the dominant systems that reproduce inequity. His work formed the core of this investigation. CRT literature further defined or challenged this literature. The study abroad literature has not addressed Third Space. 
Identity development has a complex and multi disciplinary history. Identification of relevant article began with an article that presented a CRT critique of major theories of identity development from psychology and student affairs development (Torres, Jones, \& Renn, 2009). This article provided a starting point for my examination of identity theory. Branching provided a method for identifying . foundational literature. This guided a review of research on identity in the study abroad literature.

\section{Study abroad literature}

Database research was the primary tool in this review of study abroad literature. To focus on the most current literature the search was limited to empirical articles in peer-reviewed journals from the last five years. Databases included ERIC, Academic Search Premier, Education Research Complete, ProQuest Education Journals, Center for Global Education's study abroad research website, and the Database of Research on International Education (Australian Government \& Australia Education International, 2009; Center for Global Education, 2009). Search terms included study abroad, education abroad, underrepresented students, students of color, diversity, non-traditional students, identity, racial identity, ethnic identity, global identity, ethnicity, social capital, cultural capital, Critical Race Theory, race, racism, Third Space, and heritage.

Public domain bibliographies of study abroad research further supplemented my database research by providing the practitioner perspective in an historical context. 
Study abroad is a practitioner driven interdisciplinary field, so, perhaps it is not surprising that no stand-alone literature reviews have been published. However, the profession has an ethos of sharing resources, and five bibliographies of study abroad research available in the public domain. These bibliographies provided a practitioner's perspective on the state of study abroad research and allowed me to track the growth of study abroad research related to students of color.

Weaver's 1989 bibliography provided an historical perspective on research on U.S. study abroad through 1987 . His work demonstrates that most study abroad research through 1987 related to language learning, intercultural sensitivity, and psychosocial impacts of study abroad. There are only two references to non-traditional, minority, or underrepresented students in Weaver's annotated bibliography and neither was an empirical source from a peer-reviewed publication. Thus they were not included in this review.

In 2001 Chao published an updated bibliography with abstracts that included articles from 1987 through 2001. Her bibliography demonstrates rapid growth in research on U.S. study abroad yet contains only five references to underrepresented students and study abroad. Just one of these was an empirical article from a peerreviewed source (Talburt \& Stewart, 1999). This article was included in this review in the section on outcomes research literature. 
Comp (2008a) further developed this bibliography with research through 2006. His work demonstrates increasing breadth in study abroad research and highlights broader concerns about underrepresentation in study abroad. His review included 13 publications related to students of color and study abroad. Of these publications two were empirical articles from peer-reviewed journals focusing on study abroad students of color (Landau \& Moore, 2001; Morgan, Mwegelo, \& Turner, 2002). These articles were explored further in the outcomes research section of this review.

To address the topic of underrepresentation in study abroad in greater depth, Comp (2008b) published a focused bibliography on underrepresentation in study abroad. This bibliography has been cited in empirical articles related to study abroad students of color as a key resource (McClure, Szelenyi, Niehaus, Anderson, \& Reed, 2010) and has been highlighted as a key resource to the field at workshops and sessions related to underrepresentation in study abroad (Flores, Lewis, \& Le, 2009; Tillman, 2010; Wick, Jackson, \& Flores, 2009).

To ensure that my database research, review of abstracts in relevant journals, and examination of the public domain bibliographies identified the existing literature on study abroad students of color I also used branching. This technique of reviewing reference lists from key articles helped me identify landmark studies and find studies not indexed in the databases or listed in the bibliographies above (Bryman, 2007). 


\section{Inclusion and exclusion criteria}

The criteria for including or excluding literature were distinct for the theoretical literature and the study abroad literature. These two sets of criteria were designed to facilitate an appropriately comprehensive review of both types of literature.

\section{Theoretical literature}

The CRT literature framed the theoretical section. From the landmark article on CRT and education I focused on CRT literature that described research methodologies. Three constructs stood out in this literature as potentially relevant to this examination of study abroad for students of color. These are social and cultural capital, Third Space, and identity. Once identified, I looked for intersections between these theories and CRT. I emphasized the empirical and theoretical articles that examined the intersections between CRT and these constructs to broaden or challenge my understanding.

\section{Study abroad literature}

This review represents an effort to identify the current state of research on study abroad students of color. The existing study abroad literature tends to not disaggregate results by student demographics. Thus, the emphasis of this review is on peer-reviewed empirical research that directly addresses this population. Given the limited nature of this literature I supplemented it with recent doctoral dissertations.

Through my review of the study abroad literature I identified three categories of literature that I examined in this review; barriers research, anecdotal advice literature, 
and outcomes research. Barriers research literature represented empirical research on why students of color do not study abroad. This research indirectly supports much of the anecdotal advice literature in the second section. This advice literature is a practitioner literature on practices for increasing diversity in study abroad programs and comes from practitioner publications and sources such as The Chronicle of Higher Education, IIE Networker, and International Educator. The final category, outcomes research includes all published peer-reviewed empirical research on study abroad students of color. Because of the small number of sources in addition to reviewing peerreviewed sources I examined dissertations from the last 6 years on the topic of study abroad students of color, identity development on study abroad, or race and racism. Structure of Review

This review began with a review of arguments for participation in study abroad by students of color. To frame this review I continued with a review of justifications for why students of color should study abroad. I followed with a theoretical framework to contextualize the life and educational experiences of students of color in the U.S. This framework includes a discussion of Critical Race Theory, and then presents its intersections with social and cultural capital, Third Space, and identity negotiation theories. These intersections are contextualized in the study abroad literature.

The second section of the review examines the study abroad literature on students of color. My review of literature on study abroad students of color identified 
three categories of literature: a) barriers research literature comprised of empirical studies published in peer-reviewed journals on students of color who did not plan to study abroad and how they came to that decision, b) anecdotal advice literature by practitioners about how to increase access to study abroad published by associations in professional magazines, in edited volumes, and online and c) outcomes literature represented peer-reviewed empirical research and recent dissertations that described the experiences of study abroad students of color. I outlined the main themes and subthemes in sections related each of these bodies of literature.

\section{Literature Review}

Why should students of color study abroad?

Given persistent underrepresentation and decades of presentations, special conferences, and attention (Comp, 2008b) I expected to find many answers to this question in this literature. Instead, I noticed that the research, theoretical, or anecdotal literature has not generally addressed this question. Instead, rationales for increasing study abroad participation by students of color were almost always framed in terms of necessity for competition in the global workforce. The articles and reports calling for increased participation in study abroad by students of color used arguments about the general importance of study abroad in competing for jobs in the global economy rather than emphasizing any special benefit to this group of students (American Council on Education, et al., 2008; Commission on the Abraham Lincoln Study Abroad Fellowship 
Program, 2005; Hoffa, Pearson, Martin, \& NAFSA: Association of International Educators, 2005; IES Abroad, 2009; Obst, et al., 2007). The barriers research, empirical research on why students of color chose not to study abroad, examined in this review also cited the role of study abroad in preparing students for the global workforce as the primary reason why students of color should study abroad (Kasravi, 2009; McClure, et al., 2010; Murray Brux \& Fry, 2010; Stroud, 2010; Van der Meid, 2003). CRT has challenged this type of human capital development role of education and the assumption that access is enough (Apple, 1990; Delgado Bernal, 2002). The absence of the CRT framework in the study abroad literature may explain this lacuna.

Some literature proposed unique benefits of study abroad for students of color. These include benefits to the students' home communities because students bring back a global perspective, benefits to the host community abroad because they gain a different view of the U.S., benefits to fellow study abroad students who may begin to understand race issues better as they watch their fellow traveler grapple with racism abroad, and benefits to the student traveler (Guerrero, 2006; Jackson, 2005, 2006; Talburt \& Stewart, 1999). These benefits were not examined empirically, leaving some question. In much of the advice literature arguments about benefits of study abroad are simply not made (Picard, et al., 2009; Tillman, 2010); instead, study abroad is presented as an unquestioned good that should be accessible to all students. Only one theoretical article in the study abroad literature (Reilly \& Senders, 2009) challenges the market function 
or neutrality of education as many CRT researchers frequently do (Apple, 1990; Ayers, 2005; Delgado Bernal, 2002; Iverson, 2007; Solorzano \& Yosso, 2001; Yosso, 2005). Reilly and Senders article focuses on issues of class, nationality, and inequity, but does not address race. Evaluating the goals of study abroad from a CRT perspective may lead to new thinking about the role of study abroad in the education of students of color. CRT perspectives also led me to design a study that questions study abroad and assumes that it may not be good for students of color, rather than accepting the arguments that have been made about its necessity.

Theoretical framework

The central idea in this theoretical framework is that Critical Race Theory is the most compelling framework for examining the educational experiences of people of color in the U.S. This framework guided my research on the other theories and led me to seek recent literature that discussed intersections between CRT and the other frameworks. I also searched for connections in the study abroad literature and presented these when available.

Based on this I examined theories that describe or problematize the educational experiences of people of color. Social and cultural capital theories help to explain how people access education and demonstrate how these forces reproduce inequity. The construct of Third Space presents a model for communication and an opportunity for increasing meaning between dominant and oppressed people. Finally, I presented 
theories of identity development and negotiation because of their importance in the educational lives of students of color.

\section{Critical Race Theory}

Theoretical literature on Critical Race Theory provides an important lens for reevaluating the study abroad literature on students of color. In many ways study abroad can act as a method of re-centering the content and goals of education (Jackson, 2006; Landau \& Moore, 2001; Stallman, 2009; Talburt \& Stewart, 1999; Wick, et al., 2009). The research on the impact of U.S. study abroad students on host communities makes the closest connection to these theories. Research suggesting that study abroad leads to student engagement and promotes an interest in social justice or giving back to home communities among students of color begins to align with this theoretical framework (Jackson, 2006; Kuh, 2008).

Critical Race Theory (CRT) is often described with five guiding tenets, (a)

centrality of race and racism, (b) the challenge to dominant ideology, (c) a commitment to social justice, (d) centrality of experiential knowledge, and (e) an interdisciplinary perspective (Delgado Bernal, 2002; Ladson-Billings \& Tate, 1995; Yosso, 2005). The primary argument in CRT is that race and racism are central to understanding the systems and structures that oppress people of color and maintain hegemony (LadsonBillings \& Tate, 1995). The intersections between race and other aspects of identity 
such as socioeconomic status, age, gender, and sexuality are also included in this critical race perspective.

CRT challenges dominant ideology by questioning the goals of education. When Duncan-Andrade and Morrell (2008) suggest that education in the United States is doing exactly what it is designed to do, they are challenging the notion that schools are objective institutions that provide equal opportunity in a meritocratic system. For the most part advocates for increasing study abroad for students of color have used these arguments. As noted above, the arguments for increased participation in study abroad are largely based on this same logic and thus run counter to the values of CRT.

An application of CRT's focus on social justice in education has been Critical Pedagogy. Authors in this area suggest that integrating social justice into pedagogy disrupts the systems that reproduce inequity by naming inequities, challenging the structures of power and privilege, and providing tools for working towards change (Duncan-Andrade \& Morrell, 2008; Freire, 2009; Giroux, 1997, 2010). Within Critical Pedagogy, the purpose of education is social justice. This is a key construct throughout Paulo Freire's Pedagogy of the Oppressed (2009). He argues for liberation of oppressed people and oppressors in a cycle of continuing liberation. Duncan-Andrade and Morrell (2008) report on their practitioner research on critical pedagogy in urban schools. In their work they show how learning to identify and challenge structural inequity enhances academic and personal outcomes of education. 
Freire (2009) argues that words have been stolen from the oppressed. Indeed, dominant narratives drown out the narratives of people of color and other oppressed groups in curricula, media, and society at large (Duncan-Andrade \& Morrell, 2008). CRT seeks to amplify these voices as counter narratives (Solorzano \& Yosso, 2001). These counter narratives make it possible to better understand how racism functions and provide a "vehicle for psychic preservation" (Ladson-Billings \& Tate, 1995, p. 57).

Finally, CRT has an interdisciplinary focus that invites perspectives from the social sciences, arts, humanities, and other disciplines. This openness to multidisciplinary perspectives recognizes the relationships between science, history, psychology and other disciplines in creating and sustaining notions of race. Critical Race Theorists then use all of these tools to challenge the systems and structures that reproduce inequity.

Perspectives similar to CRT have been examined in two study abroad-related articles (Caton \& Santos, 2009; Schroeder, Wood, Galiardi, \& Koehn, 2009). Caton and Santos' (2009) qualitative research deconstructs the images used in promoting study abroad. Their research suggests that the images represent Western hegemony over other non-Western cultures, while the words outline the personal growth an international understanding that Western students can gain. The potential of study abroad to have a reinforce inequity through study abroad is also central to Schroeder et al.'s article. They add that it is extremely difficult to design and run a study abroad program that does not 
negatively impact the host community, thus introducing a new challenge to the field of study abroad. Both of these articles challenge both the goals and rhetoric of study abroad. Neither of these articles was published in an international education journal and they have not been cited in any study abroad research since they were published. This suggests that this Critical Theories are still largely absent from the larger study abroad literature. One theoretical article introduces Critical Theory and proposes a fundamental reexamination of the purpose and practice of study abroad (Reilly \& Senders, 2009). These articles suggest an emerging interest in pushing international educators in new directions.

From social and cultural capital to community cultural wealth Bourdieu's concept of social capital provides a foundation for examining the assets that, he argues, people need to access opportunities. The current study considers study abroad one of these opportunities that requires social and cultural capital to access. This section on social and cultural capital presents a definition of each of these terms and their relationship to education and study abroad. This is followed by a review of the CRT literature on social and cultural capital. The section closes by examining relationships between social and cultural capital and community cultural wealth.

Bourdieu (1986) describes social capital as material and immaterial aggregated resources that individuals can access through their social ties. He defines cultural capital as the educational or intellectual assets that individuals can leverage to access 
institutions (Bourdieu, 1986). According to Bourdieu (1986) these forms of capital cannot generally be purchased. One theoretical article has proposed that participation in study abroad increases both forms of capital, thus creating an opportunity to purchase more social and cultural capital (Reilly \& Senders, 2009). Social capital, and to some extent cultural capital, have become prominent in educational research (Fulkerson \& Thompson, 2008; Grenfell, 2009; Koniordos, 2008). These authors explain the complex and contested nature of the concept of social capital and the ways in which it has evolved since it was first evoked by Bourdieu (1986) and Coleman (1988). At the same time, there seems to be some agreement in the educational literature that social capital influences parental support networks and educational attainment (Horvat, Weininger, \& Lareau, 2003; Lew, 2007). Socio-economic status, race, and ethnicity relate to social capital, and have been closely linked to the ways in which parents are able to support their children's education endeavors (Akom, 2003; Horvat, et al., 2003; Lew, 2007). These studies underscore the intersectionality of social locations and underscore the difficulty of overcoming inequitable systems that place a high value on the accepted forms of social and cultural capital. Many CRT theorists have begun to challenge social and cultural capital as forces that reproduce inequity (González \& Moll, 2002; Moll \& Diaz, 1987; Moll \& et al., 1992; Stanton-Salazar, 1997; Stanton-Salazar \& Dornbusch, 1995; Yosso, 2005). 
In many ways existing definitions of social and cultural capital fail to recognize the strengths that students of color bring to college. This theoretical approach resembles deficit models that explain lack of success for students of color as a logical outcome of deficiencies in social and cultural capital (Duncan-Andrade \& Morrell, 2008). Moll's (Moll \& Diaz, 1987; Moll \& et al., 1992) funds of knowledge and Yosso's (2005) model of community cultural wealth are provocative counter arguments to deficit models. Moll suggests that all students enter education with social, linguistic, and cultural resources that can help them succeed in the school environment. Yosso proposes that communities of color possess six types of community cultural wealth, (a) aspirational, (b) familial, (c) social, (d) linguistic, (e) resistant, and (f) navigational. This CRT reframing of capital affirms the wealth, total accumulated assets, that communities of color possess rather than reinforcing the capital that they lack. She argues that educational institutions must recognize the strengths that people of color bring and redefine systems to recognize this wealth. I believe that this argument holds true in the context of study abroad and thus investigated this throughout this research.

Study abroad is outside the norm for many students and thus requires social and cultural capital. Three studies by the same authors have linked social and cultural capital to interest in study abroad (Salisbury, Paulsen, \& Pascarella, 2010, 2011; Salisbury, et al., 2009). Each of these studies proposes that deficiencies in capital are in part responsible for low participation rates in study abroad based. This deficit model is 
rooted in a belief that current systems and structures are fair and equitable. A CRT analysis suggests that study abroad requires many of the types of community cultural wealth that Yosso defined such as aspirational, social, linguistic, and navigational. Changing study abroad systems to recognize and value these forms of community cultural wealth could have a profound impact on increasing participation. Furthermore, study abroad may be an experience that helps students develop social capital and learn to leverage community cultural wealth because of students' outsider status. This has been implied by some of the research and theoretical literature (Dolby, 2004; Jackson, 2006; Kauffmann \& Kuh, 1984; Reilly \& Senders, 2009; J. S. Van der Meid, 2003; Wick, 2009). Gaining a better understanding of how social and cultural capital and community cultural wealth relates to the study abroad experience may allow practitioners to better serve the students who are not currently benefiting from this educational opportunity.

\section{Third Space}

Bhabha's (2004) construct of Third Space explains the importance of a mediating space in creating meaning from interpersonal interactions. This Third Space leads to personal and social transformation and to changes in the dominant systems that reproduce inequity. As a critical postcolonial theory Third Space challenges the systems that maintain inequity worldwide (Moje, et al., 2004). It emphasizes the interpretation that occurs in communication between individuals who communicate from different 
places. Bhabha argues that meaning is always mediated by cultural systems and social locations, or places, of those attempting to communicate. The Third Space is the intersection of these places in which meaning is created. He argues that the greater the social or cultural distance between the interlocutors the lesser the meaning that can be co-created in the Third Space, unless there is a mediating factor. For individuals from marginalized communities this Third Space is essential to leveraging the community cultural wealth Yosso (2005) described, or to changing inequitable systems. This construct appears to relate to some of what happens for study abroad students of color when interacting with members of their host community and other international students on study abraod.

From identity development to negotiating identity

Identity comprises the personally held beliefs about the self in relation to groups around concepts of race, ethnicity, gender, age, and others (Torres, et al., 2009, p. 119). Current student development theory intersects with CRT and suggests that identity development is a unique and complex process for people of color and that it is heavily influenced by intersections of class, gender, sexuality, and other factors (Schachter, 2005; Tatum, 1992, 1997; Torres, et al., 2009). Furthermore, these current theories focus on negotiation of identity rather than proposing a stage-based model that suggests a hierarchy or directionality to identity. 
The salience of race in U.S. society also amplifies the importance of identity development for students of color (Ladson-Billings \& Tate, 1995; Tatum, 1997; Torres, et al., 2009). Student development theorists have suggested that identity development plays an important role in achieving equity in education because it provides individuals with the self-efficacy to access resources and navigate systems (Chickering \& Braskamp, 2009; Torres, et al., 2009). Emerging research on study abroad suggests that it fosters negotiation of identity and can have a profound impact on identity development Yet, existing studies have not fully explored the relationship between study abroad and identity development for students of color.

Critical Race Theorists have discussed the ways that identity is connected to the intersectionality of social locations. As Delgado Bernal (2002) explained "what this means is that one's identity is not based on the social construction of race but rather is multidimensional and intersects with various experiences" (p. 119). Study abroad appears to be one of these experiences that can have an impact on many aspects of identity. Delgado Bernal (2002) suggested that "with increased globalization and transnational labor and communication, we have to move beyond essentialist notions of identity and of what counts as knowledge" (p. 119). Her ideas were similar to Yosso's (2005) construct of community cultural wealth but highlighted the need to see beyond the community context. Based on these frameworks it seems likely that study abroad students will need to negotiate all of their intersecting identities as they are faced with a 
new context. This changing context may help them to leverage the knowledge they possess in ways that would not be possible in the U.S.

Barriers Research

A few studies have been conducted to determine why students of color do not study abroad. I have grouped these as barriers research. Three key articles make up the barriers research (McClure, et al., 2010; Murray Brux \& Fry, 2010; Van der Meid, 2003). The subtopics below bring together the major findings from this in a few key areas; (a) not for me, (b) financial impossibility, (c) family concerns, (d) fear of racism abroad, and (e) academic concerns.

The barriers research tended to use a qualitative design and none of the studies presented any statistical analysis. These studies all began by indentifying a population of students of color who have decided not to study abroad. One of the studies (McClure, et al., 2010) uses narrative inquiry and focused exclusively on Latino students who were aware of study abroad but had decided against it. Van der Meid (2003) focused on Asian American students and distributed an online survey to study abroad students and non-study abroad students. Surveys to all students of color and focus groups with members of student clubs for students of color formed the sample for Murray Brux and Fry's (2010) study. This final study included a heterogeneous sample that included similar numbers of Latino, African-American, and Asian-American students in the focus groups and surveys. The different qualitative approaches of these studies led to 
different analytical approaches. Van der Meid's (2003) results are supported by charts and most of the results are presented synthetically rather than examining each detail separately. Murray Brux and Fry (2010) presented a combination of rich data and tables, while McClure et al. (2010) presented three vignettes from the nine participants as exemplars of their findings.

\section{Study abroad not relevant, not for me}

The idea that students did not see study abroad as something for them was common in these studies. In fact, the title of one "We Just Don't Have the Possibility Yet": U.S. Latino/a Narratives on Study Abroad (McClure, et al., 2010) forefronts this concept. At the same time, this construct did not always match Jackson's (2005) assertion that the dearth of media images led students of color to imagine study abroad as something that was for White students. In fact, just three of the nine students in McClure et al.'s study “envisioned the typical U.S. college student going abroad as White" (p. 378) and none of the students in her study felt that this made the opportunity inaccessible to them. They still had positive feelings about the possibility of time abroad at some point in their lives. They had just ruled out the possibility of study abroad during college due to the barriers described here. In one of Murray Brux and Fry's (2010) focus groups the students discussed this concept and agreed that they had not felt constrained by that factor. This idea of relevance of study abroad to the students was not apparent in Van der Meid's (2003) presentation of results. 
Each of these studies noted that students were aware of study abroad and even had a strong desire at one time. As one wrote, the "students [were] aware of study abroad programs at the university, and relatively large numbers had been encouraged by their instructors or advisors to participate" (Murray Brux \& Fry, 2010). McClure et al. (2010) noted that all of the participants in their study "uniformly expressed a positive view of traveling abroad for school or work" (McClure, et al., 2010). The lack of connection between student interests and their belief that they could access study abroad presents an interesting problem for considering study abroad from CRT perspective. One possibility is that despite encouragement the students do not possess the social and cultural capital to pursue the possibility. From a critical perspective this might suggest that the institution does not recognize their community cultural wealth in ways that allow them to access this program that they would like to pursue. This lack of follow through may also be the logical extension of deficit thinking. One author writes of low expectations from teachers and advisors of students of color (Murray Brux \& Fry, 2010). CRT scholars have suggested that this type of thinking has an impact on academic performance and involvement in non-traditional activities such as study abroad (Delgado Bernal, 2002).

Financial impossibility

Financial concerns are central to all of the narratives presented in McClure et al.'s (2010) study. Each of the exemplars emphasized the importance of finances as the 
most common reason presented for non-participation. These concerns were highlighted as concerns over lost income, obligations to support family, and fear of asking more of family when they were already struggling to pay for college. Murray Brux and Fry (2010) highlighted the fact that all of the students in their study who indicated that they would like to participate cited finances as the primary reason for nonparticipation. Van der Meid's (2003) presentation of the finances concern was most striking since his study included both study abroad students and students who had not studied abroad. Across most measures his study abroad and non-study abroad were similar, but he noted that those who had not chosen to study abroad tended to indicate that finances were a major barrier, whereas those who were abroad did not cite this as one of the challenges that they had to overcome. In other words, finances may be more of a perceived barrier since those who chose to study abroad no longer mention it. There may be other factors such as financial aid status and home institution that play a role in these results. These details were not provided.

These results suggest that there may be a change that occurs when students decide to study abroad. For the students who have decided not to study abroad, most of the respondents in this study, the barriers appear insurmountable. This could be similar for decision making around going to college. One explanation for the large numbers of Asian-American students in community colleges mentioned in this literature is the financial cost and opportunity cost to the student and his or her family (Van der Meid, 
2003). Still, some students with limited financial means chose to attend a four-year institution despite the burden on themselves and their families. Additional study on that phenomenon may help to explain what is happening for study abroad students. Van der Meid's (2003) comparison to the students who were abroad suggests that something shifted when the students decided to pursue study abroad. Further examination of this phenomenon could help to better understand why some students acted on their latent interest in study abroad and others did not.

\section{Family concerns and closeness}

Family responsibilities or lack of support are common themes in all three of these articles. Van der Meid (2003) attempted to break down this barrier by examining the relationship of family immigration history to concerns about family, but had inconclusive results. Despite its presence in the anecdotal advice literature family was not raised as a concern in his study. McClure et al.'s (2010) narrative inquiry placed family as the most important concern for the Latino students in the study. They interpreted this finding as related to a closeness and emotional attachment in families that is integral to Latino culture. Given the limited consensus across these three studies it is difficult to draw conclusions in this area.

Fear of racism abroad and safety concerns

Although all of the studies noted fear of racism abroad in their literature reviews none of them found that this was a top concern in their studies. For some this was 
wrapped up in a more general category called safety concerns (McClure, et al., 2010; Murray Brux \& Fry, 2010). For the final study this concern ranked at the bottom of the list of concerns.

At the same time, all three of these studies suggested that their participants were interested in study abroad related to heritage destinations. The authors of all three articles suggested that this gap was a major factor in nonparticipation. This interest in heritage, language and/or culture, appeared to be connected to a perception that those locations would be more comfortable or accessible (McClure, et al., 2010). It may also be connected to the fact that none of these students had been made to believe that study abroad was a real possibility.

Academic concerns: time to graduation, relevance, and more

Graduating on time was a key concern for many in this body of research. For the students in McClure et al. (2010) concerns about extending time to graduation were major factors. Murray Brux and Fry (2010) mentioned this concern as one of academic scheduling and cited it as the number one issue in their survey. This was also the case for the non-study abroad students in Van der Meid's (2003) study of Asian-American students. He found that academic compatibility of programs abroad was the number one barrier for students who did not go abroad, whereas those studying abroad ranked it sixth. This finding presents another area in which those who did not study abroad are blocked by something that the study abroad population overcame. This should not be 
read to suggest that students should not remain concerned about academics since the students abroad are all presumably making progress towards their degrees. Instead, these findings suggest that the students who had decided not to study abroad had not been made aware of the academic ramifications of participation effectively.

These findings around academic barriers could be read from a CRT perspective as an area in which the institution is not successfully creating a Third Space for the students to leverage their capital and access a program (Delgado Bernal, 2002; Moje, et al., 2004; Yosso, 2005).

\section{Untested barriers}

Other than Van der Meid (2003) none of the barriers above has been examined in relationship to students who participated in study abroad. His sampling technique of posting a survey to a website presents some uncertainty. Furthermore, he presented limited statistical evidence for his findings. Still, the suggestion in his study that the factors that motivated students to study abroad may have been different from the barriers that kept some from studying abroad presents a rich environment for future

research. This leaves a gap in knowledge about how students of color who do study abroad perceived the barriers before they chose to apply. Nor does this literature identify strategies that study abroad participants used to overcome the barriers that they perceived. Van der Meid (2003) proposes that further research on the effect of study 
abroad on Asian-American students is critical to gaining an understanding of students' decisions to study abroad.

Recommendations tend to follow a deficit model whereby offices must manage the elements that students are missing, or help students overcome fears or ties to family in order to help them get past the barriers. Many of the recommendations in this literature connect closely to the anecdotal advice literature in the following section. None of the existing barriers research has substantively challenged the assumptions made in the advice literature.

This limited literature has many gaps that present opportunities for future research. To date only one of these studies have compared students who studied abroad with students who did not (Van der Meid, 2003) albeit with an acknowledgement that sampling techniques and sample size were problematic. Additional research on the challenges and barriers that students who participated in study abroad perceived would help identify which of the individual and institutional factors were real and which were perceived. By focusing on students who had decided not to study abroad this literature is subject to threats that any perception-based study presents. None of these studies discussed this problem or designed systems to increase reliability and validity in their self-report surveys or focus groups. Finally, many of the recommendations and implications in this literature do not flow from the data presented. Instead, they are almost identical to the anecdotal advice literature in the next section. McClure et al.'s 
(2010) study flows the most directly due to the rich descriptive data presented through a narrative inquiry approach. Most of the authors of the barriers research are professionals in the field of international education. Thus, the correlation between the results of their research and the anecdotal advice literature may be due to the powerful forces that reproduce inequity in the U.S. Conducting CRT research on study abroad students and their institutions may lead to new ideas that begin to break down the barriers that are preventing students of color from accessing study abroad.

\section{Anecdotal Advice Literature}

The study abroad community has expressed concern over the persistent underrepresentation of students of color. The persistent underrepresentation mentioned above has led to a literature that focuses on strategies for increasing participation by students of color (Blumenthal \& Gutierrez, 2009; Comp, 2008b; IES Abroad, 2009). This literature is generally made up of case studies that contextualize practitioner advice related to advising, outreach, or program design (Flores, 2008; Le, 2008; Lewis, 2008; Martinez, Ranjeet, \& Marx, 2009; Murray Brux \& Fry, 2010; Picard, et al., 2009). A few of these pieces have begun to examine issues related to first-generation college students and students with low socio-economic status (Martinez, et al., 2009). Because parental education level is not tracked in the national data on study abroad analysis has been limited. 
Organizations related to international educational exchange have begun to look more strategically at initiatives to diversify study abroad participation and destinations. In 2007 the Institute of International Education (IIE) launched a series of research-based white papers (Blumenthal \& Gutierrez, 2009; Blumenthal \& Laughlin, 2009; Gutierrez, Bhandari, \& Obst, 2007; Gutierrez, Hawthorne, Kirk, \& Powers, 2009; Obst, et al., 2007; Raby, 2008). These papers have highlighted IIE initiatives on behalf of government agencies that have successfully diversified study abroad students, fields of study, institutions, and destinations. Because of this fiscal connection, these reports must be evaluated with a careful eye to potential bias. Still, they provide perspective on the challenges of maintaining current growth rates in study abroad and on helping study abroad reach a broader student population.

The sub-topics below provide additional details on the main themes in this anecdotal advice literature. These items provide a structure for the many individual pieces of advice and present a base for comparing my findings.

\section{Reduce institutional barriers}

Many of the topics in this literature fall under this category. Most of the authors recommend diversification of office staff in order to create a more welcoming environment for students from diverse backgrounds (Hoffa, et al., 2005; Jackson, 2005). Additionaly, most of these publications recommends diversifying student assistants and outreach volunteers (Picard, et al., 2009). Some authors have also added a focus on the 
importance of educating study abroad staff on the life histories of students of color (Flores, 2008; Le, 2008; Lewis, 2008). Others have highlighted the importance of maintaining resources such as details on racism abroad, information for heritage seekers, and even practical tips on hair care and other day-to-day concerns that may be magnified when a student is an outsider in a homogeneous host culture (Jackson, 2005).

\section{Reach out to students of color}

Many of these articles recommend reaching out to students of color by collaborating with other campus offices. Federal TRIO-SSS programs are often mentioned as a good source as are financial aid offices, multicultural offices, and others who serve a diverse community (Flores, 2008; Hoffa, et al., 2005; McClure, et al., 2010; Picard, et al., 2009). When reaching out to this student population some authors recommend addressing race in relationship to study abroad in initial presentations (Jackson, 2005; Lewis, 2008).

\section{Heritage seeking programs of short duration}

Much of the advice literature claims that the lack of heritage study abroad options is the main reason that students of color do not study abroad (Comp, 2008b; LeMay Burr, 2005; Martinez, et al., 2009; Obst, et al., 2007; Picard, et al., 2009; Raby, 2008). Heritage seeking in study abroad was described as the act of seeking out a study abroad venue based on perceived shared ethnic, religious, cultural, and/or linguistic familiarity at the host location (Comp, 2008c). This claim that heritage seeking is a 
primary study abroad goal has not been examined empirically. National data on study abroad contains only institutional summaries making it impossible to disaggregate program location by race and ethnicity (Chow \& Bhandari, 2010).

Recommendations around heritage study abroad often propose that students of color have job responsibilities, financial constraints, and family structures that prevent them from studying abroad for more than a few weeks. This has led to calls for shorter study abroad programs to serve these students (Comp, 2008b; LeMay Burr, 2005; Martinez, et al., 2009; Obst, et al., 2007; Picard, et al., 2009; Raby, 2008). This topic will be explored further in the section on study abroad outcomes for students of color as those findings have added complexity to this topic.

\section{Address race and build capital}

Although none of this literature mentions social and cultural capital a subset of the recommendations appear to be efforts to increase or recognize the social networks and cultural capital that students of color possess in order to help them access study abroad. For example some mention adapting admissions processes to better value different life experiences, others suggest that selection processes with high-stakes interviews, or homogeneous selection panels could disadvantage certain students. These ideas often connect with recommendations to diversify student clubs, peer mentor programs, and student assistants or to connect applicants to international students earlier in the process (Jackson, 2005). The interplay in these examples between tactics 
designed to increase social networks and strategies for changing institutional practice to better recognize a diversity of experiences places this literature at the intersection between traditional constructs of social and cultural capital (Bourdieu, 1985; Coleman, 1988) and CRT frameworks like community cultural wealth (Yosso, 2005).

When Students of Color Study Abroad: Outcomes and Experiences

This section begins with a discussion of the state of research on outcomes of study abroad and then examines all of the published literature on study abroad students of color.

\section{The state of study abroad outcomes research}

The study abroad community turned its attention to research on student learning. This attention on outcomes assessment is in alignment with larger trends in education (Hamilton, et al., 2007). Hulstrand (2006) described this movement as a coming of age for the field of study abroad. The trend towards assessment of learning outcomes in study abroad is evidenced by the 2004 special issue on assessment in Frontiers the only U.S. journal solely focused on study abroad (Vande Berg). Bolen's Guide to Outcomes Assessment in Education Abroad (2007) is the first publication of its kind for the field. Statements throughout Bolen's work supported Hulstrand's (2006) characterization and further demonstrated the growing interest in outcomes assessment in study abroad.

In her edited volume Bolen (2007) decried the lack of empirical research on study abroad learning outcomes. She presented her work as toolset to help practitioners 
and researchers overcome that gap. A gap, which has gained more attention with the growth in study abroad participation and the current climate of assessment in education (Steinberg, 2007). This attention is further evidenced by the publication of The handbook of practice and research in study abroad: Higher education and the quest for global citizenship edited by Ross Lewin (2009). This volume focused on presenting research that defined study abroad and global citizenship and proposed models for practice and assessment. Lewin's handbook continues the trend in study abroad of presenting empirical studies alongside anecdotal advice articles. In the increasingly data-driven political climate this mixed approach could limit international educators' ability as to convince administrators, lawmakers, business leaders, and the public of the necessity of study abroad in U.S. higher education for all students.

The international education community was not alone in their interest in understanding the impact of study abroad. Many associations and disciplines have begun to focus on study abroad outcomes in their publications. For example, the Association of American Colleges and Universities has been a strong advocate for the value of study abroad in higher education (2007). Their support became more concrete when they dedicated the Fall 2009 issue of Peer Review to study abroad learning outcomes (Anonymous, 2009). This issue showed how important learning outcomes of study abroad have become in higher education overall. The Journal of Geography also dedicated its May/June 2009 issue of its journal to study abroad (Pandit, 2009; Veeck \& 
Biles, 2009). The Journal of Studies in International Education dedicated its November, 2010 issue to study abroad (Adams \& de Wit, 2010). The fact that these three publications focused an entire issue on the personal and academic importance of study abroad that emphasized emerging research on the outcomes of study abroad underscores the increased attention on outcomes assesșment in study abroad.

\section{Limited research on study abroad students of color}

The momentum toward research on study abroad outcomes has not generated a substantial body of research on the experiences of study abroad students of color. Almost none of the empirical research in peer-reviewed publications has been disaggregated to by race and ethnicity, leaving their experiences out of the literature. To date only four empirical articles focusing on the experiences of study abroad students of color have been published in peer-reviewed journals (Day-Vines, Barker, \& Exum, 1998; Landau \& Moore, 2001; Morgan, et al., 2002; Talburt \& Stewart, 1999). Together these articles represent research on 26 African-American study abroad students. No other study abroad students of color have been included in peer-reviewed empirical studies. Two of the studies relate to programs in Ghana (Day-Vines, et al., 1998; Landau \& Moore, 2001), one in Spain (Talburt \& Stewart, 1999), and one includes the narratives of an African-American professor who traveled abroad, an international student from Africa, and an African American undergraduate woman who was considering study abroad (Morgan, et al., 2002). 
There appears to be growing interest in this area. Since 2006 six dissertations have directly or indirectly addressed the role of race and ethnicity in study abroad (Andriano, 2010; Guerrero, 2006; Jackson, 2006; Souders, 2009; Stallman, 2009; J. Young, 2009). This new research helps to overcome some of the gaps left by the limited published peer-reviewed empirical sources.

These dissertations provide some additional perspectives, but left many questions about the role of study abroad for students of color unanswered. Andriano's (2010) study on first generation student engagement in relation to study abroad does not disaggregate data by race and ethnicity making it impossible to know what role race and ethnicity played in the study abroad participation rates of study participants. One of the studies examines the impact of study abroad on White students' racial awareness (Stallman, 2009). It is thus related, but not directly applicable to my investigation. In her examination of national identity negotiation through study abroad Souders (2009) included one African-American student in a ten student qualitative research project and made some connections to the limited existing research on this population. Three of these dissertations focused primarily on students of color or included significant numbers of these students in their sample. Those were Jackson's (2006) research on the study abroad experiences of nine African American women, Guerrero's (2006) study on 15 Latino study abroad students, and Young's (2009) research on negotiating global identity in which 31 of the 40 respondents were people of color representing a range of 
racial and ethnic groups. The topics below emerged from this limited body of peerreviewed and doctoral empirical research.

\section{Heritage sought but not found}

Many of the heritage-seeking students in this research found that their expectations were not met. Limited empirical research on heritage study abroad makes it difficult to assess the claim that these programs increase participation by ethnic minority students (Morgan, et al., 2002). One study on students in Ghana looks at another aspect of this issue (Landau \& Moore, 2001). For Landau and Moore the fundamental question relates to the impact that studying in post-colonial or third world countries has on study abroad outcomes and the impact that the study abroad students have on the local community. Comp (2008c) provides a different perspective on heritage study abroad. His research proposes that minority students may find heritage connections with minority communities in their host country. This finding appeared to be in alignment with Jackson's (2006) finding that study abroad caused shifts in self awareness for students of color rather than the study abroad location and its connection to personal heritage.

Researchers on heritage study abroad identify a few key recommendations for practice. When considered with the anecdotal advice literature most suggest that there is a need for more heritage study abroad options (IES Abroad, 2009; Martinez, et al., 2009; Murray Brux \& Fry, 2010; Picard, et al., 2009). The research on heritage study 
abroad also indicated that heritage study abroad presented new challenges for students because of their expectations of fitting into the local culture (Bond, 1988; Landau \& Moore, 2001; Morgan, et al., 2002).

Some emergent research suggests that U.S. study abroad in developing nations can run counter to the social goals of the programs. The limited literature in this area presents provocative arguments about the nature and benefits of study abroad. Looking at the use of images in study abroad promotional materials led Caton and Santos (2009) to conclude that study abroad marketing materials for the program they studied tended to reinforce Western hegemony and to re-assert western superiority. According to some researchers short-term study abroad commonly resulted in a strict separation between study abraod students and the host culture (Janes, 2008). Other researchers found that short term study programs had a negative impact on host communities and proposed strategies for mitigation (Schroeder, et al., 2009). In their evaluation of resources for study abroad assessment Comp, Gladding, Rhodes, Stephenson, and Vande Berg (2007) proposed research on the impact of study abroad on host communities abroad. Within this context Biles and Lindley (2009) and Reilly and Senders (2009) proposed that the field is in need of a progressive re-positioning in order to overcome current dogma and ensure that the idealistic goals of study abroad are met for both students and host communities. 


\section{Rethinking identity through study abroad}

Even with this limited pool of research there appears to be growing agreement that study abroad can be a powerful site of identity negotiation. Researchers have begun to identify changes in identity as common study abroad outcomes (Angulo, 2008; DayVines, et al., 1998; Dolby, 2004, 2005, 2007; Jackson, 2006; Souders, 2009; Stallman, 2009; Talburt \& Stewart, 1999; Wick, et al., 2009, October; J. Young, 2009). The emergent nature of this area of inquiry is demonstrated by the fact that half of these sources on this topic are unpublished doctoral dissertations

The literature has begun to show that students reexamine their national identity because of their study abroad experiences. Dolby's $(2004,2005,2007)$ extensive work frames this area of inquiry. She has focused on examining national identity for study abroad students from the U.S. and Australia. She argues that encountering and negotiating American identity abroad is the most significant component of the study abroad experience (Dolby, 2004). For her these findings connect to discussions about the democratizing effect of education. She believes that the active view of American identity that students developed made them more connected, critical, and concerned about their home country. Of the 26 participants in her 2004 study three were students of color and their perspectives were not distinguished in her presentation of her data. One of her sections emphasized the surprise and discomfort her participants felt at being perceived as an outsider. CRT would suggest that students of color would be more 
familiar with this outsider feeling. Dolby's characterizes American identity as property that study abroad students carry. As students come to recognize this property they begin to examine its contents and develop new ways to live with it and benefit from this property they carry.

In addition to Dolby's research three of the dissertations I examined focused exclusively on identity in study abroad (Angulo, 2008; Souders, 2009; J. Young, 2009) as did one of the peer-reviewed empirical articles (Day-Vines, et al., 1998). Each of these studies takes a different approach and looks at a different aspect of identity. Together they suggest that study abroad may present powerful opportunities for positive identity negotiation. Only two of these works includes a sizeable number of students of color leaving many gaps in knowledge about these students.

One study (Angulo, 2008) focused on students participating in semester-long programs with quantitative instrumentation provided before during and after the study abroad experience. Her study used multiple quantitative measures administered before, during, and after to examine changes in identity because of study abroad. To provide a control group she administered a similar measure to students who had been accepted to study abroad. She was unable to complete the second phase of the control group research. She did not disaggregate her data by race and ethnicity or discuss impacts on these aspects of identity. From this research Angulo (2008) found that study abroad students experienced shifts in identity that were most closely correlated to living 
arrangements and level of involvement with local students. In her conceptual framework she suggested that identify development occurred for all of the students in her study, but that this identity was a broadening of U.S. identity for students who spent most time with students from the U.S. and an integration of host culture identity for those students who integrated more. The power of her statistical sample and limitations of her control group limited the generalizability of these findings.

Some of this literature begins to define the results of identity negotiation as global citizenship or global identity. Young's (2009) research included both focus groups and interviews to determine how study abroad students negotiated their new environments. She described them as having global identities, a construct that in some ways resembles Anzaldúa's (2007) idea of borderlands. This idea is close to Dolby’s (2005) construct of global citizenship based on her research on study abroad students from Australia and the U.S.. Both of these constructs emphasize an awareness of the interconnectedness of people across national boundaries and suggest a commitment to greater understanding among people. Together these constructs suggest that identity negotiation abroad may lead to another aspect of identity that may be called global identity, if focusing on the self, or global citizenship, when focusing on relationships to society. A similar construct of global citizenship forms the core of Reilly and Senders' (2009) critical study abroad. 
National identity formation was the subject of another recent study. Souders' (2009) study on national identity formation and study abroad provided additional support for changes in identity as an important outcome of study abroad. His qualitative research included a pre-departure and a post-return interview with each of the 10 participants. He found that students questioned their national identity as a result of their experiences on study abroad. His study included only one student of color. The differences between Angulo (2008) and Souders' (2009) two studies is striking. Both propose that shifts in identity occur during study abroad. Angulo's primarily quantitative study focuses on the psychological idea of identity as self-image or perception whereas Souders' grounded theory research emphasizes national identity and notes changes in this construct while abroad. Despite thes differeces both reach a similar conclusion. While on study abroad students tend to develop a more complex national identity that includes a greater sense of the world.

Ethnic identity was examined in one peer reviewed empirical article (DayVines, et al., 1998). Their study on African-American students participating in a twoweek program in Ghana suggested that the study abroad experience led to profound thinking about ethnic identity and had a liberating effect. However, the short duration of this program and controlled curriculum may have significantly impacted the students' focus on ethnic identity. Overall, these three studies most clearly demonstrate that 
identity is an important outcome of study abroad, yet they leave many questions unanswered about the impacts for students of color.

Identity appears to be highly malleable in the context of study abroad. Many of the researchers above noted that study abroad provided a useful research environment for studies on identity change since changes appeared more quickly than would be expected (Angulo, 2008). This work also hints at complex intersections between personal (Angulo, 2008), ethnic (Day-Vines, et al., 1998; Jackson, 2006), national (Souders, 2009), and global (D. Young, 2008) identities. Identity negotiation is a core construct in CRT. These results suggest that study abroad may create a unique environment for negotiating multiple identities free from the constraints of U.S. norms. For students of color study abroad can lead to a profound re-examination of national, ethnic, and racial identity. Jackson (2006) examined all of these details in her dissertation research and presented a compelling case for negotiation of intersecting identities on study abroad for the African-American women in her study. The three studies that Wick, Jackson, and Flores presented in 2009 demonstrated that study abroad students of color questioned their national, ethnic, and racial identity as a result of the study abroad process. They noted that this process of identity development led to renewed self-awareness and may have validated their experiences and added to their social and cultural capital. Their findings also suggested that study abroad propelled identity development and fueled a desire to make a difference in their home 
communities. This work suggests an important area for further study because of its connection to the experiences of students of color and connects to the social justice goals of CRT.

Personal growth and agency

The new perspectives gained on study abroad appear to have helped students grow in many ways and also develop agency. This view was most evident in Jackson's (2006) work. She noted that return students were very engaged and sought to give back to the program and their communities. This may be related to the sensitivity, maturity, flexibility, and confidence that all of these studies highlighted in the study abroad returnees. This agency may also be connected to the opportunity students had to negotiate identity abroad. This negotiation seems to have created opportunities to leverage existing social and cultural capital and also allow students to use their community cultural wealth in ways that had not been possible, recognized, or valued at home in the U.S.

\section{Conclusions and Implications}

The theoretical framework of CRT and its intersections with social and cultural capital, Third Space, and identity theories provided me with a lens for critically examining the existing literature on study abroad students of color.

The barriers research literature used focus group and survey research to determine why students of color do not study abroad. A CRT assessment of these studies suggests that 
most are rooted in deficit thinking about students of color (Delgado Bernal, 2002). Instead of challenging the institutional or societal factors that may have pushed study abroad beyond the reach of these students they present deficiencies in the students such as finances, family, and fear that prevented them from participating. Certainly all of the studies propose institutional changes to overcome these barriers, still most of these are marketing and outreach strategies designed to change the student rather than proposing changes to institutional pracice. Furthermore, the recommendations offered in the discussions tend to be closely aligned to the practitioner research. This may be due to the fact that all of the studies take a positivist perspective. CRT research on study abroad students and their institutions may yield different results by re-centering the research methodology and challenging commonly held beliefs about students of color and study abroad (Delgado Bernal, 2002; Ladson-Billings \& Donner, 2005; Solorzano \& Yosso, 2001).

Much of the anecdotal advice literature on study abroad students of color focuses on best practices for recruitment, advising, and program design. This emphasis seems to have distracted the field from looking at the relevance of inequity and the possible impacts on students, programs, institutions, and host countries. Many of the arguments in this literature are also heavily influenced by Eurocentric views on meritocracy and equality of opportunity and interpret many of the reasons students do not participate as deficits that 
education, mostly in the form of marketing and outreach, must overcome (Apple, 1990; Bourdieu \& Wacquant, 1999; Delgado Bernal, 2002).

For the most part discussions of diversity in the study abroad literature emphasize the benefits of multiple perspectives to programs and nations. A small literature problematizes the U.S. student presence in post-colonial or developing countries. These articles posed serious questions about the notion of study abroad as an unquestioned good (Caton \& Santos, 2009; Schroeder, et al., 2009). None of the current literature describes the underrepresentation in study abroad as a symptom of systemic inequity in U.S. education. One theoretical article challenges the study abroad community to develop a critical study abroad that challenges current rationales for study abroad and proposes changes designed to align it more closely with democratization and humanization (Reilly \& Senders, 2009).

Very few studies address learning outcomes for students of color and other underrepresented groups. Much of this research connects to research on identity negotiation. The articles and dissertations examined here suggest that study abroad is a powerful site for negotiating multiple identities and that this negotiation seems to provide students with new strengths. The limited research on heritage study abroad and identity development suggests that the outcomes for underrepresented students can be challenging in heritage locations due to the fact that their reception is rarely simple. A further examination of these results may lead to recommendations for practice. 
This review of empirical literature on study abroad students of color uncovered many gaps in knowledge: Most importantly, their narratives are almost completely absent from the literature, a total of 26 participants in four empirical studies published in peer-reviewed journals. Those who are included represent a very limited group, primarily African-American women who studied in Ghana. Furthermore, none of the existing literature connects their experiences abroad with their experiences as people of color in the U.S. Including recent dissertations in this study added a strong emphasis on negotiation of personal, ethnic, national, and global identity to the findings. Even when the studies did not focus on students of color they presented compelling evidence of the study abroad experiences as a vital context for identity negotiation. CRT suggests that building tools to negotiate the intersections between these identities can have powerful implications for social justice. These implications have only been minimally examined for study abroad students of color and the groups studied have been limited by the methods or samples in the studies. The present study is designed to provide insights related to the gap in knowledge about the experiences of students of color when they study abroad, the gap in connections to theories that help to explain inequity such as CRT and social and cultural capital theories, and the gap in frameworks for understanding identity negotiation while abroad for students of color. 


\section{Chapter Three: Methodology}

This chapter details the methodology for my study on how students of color leverage capital and negotiate identity through study abroad. The first section covers the design of this participatory qualitative study and presents the instrumentation. The next section outlines my role as a practitioner researcher and as an advisor to the participants in this research. My research questions and propositions form the third section and directly guided the next two sections on study context and participants. Research standards, and my own concern for the personal and intellectual development of the participants, guided the sixth section on ethics and protection of human participants. In the final three sections I outline data collection, validity, and data analysis procedures.

To address the gaps in the study abroad literature outlined in chapter two I conducted a qualitative study of study abroad students of color at two different points in the study abroad process: around three months after return and over a year after return. The literature review led me to the question: How does the study abroad experience shape the identity and goals of study abroad students of color? San Francisco State University provided an ideal context for this study due to the high percentage of students of color in its study abroad programs and the emphasis on a single program type, long-term cross-cultural immersion programs. The research question guided design and analysis, and pointed to my use of a participatory design (Fontana \& Frey, 2008; Kamberelis \& Dimitriadis, 2008) that included member checking with 
participants. This approach integrated participant voices into analysis, mitigated my bias as a researcher, and provided additional data. Sharing my process and findings with the participants allowed me to adapt my design during the research to respond to the needs and interests of the participants as they adjusted to life in the U.S. following study abroad.

I divided my study into two stages both of which included students from the 2008-09 study abroad cohort. The first stage consisted of open-ended interviews with four participants. The second stage consisted of five focus groups with an instrument informed by the interviews. I also reviewed participants' study abroad application essays and integrated topics and themes from these documents into instrument design and analysis. I used constant comparison to integrate data collection and analysis throughout my study (Bogdan \& Biklen, 2008).

In addition to the perspectives of my participants, I included additional perspectives by working with critical colleagues and research assistants. I defined critical colleagues as fellow researchers from my doctoral cohort who provided input and challenged my design, added perspectives on my analysis, and shared relevant literature throughout my study. They functioned in a way similar to critical colleagues in the teaching profession by providing a critical outside eye (Males, Otten, \& HerbelEisenmann, 2010). In these ways the critical colleagues helped me confront my own bias and expand my thinking. Two volunteer research assistants participated in my 
research process. They co-facilitated the focus groups, participated in data analysis, and reviewed my writing.

\section{Research Question and Guiding Propositions}

The guiding question for my research is: How does the study abroad experience shape the identity and goals of college students of color? I approached this question from a qualitative perspective to emphasize inductive reasoning, allow the findings to emerge from the data, and develop new theoretical frameworks (Bogdan \& Biklen, 2008). This research approach was well suited for examining identity negotiation during study abroad for students of color since the topic has not been examined.

I am basing my methodology on Critical Race Theory (Ladson-Billings \& Tate, 1995; Solorzano \& Yosso, 2001; Yosso, 2005). This theoretical perspective has been absent from the study abroad literature and is essential to understanding the experiences of people of color in the U.S. Using this framework led to my emphasis on student narratives and supports my focus on identity negotiation and capital. Bernal's (2002) comments support this approach. She wrote "researching from within this framework offers a way to understand and analyze the multiple identities and knowledges of people of color without essentializing their various experiences" (p. 119). Furthermore this approach introduces a new perspective into the literature. Bernal's (2002) statement that "the Eurocentric perspective has for too long viewed the experiential knowledge of 
students of color as a deficit or ignored it all together" (p. 121) describe much of the study abroad literature examined in chapter two.

Research Propositions

Six research propositions guided my research process.

- Study abroad should not be accepted as an unquestioned good for all students. Its benefits must be examined and may not be the same for all populations.

- Participation in study abroad requires social and cultural capital.

- Race and identity are central to the study abroad experiences of students of color.

- Study abroad creates opportunities for students of color to renegotiate their identity because intersectionality of race, class, and gender play out differently in a new cultural context.

- The process of identity development while abroad may augment the social and cultural capital that study abroad students of color leverage throughout the study abroad process.

- The narratives of students of color will reveal strategies and skills that help these students benefit from study abroad.

\section{Design}

The experiences of students of color are nearly absent in the study abroad literature. This gap led me to a qualitative research method. Qualitative research is most effective at gaining insights into topics or constructs that have not yet been fully explored (Bogdan \& Biklen, 2008). In contrast, quantitative or mixed methods are not ideally suited for examining the experiences of a population or phenomena that has not 
been fully described in the literature (Bogdan \& Biklen, 2008; Denzin \& Lincoln, 2008; Fraenkel \& Wallen, 2009).

I constructed the research in two main stages which both included students from the 2008-09 study abroad cohort. First, I interviewed four study abroad students of color within 6 months of their return from study abroad. I designed these open-ended interviews to gain insights into their study abroad experience and to expose relevant themes. The interview themes guided my planning for the second stage of data collection with the focus groups. Second, the focus groups provided a variety of perspectives and identified commonalities among participants. Furthermore, the experience of meeting together to discuss study abroad provided some benefit to the participants by connecting them to others who shared similar experiences and concerns. The focus groups became opportunities to process the study abroad experience and the challenges of re-adjustment in ways that participants appreciated. Following each group I received many email messages expressing appreciation for the opportunity to participate. As one wrote "thank you so much for that wonderful focus group experience yesterday." Others described what they found meaningful in the experience. As one student wrote "I really appreciate the opportunity to connect with the other study abroad participants." Even more than a year after returning from study abroad feedback on focus group participation suggested that it was a beneficial and positive experience. 
"It was so much fun to relive my experience among other students that also studied abroad and have been back for some time."

My selection of qualitative methodology was also tied to Critical Race Theory (CRT). Critical Race Theorists recognized that qualitative methods, and specifically research that amplifies the voices of people of color to create counternarratives that become tools for challenging social and cultural reproduction of inequity (Delgado Bernal, 2002; Denzin \& Lincoln, 2008; Ladson-Billings \& Tate, 1995; Solorzano \& Yosso, 2001). By documenting and disseminating these counternarratives they argue that research can become a catalyst for reducing inequity. The CRT perspective has been absent from the study abroad literature, and its application may lead to insights into the nature of study abroad for students of color.

The CRT scholars above also reminded me of the importance of making my research inclusive and emancipatory for participants. As Denzin and Lincoln (2008) caution, "qualitative research in many if not all of its forms (observation, participation, interviewing, ethnography) serves as a metaphor for colonial knowledge, for power, and for truth" (p. 1). Researchers have examined the potential colonial overtones of study abroad (Biles \& Lindley, 2009; Caton \& Santos, 2009; Schroeder, Wood, Galiardi, \& Koehn, 2009). Integrating a CRT perspective allowed me to challenge these histories by seeking ways that my research, and the programs I am studying, could facilitate the reduction of inequity. 
Participatory research allowed the participants to contribute to my research process, minimized the distance between researcher and "subject," and reduced the danger of the research simply strengthening my existing values and beliefs. In addition, participatory research may have a transformative impact on the participants and researcher that leads to positive change (Kamberelis \& Dimitriadis, 2008). The participatory element allowed me to learn with the participants and guided my choices, thus ensuring that participating the research met some of their personal and educational needs as study abroad returnees

The research design integrates longitudinal elements as well, through use of a synthetic longitudinal group. These elements were added in order to provide an historical perspective on the participants and to determine if their perspectives on study abroad changed as they re-integrated to life in the U.S. All participants in this study were from the same 2008-09 cohort of study abroad students as shown in figure 4. To achieve a pre-post perspective I reviewed application essays prior to each interview and focus group. These documents gave me insights into the participants' pre-study abroad presentation of identity. Many of the essays also provided clues about the social and cultural capital and agency that participants possessed prior to study abroad. To gain an additional longitudinal perspective focus groups from this cohort were assembled at different points in relationship to their study abroad experience. Since all participants studied abroad in 2008-09 the two groups in fall 2009 included recent returnees who 
had been home less than three months, and three groups in fall 2010 included participants who had been home more than a year. This design served the goal of gaining a multiplicity of perspectives, which is key to qualitative approaches (Bogdan \& Biklen, 2008; Denzin \& Lincoln, 2008). Identity, the primary construct I am examining is shifting and performative (ASHE-ERIC, 2002a, 2002c; Moran, 2003; Torres, Jones, \& Renn, 2009). This synthetic longitudinal structure provided insights into the dynamic nature of identity negotiation as students reintegrated in U.S. society.

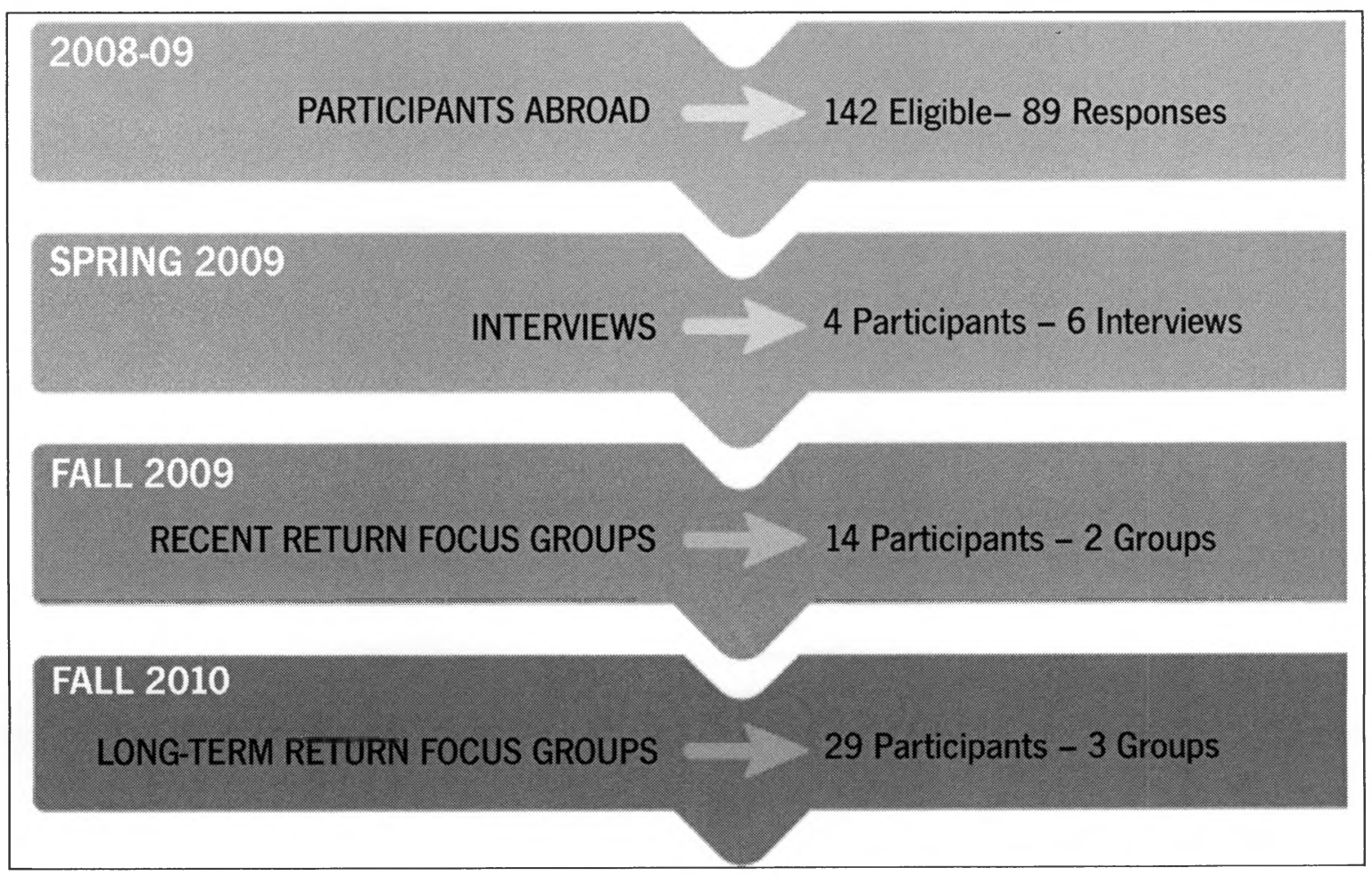

Figure 4. Timing and sample for this research. 
Stage One: Interviews

I chose open-ended interviews as the first stage of my research in order to allow the participants interests, needs, and perspectives to direct our discussion and the course of my research, to emphasize participant voices, and to generate rich data (Denzin \& Lincoln, 2008). This was especially important to me given that interviews are inherently political situations (Fontana \& Frey, 2008) in which I was in the position of power as their advisor and a White male. By re-enforcing how much their perspectives were helping me learn about my topic and design my research I sought to distribute that power more evenly. I conducted a total of six interviews with four participants. Each interview was approximately 90 minutes long and was recorded on a digital recording device with a backup recording on my computer. I interviewed the first two participants twice to get a detailed view of the themes for subsequent interviews and focus groups. I conducted initial analysis of the interviews with the first two participants before conducting one interview each with the remaining two interview participants.

As noted above, before each interview I reviewed participants' study abroad application essays. In addition to the longitudinal perspective mentioned above, these documents helped me to connect with participants more quickly during the interview as I had reacquainted myself with their backgrounds and study abroad goals. I used these insights to develop the interview question bank in Appendix B. To address my research question I did not adhere strictly to the question bank, but instead let the conversation 
weave through topics based on participant interests (Bogdan \& Biklen, 2008). In this way, I sought to avoid controlling the unknown in qualitative research by "imposing the structure of one's preconceived ideas" (Bogdan \& Biklen, 2008, p. 53). Thus, my planning prepared me for the interviews without constraining them. In addition, Bogdan and Biklen's suggestion that "equality, closeness, and informality" (p. 83) are desirable in interviews informed my approach during each interview.

I used the interviews to guide my planning for the second stage of my research. Reviewing the trajectory of the interviews helped me to see which topics and issues were most relevant and beneficial to the participants and most relevant to the research question. These observations provided me with key design insights for the focus groups and led to an instrument that emphasized creating connections by sharing stories.

\section{Stage Two: Focus Groups}

In stage two I conducted five focus groups. I conducted the first two groups with study abroad students within three months of return from study abroad and the remaining three with students who had been home for more than a year. I chose focus groups because they make it possible to obtain many perspectives while identifying shared understandings (Kamberelis \& Dimitriadis, 2008). In addition, focus groups create a fertile social environment for shared learning as participants co-construct knowledge (Bogdan \& Biklen, 2008; Kamberelis \& Dimitriadis, 2008; Stewart \& Shamdasani, 1990). It was my hope that the participants would enjoy the groups and 
would benefit from their participation. At the end of each group were reluctant to leave the room. They continued conversations in small groups. In addition to hugs or handshakes to express appreciation after the focus groups at least two students from each group wrote email messages to express their appreciation. As noted above these comments ranged from expressions of appreciation to descriptions of what they enjoyed about the groups with additional ideas or comments to add to my research. This level of appreciation from people who had traveled as many as 50 miles with no compensation suggested that the focus group had been meaningful and beneficial to the participants.

I used three sources to construct the focus group instrument. I developed initial questions from the results of my interviews. My analysis of the interviews guided the overall structure of the instrument by showing me which questions elicited the strongest response from interviewees and appeared to be the most beneficial for them. Second, I reviewed questionnaires used in research on related topics to connect my research to other research in the field of study abroad (Angulo, 2008; Flores, Lewis, \& Le, 2009, May; Jackson, 2006; Souders, 2009; Wick, Jackson, \& Flores, 2009; Young, 2009). Finally, I reviewed my instrument with study abroad professionals, critical colleagues, and research assistants. These sources allowed me to construct a comprehensive instrument that I could use as a question bank (Appendix C).

For the longitudinal aspect of the study I chose to conduct focus groups with participants at different stages in relation to their study abroad experience. My intention 
was to determine if there were differences in perceptions related to capital, identity, and agency as participants assimilated back into life in the U.S. I invited different participants to each set of focus groups and did not include interview participants in any of the focus groups. I took this approach rather than meeting students more then once in order to reduce testing bias, the threat of changing results by exposing participants tot he topic of the study (Bogdan \& Biklen, 2008; Fraenkel \& Wallen, 2009). I was concerned about this threat to internal validity because participants were examining many of the topics in the focus group for the first time and could begin to grow and change their perceptions as a result of their participation in an interview or focus group. Indeed, one of my goals for the interviews and focus groups was to give the students an opportunity to reflect on their study abroad experiences and its relationship to their identity. This participant selection approach also reduced mortality threats (Fraenkel \& Wallen, 2009). Mortality, leaving the study before completion, may have been a threat if I had tried to meet the same students within three months of return and 12-18 months after return since since many of the participants were close to graduation and likely to leave the area.

Focus group research has some important limitations. The main limitation of using focus groups is their tendency to normalize data, to reduce the importance of outliers, and silence divergent voices (Bogdan \& Biklen, 2008; Stewart \& Shamdasani, 1990). I began each group by explaining my background and goals for my research and 
explained the importance of gaining many perspectives. To further minimize this risk I used a system of member checking after every focus group. Immediately after each group I wrote individual messages to express my appreciation and invite further comments. This yielded some insights that had not been shared in the groups. After transcribing the focus groups I invited all participants to review the transcripts and share comments and reactions. This allowed participants an opportunity to provide their opposing views or additional insights in a non-threatening environment.

\section{Recognizing Bias in the Role of the Researcher}

As a researcher I am very connected to my participants despite many demographic differences. As a practitioner researcher my role allowed this research to happen and also allowed my findings to have a direct impact on my practice. At the time of the interviews or focus groups I had known the participants for at least 18 months in my role as study abroad advisor. I had helped them identify programs, complete applications, prepare for study abroad, navigate their international experience, and return home. This extensive contact, related to a major life experience, created closeness and a deep sense of appreciation from many of the participants. At the same time, I am very different; I am a White male in a professional position that gives me some authority and power over them. I chose to research study abroad returnees to minimize this power dynamic. At the time of the interviews and focus groups they had already received the support they needed from me. I also looked for ways to address 
their needs as study abroad returnees in my design. My intent was to give them an opportunity to critically examine their study abroad experience and reinforce the strengths they brought into it while processing and enhancing what they gained.

My relationship to the participants biases my research. Despite efforts to manage bias in the focus group instrument and with the research assistants I did not expect to capture many negative experiences or challenges to the study abroad experience. This would have been a major concern if I had been assessing the efficacy of study abroad. Since the goal of this was instead to identify a broad range of experiences and share student voices this bias presented an acceptable limitation.

\section{My Relationship to Participants and Institution}

As a study abroad advisor I have a close relationship to the students and institution in this study. I worked with all of the students before, during, and after study abroad. Each time I invited students to participate in this research large numbers responded enthusiastically. All of the students I contacted for interviews willingly participated in my study. Of the 142 students I invited to participate in the focus groups 89 responded enthusiastically within a few days. One student wrote, "I would love to help in your study! After all, without your help I probably wouldn't have even gone to Italy." Others offered to take time off work or make other schedule changes in order to participate in focus groups. These responses suggest a close relationship, and positive feelings that had an impact on the data that I collected. 
My connection to the institution introduced bias as well. I am invested in the success of the study abroad program and believe that study abroad has a positive transformative effect on students. This relationship introduced bias into data collection and analysis and could limit my ability to find results that are contrary to my beliefs. Because I am approaching this research from a CRT perspective I conducted it with the intention of challenging myself, and other international educators, to examine whether study abroad supports equity and to question the notion of study abroad as a beneficial experience for all students.

\section{Relationships in Participatory Research}

Conducting participatory research changes the role of both researcher and participants. In this research I sought to continue my role as collaborator with and advocate for my research participants and my students in general (Angrosino, 2008). “Continually taking your participants' welfare and interests to heart, and incorporating them into your practice" (Denzin \& Lincoln, 2008, p. 53) guided every aspect of this process. Conducting this research had an immediate impact on my work as I describe in chapter five.

The Researcher as Participant

By conducting qualitative participatory research I acknowledged that I could not fully control the direction of the research and also recognized that some of my findings would be about myself. In my field notes I documented how my findings challenged me 
to think differently about how my students experience study abroad. I also noticed how my interest in creating an enjoyable experience for my participants led me to be less direct about the most sensitive aspects of issues related to my topic such as race and class. I also appreciated the perspective that my role in this research is not only as designer, but also as instrument (Richardson \& St. Pierre, 2008). This means that I continually examined my influence.

\section{Critical Colleagues}

Critical colleagues played a key role in this research. Given the importance of multiple perspectives in CRT and the role that my position as a White male plays in my experiences I sought to include people with other life experiences in my research process. During my doctoral program I became very close to two other students due to

similar theoretical, social justice, and research interests. As we began to define our research we decided to work closely together to examine our design, writing, instruments, and data. This relationship is similar to that of critical colleagues as have been described in the literature (Males, et al., 2010). These women of color greatly enhanced my research through their insights and support as critical colleagues.

\section{Research Assistants}

Two volunteer research assistants participated in this project at different stages. These assistants also added to the multiple perspectives that CRT encourages because they brought different disciplinary perspectives and life experiences. They also 
enhances the dynamic of the focus groups and changed the power dynamics. In this way panelists were speaking with one person whom they did not know and who was not directly connected to their study abroad experience. The research assistants were people of color and brought their identity and perspective to this research. They volunteered to participate because of their transformative study abroad or international experiences and their desire to help amplify narratives of study abroad students of color to the study abroad literature. In the focus groups the research assistants provided additional perspectives on the topic. They also may have helped make the focus group environment more comfortable.

\section{Anticipated Bias}

Given the relationships above, bias is expected in the interviews and focus groups. First, all of the participants worked with me prior to and during study abroad. Many of them may come back to ask me for recommendations or other forms of academic, personal, or career support. Thus, many of the participants may want to say the right thing. In the initial prompts for the interviews and focus group I explained that the intention of my project was not to support the office or program, but to add to or challenge commonly held beliefs about the nature and meaning of the study abroad experience. The openness and candor of participants suggested that my role as their advisor did not limit their willingness to critique their experience or the role of the 
office. Even so, bias was a question that I returned to frequently in my field notes and data memos and discussed regularly with my critical colleagues and research assistants.

\section{Context}

The persistent underrepresentation of students of color on study abroad discussed in chapter two results in widely dispersed and small population of potential participants for this study. The range of study abroad models, institutions of higher education, and study abroad program providers break down this limited population even further. San Francisco State University provided an ideal location because it is a highly diverse institution, with unusually high rates of study abroad by students of color and a uniform study abroad model.

The site of this study is San Francisco State University (SF State). SF State is a public comprehensive university and has been designated as a Minority Serving Institution for its high percentage of students of color.

SF State is also a leader in study abroad. The percentage of students of color in study abroad (52\% in 2008-09) is much closer to the percentage of students of color in the campus population (64\%) than national averages which reached an all time high of 19.5\% in 2008-09 (Chow \& Bhandari, 2010). SF State's study abroad program has been highlighted as a leader in study abroad for students of color (Chow \& Bhandari, 2010; Institute for International Education, 2008; Norton, 2008a, 2008b). A commitment to exchange-based study abroad has created an affordable, scalable, sustainable, and 
replicable platform for continuous increases in participation and for diversification of destinations. SF State's focus on making long-term programs accessible to its diverse student population is rooted in the university's social justice and equity agendas. Given the persistent underrepresentation of students of color in U.S. study abroad this is a fairly unique setting and an ideal one for examining the study abroad experiences of students of color.

In addition, SF State emphasizes one type of study abroad. Of the five models defined by Engle and Engle (2003) all programs at SF State fall into the category of cross-cultural immersion programs. These programs are characterized by integration with local students, duration of at least a semester, living arrangements similar to local students, and curriculum related to the host country, language, or culture. This standardization makes it more likely that the results of this study will be transferrable to similar students on similar programs. Such a setting minimizes some of the program type problems that complicate other study abroad research (Engle \& Engle, 2003).

The Office of International Programs granted access to participants upon receipt of research approval from Office for the Protection of Human and Animal Subjects. This access consisted of a list of email addresses and application essays for students who had studied abroad during the research time period and declared a race or ethnicity other than White in campus demographic surveys. I wrote an individual email message and follow up messages to each participant inviting her or him to participate in study. 
Establishing the working relationship with participants went smoothly since they were already acquainted with me as their advisor. Still, to facilitate development of a researcher-participant relationship I began each interview and focus group by sharing my study abroad experiences and my interest in the topic. Showing that I was a student, albeit at the doctoral level, shared the experience of studying abroad, and valued their insights seemed to create a comfortable environment for data collection. This environment was further enhanced by the participation of the research assistants.

\section{Participant Selection}

The population for this study was comprised of study abroad students of color at San Francisco State University. The participants were all degree-seeking students when they participated in study abroad. For the interview a purposive sample was taken from students who met the above criteria between three and nine months after their return from study abroad. For the focus groups, all students who met study criteria were recruited at two stages in the study abroad process: (a) within six months of return from study abroad, and (b) more than a year after return from study abroad. The interviews included 4 participants. Five focus groups were conducted with 4-11 participants per focus group depending on responses to recruitment efforts. All participants were over the age of 18. Participants are not a vulnerable population and did not require any special accommodations. I know all of the participants through my work as their study abroad advisor. 
A total of 47 students (Appendix A) participated in this study. All of the students participated in what can be considered cross-cultural immersion study abroad programs (Engle \& Engle, 2003) of at least one semester in length. This research pool was very different from the typical study abroad student, who has been described in the literature as a White female, middle or upper middle class full-time student in the humanities, social sciences or business whose parents have completed college (Bhandari \& Chow, 2009; Hoffa, Pearson, Martin, \& NAFSA: Association of International Educators, 2005; Martinez, Ranjeet, \& Marx, 2009; Picard, Bernardino, \& Ehigator, 2009). In contrast to the typical demographic, all participants in this study were students of color, $64 \%$ were first generation college students, $45 \%$ received Pell Grants, a common indicator of low socioeconomic status, and their average age at the time of study abroad was 23 years old. Gender was not the focus of this study, still the percentage of $55 \%$ female to $45 \%$ male students was intentionally similar to the campus demographic of $58 \%$ female to $42 \%$ male (San Francisco State University, 2010).

\section{Interview Participants}

Interview participants were selected using purposive sampling. Because of the small number of interview participants I sought to have some variation in gender, ethnicity, study abroad location and study abroad duration. The four respondents represented study abroad students of color who studied in a variety of locations on longterm cross-cultural immersion programs. All four of the participants who were invited 
agreed to participate in the study. I conducted all interviews in spring 2009. Each interview lasted around 90 minutes. Figure 5 introduces these participants and provides demographic, academic, and study abroad destails.

\begin{tabular}{|c|c|c|c|c|c|c|c|c|c|}
\hline & 曽 & 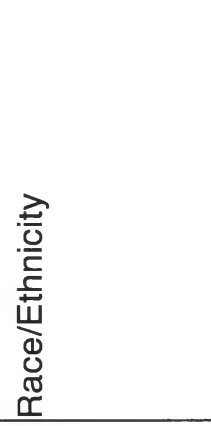 & $\begin{array}{l}\bar{\Phi} \\
\frac{\Phi}{0} \\
\bar{\Phi} \\
0\end{array}$ & 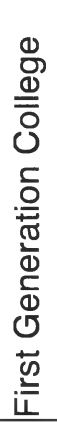 & 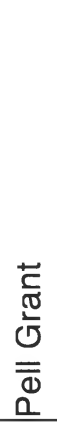 & 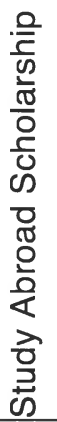 & $\begin{array}{l}\text { Zे } \\
\text { 壱 } \\
0 \\
0\end{array}$ & 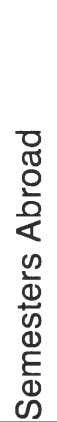 & $\frac{\bar{\partial}}{\sum^{\pi}}$ \\
\hline $\begin{array}{l}\text { Farryn } \\
\text { Bellamy }\end{array}$ & 26 & $\begin{array}{l}\text { African- } \\
\text { American }\end{array}$ & $\mathrm{F}$ & $\mathrm{Y}$ & $\mathrm{N}$ & $\mathrm{N}$ & Sweden & 2 & Liberal Studies \\
\hline John Chan * & 24 & $\begin{array}{l}\text { Chinese- } \\
\text { American }\end{array}$ & $M$ & $\mathrm{Y}$ & $\mathrm{N}$ & $\mathrm{Y}$ & Netherlands & 1 & Accounting \\
\hline Phuong Tran* & 22 & $\begin{array}{l}\text { Vietnamese- } \\
\text { American }\end{array}$ & $\mathrm{F}$ & $Y$ & $Y$ & $Y$ & Taiwan & 2 & $\begin{array}{l}\text { Health } \\
\text { Education }\end{array}$ \\
\hline Hady Ingham & 25 & $\begin{array}{l}\text { Arab- } \\
\text { American }\end{array}$ & $M$ & $\mathrm{~N}$ & $\mathrm{Y}$ & $Y$ & Hong Kong & 1 & $\begin{array}{l}\text { Environmental } \\
\text { Science }\end{array}$ \\
\hline
\end{tabular}

Figure 5. Interview participant details using pseudonyms demonstrating breath of perspectives. The participants with an * each participated in two interviews. Others participated in one interview.

\section{Focus Group Participants}

As with the interviews, the focus group sample was generated from study abroad students of color, as determined by responses to campus demographic questionnaires at the time of admission. The sample included students who studied abroad at all locations offered at SF State on long-term cross-cultural immersion programs during 2008 or 2009. The total eligible population was 149. Due to incorrect email addresses I was unable to reach 7 of the students. This reduced the population to 142 . 
I sent a personalized invitation email message to all eligible participants with one follow up message to those who had not responded. From these invitations, 89 responded that they would be willing to participate in a focus group. This represents a $62 \%$ response rate. Based on schedules a total of 47 students were able to participate in an interview or focus group. Thus $33 \%$ of the eligible population participated in the study. Four students participated in the interviews as described above. The recent returnee (around three months) focus groups included 14 participants and the long-term returnee (over one year) groups included 29 participants.

The demographic questionnaires that the interview and focus group participants completed allowed me to construct a demographic profile of the students. The participant profile presented in Figure 6 shows the distribution of students by race and ethnicity, gender, first generation college status, and Pell Grant status. These factors present a picture of the diversity of the group that is very different from national study abroad cohort (Chow \& Bhandari, 2010) as shown in figure 6. 

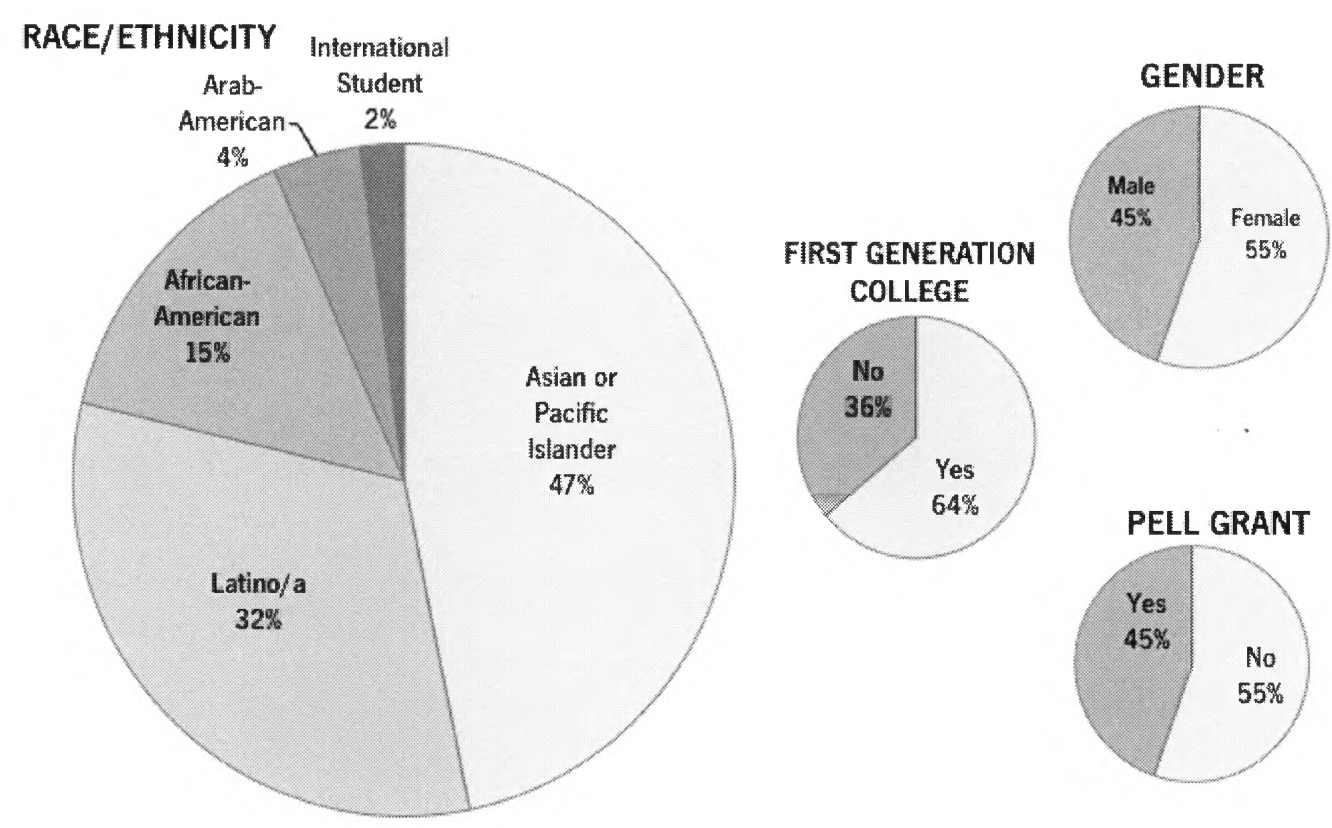

Figure 6. Participant demographic highlights $(\mathrm{n}=47)$ by race and ethnicity, gender, parental education level, and Pell Grant status. Additional detail is available in Appendix A.

I conducted the recent returnee groups in fall 2009; around 3 months after the students returned from study abroad. One year later, in fall 2010, I recruited additional participants from the same study abroad cohort to assemble to non-recent returnee focus groups. Each focus group lasted approximately two hours.

Focus group participants traveled to the focus group site and spent approximately two hours sharing their experiences with no compensation. Based on comments from participants and messages from students who could not participate it appeared that students agreed to participate because they had a positive experience with the study abroad office and on study abroad. 


\section{Ethics and Protection of Human Subjects}

Guidelines from the Office for the Protection of Human and Animal Subjects informed all aspects of my research. I discussed the intent of the research with all participants prior to data collection. I gave participants time to review and sign the consent form prior to participation in interviews (Appendix D) and focus groups (Appendix E). Each focus group participant also completed a demographic information form in order to provide standardized information on each participant (Appendix F). Participant data has been stored using pseudonyms selected by the participants and all identifying information has been removed to protect the identity of participants.

Theoretical discussions on participatory and emancipatory research methods challenged me to find ways to integrate participants in the research process (Angrosino, 2008; Denzin \& Lincoln, 2008; Kamberelis \& Dimitriadis, 2008). Because the goal of these types of participatory research is to bring out participant voices and specifically to understand the impact of study abroad on students of color I have integrated methods of member checking such as sending transcripts and data memos to participants. This resulted in some clarification of content and allowed participants to control how their voices were represented in my research.

\section{Data Collection}

The primary instruments for this study are the interview (Appendix B) and focus group (Appendix C) protocols. As indicated in the section on validity these instruments 
are based on a review of student essays, a review of procedures used in related research, and input from study abroad professionals, critical colleagues, and research assistants. The instrument for the focus groups was also influenced by the results of the interviews. These protocols were used as question banks in order to allow the discussions to evolve organically based on the needs and interests of the participants and researcher. Interviews and focus groups were recorded electronically and fully transcribed by a transcription service.

To engage participants in the research each was given a copy of her or his application essay to review upon arrival at the interview or focus group. This allowed participants a chance to consider their development since they applied for study abroad. Participants responded positively to the opportunity to look in the mirror in this way and saw this as one of the benefits of participation.

I recognize that my perspective as a researcher may have had a greater influence on the data I collected than the instruments themselves. This realization comes from Richardson and St. Pierre's (2008) assertion that the researcher is the most influential instrument in qualitative research. This perspective, and my commitment to amplifying participant voices, strengthened my desire to include the participants in every aspect of my research. Thus, I asked them to share their perspective on the interview questions and my developing ideas. I shared transcripts and data memos, and I invited them to 
contact me with other ideas. The critical colleagues and research assistants further expanded the research perspective.

I collected interview data through one or two interviews with four study abroad returnees. The students were equally distributed by gender and ranged in age from 22 to 26 when they studied abroad. All interviewees demonstrated high financial need, three were first generation college students, and all described themselves as members of racial or ethnic minority populations. All of these factors are underrepresented in study abroad (Chow \& Bhandari, 2010). In many ways these students were representative of those least likely to study abroad. Several researchers have noted that little has been written about what happens when underrepresented students study abroad (Chow \& Bhandari, 2010; Jackson, 2006; Sutton, Miller, \& Rubin, 2007). Given the lack of research mentioned in chapter two the interview results helped to frame the study and were used to develop the questions for the focus groups.

Due to a technical malfunction most of the recording for the second recentreturnee focus was lost. Working with the research assistant I compiled observer notes and reconstructed the bulk of the focus group data. I sent these observer notes to the participants as a form of member checking. One student carefully reviewed the notes and provided many additional details. Others felt that the observer notes had adequately represented their views. These efforts produced a transcript with almost as much rich qualitative data as the other group. 
During the data collection phase I used a variety of methods of tracking data and my emerging understandings. As noted in the analysis section, I wrote data memos related to the interviews and focus groups (Bogdan \& Biklen, 2008; Denzin \& Lincoln, 2008). I also kept a written and an electronic field notebook with observations and met regularly with critical colleagues and research assistants to discuss emerging concepts.

\section{Validity and Transferability}

In this study I am concerned about internal and external validity or transferability. The most important element of my efforts relates to instrument and coding validity. Developing the instruments with input from participants served to strengthen their validity for the research and also for the participants. Critical colleagues and research assistants have reviewed all data and shared their insights about key themes and potential codes. These outside observers provided a form of inter rater reliability that reduced my bias as a researcher.

\section{Internal Validity}

The first step to increasing internal validity with this study was a thorough analysis of study abroad literature and identity development literature. These approaches kept me connected to my topic of identity development for study abroad students of color. Recent dissertations on other aspects of identity development in study abroad informed my interview and focus group protocols (Angulo, 2008; Jackson, 2006; Souders, 2009; Young, 2009). The identity development literature provided a 
variety of models that I tested with my data (ASHE-ERIC, 2002b; Helms, 1993; Moran, 2003; Phinney, 1992; Phinney \& Ong, 2007; Rumbaut, 2005; Schachter, 2005; Tatum, 1992; Torres, et al., 2009).

My focus on the student experiences after study abroad helps ensure that I am gaining perspectives on the meaning of study abroad for these students rather than testing efficacy of study abroad as a learning experience. Thus, I wanted to check that the concepts I was exploring came from the participants, rather than from what I had seen in the literature. Indeed, the initial interviews connected the data in my findings to the literature and confirmed that identity played a key role in the study abroad process. External Validity and Transferability

While my primary concern is transferability rather than external validity I did use a number of measures to strengthen this. Amplifying student voices with extensive excerpts from student interviews, focus groups, and written statements added to the credibility of my study. Additionally, connecting the stories that the students told me after study abroad to the statements and goals that they outlined in their application essays provided a longitudinal perspective that suggested that participation in study abroad was related to the perceptions I was documenting.

As a qualitative study I do not expect the findings to be generalizable, but I hope that they will be somewhat transferable. The most important factor in transferability is the use of rich descriptive data. Some aspects of my methodology served to strengthen 
transferability. Narrowing my focus to university students of color allowed me to connect my findings to the literature on these students. Conducting interviews and focus groups with a relatively large number of respondents who participated in a similar type of study abroad program during the same time period further enhanced transferability.

\section{Data Analysis}

Inductive thinking guided my methods. Approaching my data inductively connected my analytical methods to my goals as a researcher. My intention is not to derive meaning from student experiences. I do not intend to measure changes on identity measures, as such evaluations are better suited to quantitative research. This approach to interpreting qualitative data emphasizes multiple perspectives, closeness to participants, and informality and is closely aligned with my constructivist worldview (Bogdan \& Biklen, 2008; Creswell \& Plano Clark, 2007). This approach encouraged me to immerse myself in the data as a process of discovering interrelationships (Fraenkel \& Wallen, 2009). Finally, inductive reasoning supported my recognition of research as a situated political act and consistently pushed me to challenge my assumptions and allow many interpretations of reality to emerge from the data (Denzin \& Lincoln, 2008).

During the data collection phase I used a variety of methods of tracking data and emerging understandings. Data memos were my first approach to analysis. These consisted of informal reviews small data chunks followed by open-ended writing (Bogdan \& Biklen, 2008; Denzin \& Lincoln, 2008). Critical colleagues reviewed these 
data memos and wrote their own. Research assistants read data and wrote data memos with me. This approach to analysis came from the perspective that writing is a method of thinking, analysis, and inquiry that reinforced the creative research process (Richardson \& St. Pierre, 2008). Through writing iterative memos, I gained a surface impression of the data and connected data collection and analysis throughout my study (Bogdan \& Biklen, 2008). I also kept a hand written and an electronic field notebook with observations and reactions. These sources provided another context for writing about my experiences as a researcher and for documenting my interactions with the data.

I coded data for topics and themes using constant comparison to analyze verbatim transcripts from the interviews and focus groups (Bogdan \& Biklen, 2008; Denzin \& Lincoln, 2008). Using both open and a priori coding provided many ways to see each part of the data. The a priori codes came from my examination of the literature and my past experience with this student population. These a priori codes included national identity, adjustment to host culture, adjustment back to U.S. culture, social wealth, cultural wealth, national identity, racial identity, ethnic identity, barriers, host country academic environment U.S., academic environment abroad, critical incidents, academic identity, goals for study abroad, stress, and life goals, Throughout the data collection phase of the project I used field notes and data memos to initiate meta analysis (Bogdan \& Biklen, 2008). 
The coding and meta-analytical procedures described above allowed me to reduce the data to a set of topics, themes, and sub-themes. I entered all coded transcripts in a spreadsheet to allow for easy manipulation. Using sorting and filtering functions I was able to see connections between participants and within the data. In this way the coding allowed me to see the data in many configurations (Bogdan \& Biklen, 2008). During this stage I continued to write regular data memos and to share them with my critical colleagues and research assistants. This allowed me to test the themes as they emerged and to continually refine my understanding of the topic.

\section{Methods Summary}

The methodology described in this chapter was designed to add the narratives of study abroad of students of color to the literature. This longitudinal qualitative research included 47 study abroad returnees (Appendix A) who participated in six interviews and five focus groups that took place 3-6 and 12-18 months after return. Participants had studied abroad for a semester or year in cross-cultural immersion programs in 16 countries. Documenting these experiences allowed me to investigate the role of identity in the study abroad process and to develop a conceptual framework of the study abroad experience for students of color from a Critical Race Theory perspective as described in the following chapter. 
I researched identity negotiation and the role of capital for study abroad students of color in order to amplify their narratives in the study abroad literature. This qualitative research included 47 participants in 6 interviews and 5 focus groups over an 18-month period in order develop a conceptual framework of the study abroad experience of students of color from a Critical Race Theory (CRT) perspective.

The findings suggest two new ways of understanding study abroad. The pre-post aspect of this research suggested that the transformative impact of study abroad on students begins at the time of application. Application essays showed evidence that participants began to develop capital, negotiate identity, and show agency in their applications. Participants took part in an interview or a focus group. The interviews and focus groups were scheduled 3-6 months after return and 12-18 months after return. Gathering data at these stages suggested that the learning from study abroad continues well beyond return. These factors led to my interpretation of study abroad as a process that begins when students determine that study abroad is possible. The interviews and focus groups with returnees helped me to see how the time abroad acts as a Third Space where participants could see themselves free from the constraints of U.S. society. This Third Space allowed participants build social and cultural capital, negotiate identity, and develop agency. These constructs of study abroad as a process and the time abroad 
as Third Space provide a framework for understanding the nature of the study abroad experience for the study abroad students of color who participated in this research. These two constructs are integrated into my discussion of the three key themes of capital, identity, and agency that emerged from the data.

\section{The Findings: Study Abroad as a Process and Third Space Abroad}

This research on 47 study abroad students of color from the 2008-09 study abroad cohort provided rich data to examine the nature of the study abroad experience. Review of the students' application essays prior to interviews and focus groups provided a view of the participants before and after study abroad. Furthermore, the interviews and two sets of focus groups provided a longitudinal element because of their timing in relationship to participants' time abroad. The first set of interviews and focus groups took place around three months after return, while the final three focus groups were scheduled 12-18 months after return. Taken as a whole these data clarified the conceptual framework in chapter 2 in two key areas. First, the data supported the idea that study abroad is a process that begins when students decide to apply. Second, the data suggested that the time abroad created a Third Space that acted as a unique opportunity for change.

Data from the two sets of focus groups did not differ substantively. The first two groups, conducted 3-6 months after return from study abroad, provided an opportunity to test the focus group protocol and yielded data related to all of the key themes. The 
second set of focus groups, conducted 12-18 months after study abroad, allowed for deeper discussion of the key themes that had emerged from the interview and focus group data. The most striking difference between the two groups was that more participants responded to my call for participants in the second set of groups. Because the data from the interviews and focus groups was nọt substantively different I did not generally differentiate the groups in my presentation of findings. Conducting focus groups with the same cohort at two times in relationship to the time abroad did strengthen the findings. This longitudinal approach confirmed that the changes that participants described shortly after returning from study abroad continued to be relevant more than a year after returning from abroad.

The data extended my view of the process of study abroad. Statements in the application essays suggested that the study abroad experience was not simply an event bounded by two plane trips. Instead, it was a process that began when the students decided that it would be possible to study abroad. Each of the major sections in this chapter presents data from application essays to show how participants began to leverage capital, negotiate identity, and act with agency when they began the study abroad process.

The Third Space of study abroad provided an environment for positive change related to capital, identity, and agency. For the participants the host environment abroad was a Third Space where they could reconsider and reinvent themselves free from U.S. 
constraints. The changes related to capital, identity, and agency were interconnected and resulted from the freedom that this Third Space accorded them. The changes that occurred in this Third Space contributed to new forms of capital, identity, and agency that students were able to access well beyond study abroad. Leveraging social and cultural capital through the study abroad process appeared to facilitate the creation of a new form of capital, global capital, which is comprised of global networks, language, and culture knowledge. The process of negotiating intersecting identities that included racial, ethnic, and American identities, contributed to a global identity. The final section on agency describes the confidence, commitment, and engagement that participants demonstrated in relationship to their future and the impact that they want to have on the world following study abroad.

Within this context of study abroad as a process and the time abroad as Third Space, I identified three major themes, (a) capital, (b) identity, and (c) agency. As shown in figure 5 these themes overlap and inform one-another. They all intersect in the Third Space of the time abroad. These themes emerged from the data at all stages of the research, responded to my research objectives, and related to the gaps in the literature. These themes bring together the experiences and perspectives of participants in my study in ways that maintain the complexity and integrity of their stories and add their voices to the literature. The data suggested that participants accessed and increased capital, negotiated identity, and developed agency intensively during their time abroad 
because the host environment functioned as a Third Space that allowed for change in all of these areas as shown in Figure 7.

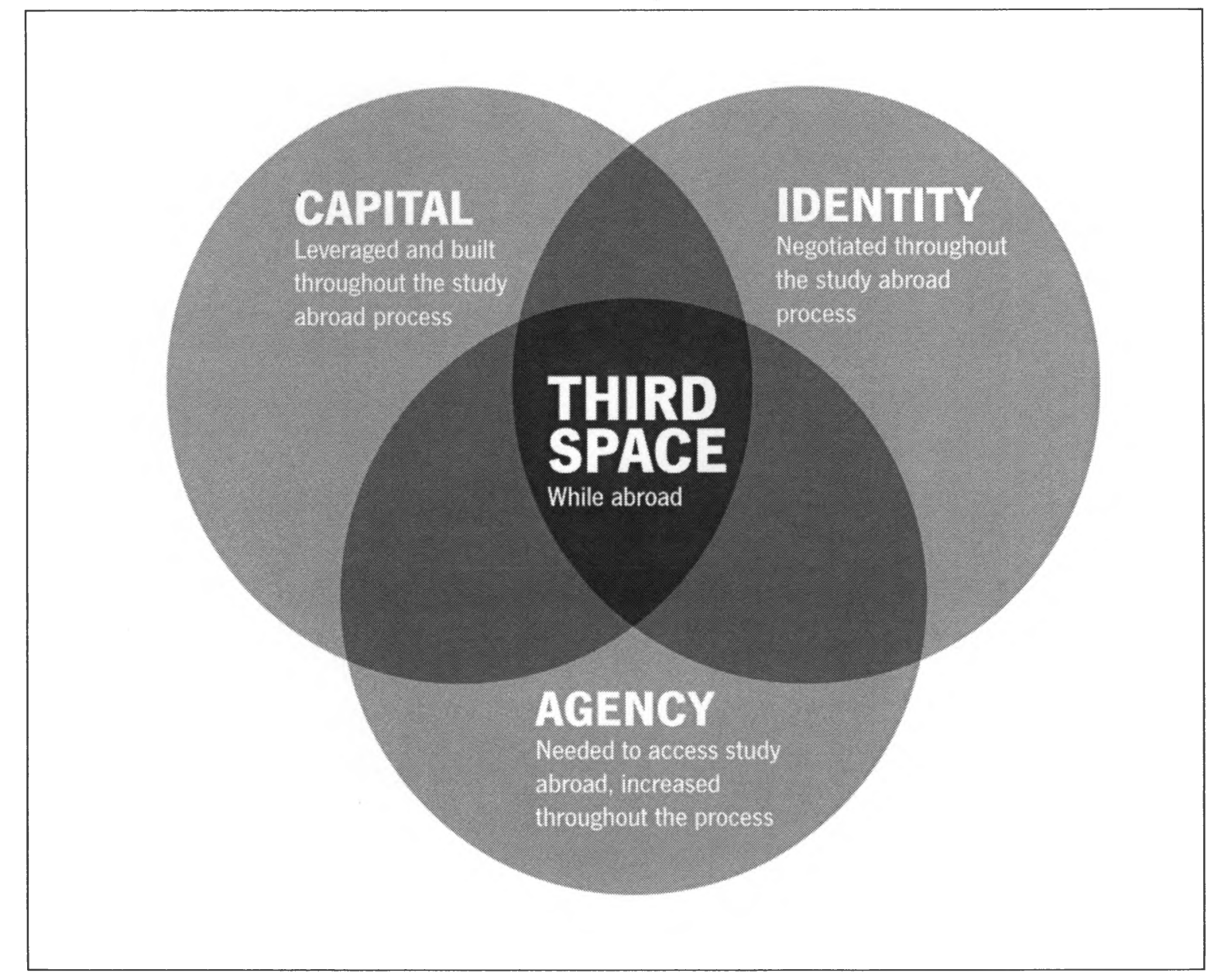

Figure 7. Diagram of relationships among findings. The three outer circles represent aspects of self that participants negotiated throughout the study abroad process. Third Space was created while the participants were abroad and provided an environment for building capital, negotiating identity, and developing agency.

The sections on capital, identity, and agency each begin with a focal narrative. I chose focal participants based on the strength of their narratives related to one of the main themes. Thus, these focal narratives serve to highlight the range of topics that will 
be covered in the section. This approach was designed to provide the reader with an organizational structure for the section without overwhelming the reader with 47 individuals to track (Appendix A). For all other participants I identify them by their study abroad location, duration of study, and self-reported ethnicity. I used these pseudonyms for clarity in cases where I compare two students with multiple quotes. All participant names are pseudonyms.

\section{Capital: Leveraging Capital and Wealth}

This section examines the ways that participants leveraged or built social and cultural capital throughout the study abroad process. Social capital, the aggregated resources that individuals can access through social ties, and cultural capital, the educational or intellectual assets that individuals can leverage to access institutions (Bourdieu, 1986) both played important roles in the study abroad process for the participants in this study. The application essays suggested that students required social and cultural capital from many sources in order to take the step to apply for study abroad. While abroad the Third Space of the host environment provided opportunities to leverage this capital. Participants also described ways that their community cultural wealth (Yosso, 2005) comprised of aspirational, familial, social, navigational, resistant, and linguistic capital, prepared them for study abroad. These assets are not generally valued in the U.S. context, but helped them succeed while abroad. Study abroad allowed participants to accumulate new resources in the form of networks of people, 
foreign languages, and knowledge that helped them develop what I am calling global capital.

To provide a structure for this section I begin with a focal student, Christine. Her story introduces most of the key themes in this sub-section. Following her narrative I examine the six sub-themes that emerged from the data in greater detail. These themes are (a) social capital from family in the U.S., (b) social capital from family abroad, (c) cultural capital from past travel, (d) social capital from peers and mentors, (e) social and cultural capital from study abroad advisors, and (f) global capital.

\section{Capital: Focal participant Christine}

For Christine, family was a key source of capital. When her parents took her to Belgium as a teenager to meet her cousins they built her cultural and social capital. She explained the impact of this experience in her application essay.

During my visit to Brussels, my seventeen-year-old cousin, Phi Ye, showed me around. However, we were unable to actually communicate. She only spoke French, whereas I only spoke English and Vietnamese. As much as we cared for each other, I deeply desired to speak with her. I wanted to communicate with family members - to share my feelings and thoughts.

The familial connection and linguistic tension she experienced created a personal connection to Europe, sparked her interest in French, and planted the seed for study abroad. She also had social capital from family at home and abroad. These forms of capital laid the foundation for her to access study abroad in college. 
Despite her long-term interest in study abroad she almost missed the deadline.

Her explanation for her late application outlined many of the questions that all students need to resolve as they consider study abroad.

I actually applied two weeks before. I was a last minute applicant. So even though I wanted to study abroad since I was a young person there are a lot of limitations, financially, I had a significant other - serious significant other, family, and I couldn't figure out how I could tie my major into going on study abroad.

Even though she possessed many forms of social and cultural capital she was still confronted with many barriers.

In order to take the next step and apply to study abroad some part of her network needed to provide additional social capital to move her to the next step. As Christine stated "what really encouraged me was, luckily, Kirsten she was a Fulbright scholar. She joined my track team - our track team. . She encouraged me everyday until I said, 'I'll go.'" Based on this encouragement Christine gathered information from the study abroad office. There she added the study abroad advisors to her network, thus building her social capital. Through this relationship with the study abroad office she learned that she could use financial aid and apply for scholarships. The social and cultural capital she gained from adding the study abroad office to her network helped her continue the study abroad process.

Making an international friend and working with the study abroad office allowed Christine to leverage her to her existing capital and moved her closer to her 
childhood dream of studying abroad. Yet, it wasn't until she made an academic plan that she knew study abroad would work for her.

I tied studying abroad in with my major at the time. I had to add-on a European Studies minor. [...] I remembered my fifth grade teacher she always traveled the world. She always brought in her slides during our field trips. We went on so many field trips for that class and I just wanted to do that for my students [when I become a teacher].

This connection back to an influential teacher suggests that she benefited from the additional cultural capital of an example of what she could do with her education to take the final step toward study abroad. It also shows that she had to increase her network by working with academic advisors in her major and her new minor.

In her comments Christine recognized that her story of almost missing study abroad was not uncommon. She also understood that challenges did not end with the application process.

A lot of people face the same, and some more challenges abroad and I think once you overcome that you come back so much whole and full and satisfied and I think that makes you a better person in whatever you decide to do.

This suggests that the capital she required to access study abroad changed her outlook and gave her new opportunities. For her, it was cultural capital from education, travel, and language studies that prepared her for the logistic challenges.

Christine's story highlights the range of social and cultural capital students may need to access in order to participate in study abroad. The cultural capital of language, travel, and academic work combined with her social capital from a supportive family in 
the U.S. and abroad was not enough. Additional connections provided the resources she needed to access study abroad. She attributed her decision to study abroad to new networks with an international student, the study abroad office, and academic advisors. Her efforts appear to have yielded results. She returned with increased social and cultural capital in the forms of global networks, language skills, and cultural knowledge that form a global capital that she may be able to adapt to any environment.

Social capital from family in the U.S.

Family encouragement provided a base of social capital for many of the students just as it had for Christine. When speaking of family, the most frequent comments among the participants described parents who believed strongly in the importance of international experience. Many students talked about how their parents acted as cheerleaders when students were nervous saying things like "You're going. This is a great opportunity," and "You've got to do it." and "You've got to do it." Many students explained that this belief was based on their parents' international background. As one Chinese American Participant who studied in Hong Kong stated "I grew up with immigrant parents. I've always had a world view that's not so, I guess, U.S.-centric." This type of social and cultural capital supported the intention to study abroad for many students and appeared to provide confidence as the students navigated the process. One student explained her father's role in her decision to study abroad in greater depth.

Actually, studying abroad in my college years was not my idea. I had to admit. I knew I was going to declare Spanish major and it was really my dad who was 
the native Spanish speaker from Mexico who encouraged me to take advantage of that opportunity and to go to Europe versus Mexico to kind of have access to all the travel while I was there.

This statement exemplifies the positive support that almost all of the participants in this study highlighted. This comment connects with Yosso's (2005) ideas around community cultural wealth and suggested that, in relationship to study abroad, the linguistic, national, and ethnic backgrounds of parents can serve as valuable forms of cultural wealth.

Based on the anecdotal advice literature, especially LeMay Burr (2005), I had anticipated that parents, especially Latino parents, would be barriers rather than facilitators in the study abroad process. Instead, all of the strongest examples of parental support were from Latino parents, as in the example above. Still, there were some examples that more closely resembled LeMay Burr's characterization of the role of Latino parents in study abroad such as this one from a long-term returnee focus group.

I'm one of the first people that - to go to college and the first to ever go abroad and stay there. So they had a really difficult time accepting it, just, I guess, culturally, too, "Why do you have that need to go somewhere else if you have everything here?" And that was difficult to really explain to them and for them to comprehend.

Another participant, a Mexican American, explained the negotiation between his father and mother about his year in France as follows.

It was easier to convince my mom because like - well, when my - like where my mom grew up, my mom grew up like in Guadalajara, Mexico. So, the, all the very affluent girls there went to France to study abroad, it's something, a dream 
that my mom never reached. So it was easier to convince her, but it was harder to convince my dad.

Thus, it was his mother's connection to international experiences, and memory of a missed opportunity, that helped secure his father's support. In doing so, he had to agree for them to travel with him to France to get him settled for his year abroad. These findings appear to be in alignment with Flores' (2008) description of the integral role that parents play in Latino students' educational choices. These findings reinforce her recommendation that study abroad offices develop the capacity to communicate with Latino parents about their students' study abroad plans. At the same time, the broader findings also demonstrate that offices cannot assume that all Latino parents will have the same reaction to study abroad.

The international experiences of parents provided many forms of social capital. One of the interview participants described how his Iranian mother had met his American father while both were international students. As he explains, this history made his study abroad semester Hong Kong seem predestined.

Both of my parents did study abroad, and they actually met, well it wasn't exactly study abroad but they were international students. They met as international students and then they kind of were teaching for a long time internationally. So, I kind of think that that was passed on as a social meme or something. I guess because I always lived in the States, but my parents had this international background, my mom's from another country and stuff. That always just gave me more of an interest in experiencing living abroad. So, in the back of my mind it always sounded really appealing. 
Thus, his social capital from his parent's international history guided his interest in study abroad. The desire to connect with parents played out for participants in many ways. His story connects to Christine's experience and with the student whose mother encouraged her because of the opportunity she missed when she was growing up in Mexico. These stories all related to social capital from parents. They also suggested that study abroad provided a way to connect with their parents' lived experience. Another aspect of this came when a participant described how his parents' experience emigrating from China to the U.S. guided his interest in study abroad and informed his choice of location.

Another big reason why I went to France is because, well, I didn't know the local language, French, like, my parents when they moved over here, they didn't know English. So I wanted to go as my rite of passage to go into another country and see if I can live on my own and adjust.

This participant exemplified what many of the participants shared, that study abroad was about connecting to their past. Yet, it stood in contrast to the heritage seeking study abroad literature presented in chapter two since these students sought to connect with parents through a similar experience, rather than by trying to trace ethnic or linguistic roots.

\section{Social capital from family abroad}

International family connections stood out as a form of capital in the application essays, interviews and focus groups. This theme was not addressed in the literature, but played a major role for many of the participants. Christine's story at the beginning of 
this section is a good example. Growing up bilingual in a Vietnamese-American household provided her with tremendous cultural and linguistic resources. Yet, for study abroad she saw the connection to her cousins living in Belgium as motivation to pursue study abroad. Similarly, one student chose the Netherlands because his Surinamese father had studied there on a scholarship and he wanted to connect to his father's experience moving from Surname to the U.S. and planned to meet extended family in the Netherlands. As he wrote in his application essay:

My dad was born and raised in Surname, a small Dutch colony in South America, and the only reason I am able to apply to this program today is because he received an opportunity to study abroad at the University of San Francisco.

Thus study abroad would allow him to connect with his father's experience of moving from Suriname to the U.S. for his studies while getting to know his extended family in the Netherlands and learning their language. For other students, it was extended family near the study abroad site that gave their parents the reassurance they needed to support study abroad. As one student explained,

Because my parents, were kind of, like a big obstacle in getting to Study Abroad, because they didn't want me to go to a foreign country. Fortunately, at that time, my aunts and uncles and grandmother, they actually lived in Denmark.

It was this family connection that convinced his Vietnamese-American parents to support his studies in Denmark. Another student talked about how her parents preferred that she study in Taiwan instead of China so that she would be closer to extended family in Vietnam. These global familial networks add to students' social capital and may 
suggest additional forms of capital that students of color may possess and can access during the study abroad process.

These narratives challenge current recommendations for increasing heritage study abroad options to entice more students of color to study abroad (Comp, 2008a; LeMay Burr, 2005; Martinez, Ranjeet, \& Marx, 2009; Obst, Bhandari, \& Witherell, 2007; Picard, Bernardino, \& Ehigator, 2009; Raby, 2008). Those sources suggest that students of color chose study abroad based on perceived shared ethnic, religious, cultural, and/or linguistic familiarity at the host location (Comp, 2008b). The narratives in this study suggest that many students of color already have worldwide networks. Study abroad students of color may also have language skills, and cultural knowledge related to other parts of the world. This breadth of social and cultural capital relates directly to what Yosso (2005) describes as community cultural wealth. The participants highlighted in this section all bring forms of community cultural wealth to the study abroad process that include familial, linguistic, and navigational capital as described by Yosso (2005). Bringing these stories to the fore may help study abroad advisors recognize the wealth of experience and global networks that students may have when they begin the study abroad process.

These stories also move away from the deficit model implied by the heritage study abroad literature. That literature indirectly suggests that students of color in the U.S. are not adequately connected to their ethnic or linguistic heritage, and therefore, 
need to go abroad to fill that gap (Comp, 2008b; Picard, et al., 2009; Raby, 2008).

These narratives show that most participants in this study have strong familial connections to their ethnic or linguistic heritage and want to use study abroad to expand upon these connections. Recognizing the social and cultural capital and community cultural wealth that students of color may bring to the study abroad process is one way to increase equity at the earliest stages of the study abroad process.

\section{Cultural capital from past travel experiences}

Similar to the participants in Jackson's (2006) dissertation research, many of the participants in this study had previous international travel experience. These past experiences appeared to provide cultural capital that supported the participant's intent to study abroad. As in Christine's story at the opening of this section, other comments in focus groups tended to provide evidence of language skill, experience with adaptation, and navigational skills. In other cases sharing stories underscored other forms of capital. For one interview participant who studied for a year in Sweden, access to travel provided her with perspectives that many in her community may not have had and gave her cultural capital that prepared her for study abroad 
I'm from, a working class and I grew up around people in the same neighborhood and what not. Most of my friends are from the church I attended, because we all went to the same church, we all went to the same schools, so we pretty much see each other 6 days a week. [It is a] lower class neighborhood and so a lot of my friends from there, they don't have the resources to travel that much. I'm not that much better off than they are, except that my Dad he retired from United Airlines and so until the time I was 25 I could pretty much fly anywhere United flew for really, really cheap!

Her travel experiences provided her with the cultural capital, and motivation to include study abroad in her education. She talked about how this motivation was strong enough to make study abroad work even after 10 years as an undergraduate moving from institution to institution as she focused her academic and career goals.

For some participants their experience immigrating to the U.S. provided both motivation and skills to related to study abroad. Participants in three of the four interviews and three of the five focus groups shared stories about how their immigration experience prepared them for study abroad. The clearest example of this came in one of the interviews because there was more time to expand. She explained the cultural capital she carried from her immigration experience as follows, "I think because for me like I understand because I was born and raised in Vietnam [until the age of 13.] I still have my cultures and all that." She believed that this background would help her as she prepared for a year abroad in Taiwan. She based this confidence on her experience learning English as a teenager and adjusting to U.S. culture.

Chinese culture and Vietnamese culture have similarities. So that is, I think, also the reason that I can adjust to the new environment or new culture very well. I also have the ability to learn languages in a short period of time. 
Her comments also illustrate her emerging understanding of the relationships between Chinese and Vietnamese culture. All of her strengths fit into Yosso's (2005) model of community cultural wealth. Yosso's model proposes that students who immigrated possess many forms of capital such as aspirational, familial, social, navigational, and linguistic. This example, combined with Christine's narrative, suggests that the participants leveraged this wealth throughout the study abroad process.

Other participants shared their past travel experiences in their application essays in order to show that they had the social and cultural capital to succeed on study abroad. For example, one Latina wrote in her application essay about how a short-term study abroad experience in Mexico that helped prepare her for the yearlong program in Sweden.

I participated in a study tour of Mexico through a Raza Studies course. [...] This was the first time I had returned to Mexico since my birth and the first time I had traveled out of the United States. During my trip I had the opportunity to observe the elections with a broadcast journalist from National Public Radio. The skills I learned in broadcasting quickly came into play. I observed the environment, took initiative, and reported next to a professional journalist during a chaotic, yet historic time.

By describing her experience in Mexico in her application essay she shows that she has acquired many forms of capital. She has cultural capital from coursework and this travel experience. She also has social capital from her international background and family. These strengths made the study tour she described possible for her. She perceived many benefits from this experience. As she wrote, "My trip to Mexico made me a stronger 
and wiser individual, the path to become the person." Another participant described similar gains in capital from her family trip Sri Lanka.

Visiting Sri Lanka for six weeks was an overwhelming experience for me. For the first time, I met many relatives that I never knew existed. I discovered a whole new world, one too complex and difficult for me to understand, and since then I wanted to learn more.

In addition to building her network through connections with family abroad, she also gained cultural capital in ways that resemble the stories shared above. These examples are representative of the types of past travel experiences to meet family or for vacation that many participants described in their application essays.

These representative narratives illustrate how past travel experiences served to extend social capital networks and deepen cultural capital in ways that prepared participants for study abroad. By highlighting the confidence and motivation they gained from past travel in application essays, these participant narratives guided me to the understanding of study abroad as a learning process that begins when students believe that it is possible. These narratives also highlighted the importance of valuing the strengths that students of color may bring to the study abroad process.

Recognizing and valuing the life experiences of people of color is one of the central tenets of CRT (Delgado Bernal, 2002; Ladson-Billings \& Tate, 1995; Yosso, 2005). The way that participants described their international connections through family abroad, and the past experiences underscored the resources that they possessed. These strengths are not necessarily what is valued in the study abroad application 
process. The essay prompts instruct students to focus on academic preparation and career-related goals for study abroad. By sharing past travel experiences in their application essays, these participants provided counter narratives that effectively conveyed evidence of social and cultural capital that prepared them for study abroad. This finding suggests that it may be beneficial for study abroad offices to change essay instructions in order to allow students of color to share their strengths. To increase equity in study abroad, offices may also need to re-evaluate the types of experiences that are valued in the selection process. This may require developing an appreciation for the forms of community cultural wealth that Yosso (2005) describes.

\section{Social capital from peers and mentors}

For many of the participants friends and mentors provided the encouragement that they needed to access study abroad. These models often seemed to create capital in multiple ways. In the example below, the participant decided to study abroad because a friend served as a role model.

Especially if you see people like you doing it, it's like, wow, why can't I - you know, and then it's - you feel like, yes, definitely, I can do it. That's how I felt when my friend went to Spain and that's what I actually did like, yes, I can do this. Yes.

Another participant talked about how his choice to study abroad came after years of community college, transfer to a four-year institution, and his decision to change majors. 
And so, I think, after a year into that I decided to do the study abroad. Actually, two of my friends they did it. And they said they had the best time. And, so, I was contemplating it. It was something new. It is not something everybody does.

This comment also forefronts the idea that study abroad is out of the ordinary. Accessing extraordinary opportunities requires capital. Furthermore, this comment reinforces the notion that study abroad is a process that begins when sțdents decide that it is possible. Direct examples like these were commonly shared in the groups. These peer interactions were often pivotal in deciding to apply for study abroad. International friends were often the source of this capital. As in Christine's story at the start of this section, the example of an international student was a powerful motivation for many. Participants talked about meeting international students and study abroad returnees in classes, clubs, and through language exchange programs in their application essays. These findings appear to support the assertions in the literature regarding the importance of role models and peer networks in increasing access to study abroad for students of color (e.g. Jackson, 2005). By connecting these ideas to social and cultural capital theories, it may be possible to develop systems that support students more effectively throughout the study abroad process.

\section{Social and cultural capital from the study abroad office}

The ways that participants talked about their interaction with the study abroad office highlighted its role in helping participants build or leverage the necessary capital 
to study abroad. This participant described the process of working with the study abroad office to prepare for her year in Spain.

Your first contact to Study Abroad is the first person you meet. And it was almost like in the beginning, I didn't have the belief, or the confidence, to think that I can: one, get into the program, and two, make it happening financially. And when I walked in and I met with you, you had all this - you were so optimistic. And it was just like, "Okay, then it's just going to work out." It's going to work out the way it's going to work out. And so I think that was really important, too, to keep on just flipping all those stones and just making it happen.

This comment highlights the fact that it was information and affirmation specific to the individual's needs that supported her process. Her comments build on Christine's story. Based on their quotes, both gained knowledge and developed networks through their connections to the study abroad office. In fact, many of the participants named specific advisors and shared stories about hearing a classroom presentation or meeting a study abroad returnee and coming to the office. This finding seems to support the advice in the anecdotal advice literature that more direct marketing to students of color will increase participation. It also adds detail related to what needs to be included in that marketing. Currently this literature emphasizes the importance of convincing students that they should study abroad in order to compete in the global job market. None of the participants in this study talked about needing to be convinced of the benefits of study abroad. They were already enthusiastic about the opportunity. What they needed were details that would help them overcome gaps in knowledge. They also needed to develop a supportive network so that they could move through the process with others. The 
study abroad office appears to have provided both of these things for many of the participants.

\section{Global capital from global networks and experiences}

The sections above describe many of the forms of social and cultural capital that appeared to facilitate participants' access to study abroad. In the Third Space abroad, participants developed strong bonds with students from all over the world who were studying at the same university while they were abroad. These new ties connected to many positive memories from abroad. They also appeared to give participants confidence. In other words, their success on the global scale reinforced their strengths and allowed them to build more capital.

Participants highlighted their new global networks in all of the focus groups. These conversations about new friends from around the world were most animated parts of the first four groups. This led me, and the research assistant, to ask one group to explain why they thought that such strong bonds had been created in just a semester or year abroad. One participant who studied for a year in the UK and a year in Australia tried to explain why these special bonds were created.

I think he's right. Just getting out of your comfort zone, getting out of that circle of friends and family, you're in a place you don't know anyone, you just have to change. You have to reach out to people.

Being outside of your comfort zone relates to the fact that study abroad is a Third Space in which new relationships are possible. The recent returnee focus groups mentioned the 
excitement of this new circle of friends. However, it was in the long-term groups that participants delved much more deeply into this topic. The fact that these new networks were still so fresh in their minds and had been maintained over 12-18 months suggests that the study abroad experience continued to enrich their lives long after their return. For this reason I believe that these networks may create a global capital that includes networks of people, language knowledge, navigational skills, and an awareness of different ways of seeing the world. Their answer supported my understanding of the Third space that is created while abroad. One participant elaborated on why he thought these networks were created abroad.

I think the fact that everyone is broken out of their comfort zone and we were in this, you know, pretty much the alien's base, really got us thinking differently, it was a big difference. When I went to Denmark, I was an introvert. I mean if I wanted to talk to you, I wouldn't have known how to. So, - and I struggle with that, but being in Denmark really forced me out of that - forced me to change. So, I guess the whole radical change of environment really does help.

His description shows how the time abroad is a Third Space that creates opportunities for developing networks in ways that may not have been possible at home. Based on these representative quotes, it appears that the other study abroad students and host nationals shared this openness to new connections.

This global capital appears to play a role in identity negotiation and especially agency development. Towards the end of the focus group Christine described how she had changed. In her description she considers how relationships at home have changed. 
She also examines how she has changed, in other words changes in identity. Finally, she describes her self-confidence and commitment to serving others.

I sure changed my perspective with my family, relationships with my family members. You know, I thought I had a good relationship with some family members and I realized it took - when I went to France, I took a step back, it helps when you're in a situation, it's hard to see clearly and when you step out and you look in, you see things a lot more clearly in different way and I'm not saying that It was - a bad change, it's just a change.

This explanation of her ability to see clearly from outside her environment supports my perspective of the time abroad as a Third Space that allows for negotiation of identities in a relatively neutral context. This context allowed Christine to develop in ways that she had not anticipated.

I think it helped me become a better person. It helped me become more assertive. It helped me to reach out to people who I could see needed this type of help and you know, I wasn't afraid to put my foot down more, and again to reach out to people and say "it's ok." So, I guess that really impacted my life. I didn't realize that until you [asked that question].

The ways that Christine, and many of the other participants, described their need to reframe relationships alongside their desire to give back to their families, institutions, and communities seemed to lead to the final results section on agency.

\section{Identity: Negotiating Intersecting Identities Abroad}

Starting with their application essays many participants connected their identities to their preparation and goals for study abroad. Given that all aspects of identity are socially mediated, it may not be surprising that an entirely new context created an opportunity for negotiation of intersecting identities that included racial, 
ethnic, and American identities. As examined in this theme, the identity negotiation that participants experienced abroad appeared to be possible due to the Third Space that was created when participants were able to examine their identities from outside the U.S. context.

This section explores the role of identity in the study abroad process and begins with focal participant Indigo. Her narrative brings together many of the key themes in this sub-section. As an African American student who studied in Sub-Saharan Africa her narrative also provided an opportunity to compare her experiences to writings on heritage seeking study abroad in the literature. The sub-themes in this section include (a) racial and ethnic identity abroad, (b) identity and heritage, (c) American identity, (d) global identity.

\section{Identity: Focal participant Indigo}

Indigo chose to study in Ghana for heritage seeking reasons as have been described in the literature (Day-Vines, Barker, \& Exum, 1998; Landau \& Moore, 2001). She focused her application essay on her ethnic identity and connection to Ghana as her primary motivation for study abroad.

I am African American and Jamaican and it is quite likely that Ghana is my ancestral home. It feels like a necessity for me to travel to Africa. [...] Traveling to Ghana will allow me to compare the differences between living in a Eurocentric country and an Afro centric country.

Her emphasis on exploring identity through study abroad in her essay lent support to my theory that the process of study abroad begins when students decide to apply. The way 
that she wrote about her goals for study abroad in her application essay matched the goals documented in the literature on African American students studying in West Africa (Day-Vines, et al., 1998; Landau \& Moore, 2001). This reinforces their recommendations to recognize this as a possible goal for African American students considering study abroad. Indigo's narrative also reinforces their findings related to the challenges of ethnic identity negotiation for African American students studying in Ghana.

Following the focus group Indigo was one of the many participants who sent written feedback to add to what they shared in the group. This excerpt from her written follow-up after the focus group describes how she negotiated her ethnic identities while studying in Ghana.

My study abroad shaped how I see myself by realizing that other people may see me differently. I am Black American/Jamaican and in America I am viewed as a "regular" Black woman. [...] But in Ghana some Ghanaians could look at me and can tell immediately that I am mixed with something else aside from West African.

This realization that she was not immediately perceived as an African was in conflict with her expectation that she was returning to a place where she belonged. The heritage seeking research describes how study abroad in West Africa is rarely a homecoming for African American students (Day-Vines, et al., 1998; Landau \& Moore, 2001). The authors also highlight the positive outcomes that can arise from this conflict.

For the first time I felt like I had to explain how I came to look the way I do. The ancestors of mine that are not African include Native American, East 
Indian, German, Irish and English. But I am predominately African. [...] I have always acknowledged my multi-ethnic heritage and seen myself as an African but I feel like I respect others views of what they perceive me to be more and I see it in myself now also.

Her words exemplify the type of comments participants in this study made about how they negotiated racial and ethnic identity abroad. Her writings suggest that she found ways to integrate all of her identities in a positive way. As was suggested in the research on African American students studying in Africa, her challenges as she negotiated her identity abroad were more intense than other participants in this study who did not travel to heritage-related locations. In the focus group she recalled that many people in Ghana believed that "If you're not white, you're not a full American. So, I have Ghanaians be like, "How did your parents tell you that you're not a real American?" And I'm like, "It's not like that."” This question sparked many reactions and affirmations in the focus group. Other participants could relate to this challenge of accepting their American identity because they were people of color. Indigo found this characterization problematic because it affected the ways that her other identities intersected with her American identity. She explained that her position as an African American woman in Ghana had a profound impact on her experience abroad.

Oh, here we go. Thank you. Okay being Black American it's different because of you're kind of caught in the middle, you know, like - sometimes you get called a White woman and you're like, "I'm not White," I don't identify as a white woman. I don't' identify with mainstream American culture generally speaking either. So stuff that they think that I do or stand for or believe in it's not, like we're a minority here, so that's not my cultural reality. 
The gap between the words used by Ghanaians to describe her and her self-perception made her experience challenging. This may have been more acute due to the fact that she expected to connect with her roots in Ghana.

After two visits to the Cape Coast Castle, a slave holding fort, she was able to make a connection with her roots. She was also able to reconcile some of her inner conflicts related to Ghana's history. She was not certain that the Ghanaians had made their peace with that history.

I got called a called a slave and some other black girl got called a slave. Cuz they, like they know how we got [to the U.S.], even though they act like they don't know, so the biggest insult they use to Black Americans is like "you're just a slave. We sold you into slavery." Like, stuff like that, it's like, whoa! Unnecessary!

In many ways her narrative simply reinforces those that have been presented in the literature (Day-Vines, et al., 1998; Landau \& Moore, 2001). What stood out in this research was the way that Indigo reached a complex sense of her intersecting identities that was overwhelmingly positive despite challenges. Indigo explores in depth the challenges she faced as she negotiated her identity in Ghana through an article she published about her experiences (Goodson, 2010). She wrote this article with the intention of sharing her experience with other African American students who study in West Africa so that they would be better prepared for the challenges of negotiating identity abroad. Her recognition of the malleability of her intersecting identities in a new context suggests a new form of identity that I called global identity and explore in 
the final heading of this subsection. This appears to have been possible due to the Third Space that she lived in during her year in Africa.

\section{Racial and ethnic identity}

The role of racial and ethnic identity emerged in my initial interviews before I asked any questions about it. This was important to me as a qualitative researcher, because I wanted to allow the themes to emerge from the participants (Bogdan \& Biklen, 2008; Denzin \& Lincoln, 2008). The fact that race emerged from the participants supported the CRT assertion that race as central to understanding the experiences of people of color in the U.S. (Delgado Bernal, 2002; Ladson-Billings \& Tate, 1995; Yosso, 2005). Its prominence also suggested that race continues to be salient when students of color leave the U.S.

Race and ethnicity have been examined to some extent in the study abroad literature. The barriers research examined in chapter two suggested that race, and specifically fear of racism abroad, is an important deterrent for many students of color (McClure, Szelenyi, Niehaus, Anderson, \& Reed, 2010; Murray Brux \& Fry, 2010; Van der Meid, 2003). Similarly, the advice literature usually includes fear of racism abroad as one of the potential impediments for students of color (Martinez, et al., 2009; Picard, et al., 2009). The presence of race in the interviews and importance in the literature led me to include a question about the role of racial or ethnic identity in the focus group protocol to gather more perspectives on this topic. 
While race was salient for many participants none described fear of racism as a major concern prior to study abroad. In each interview and focus group I asked participants to share their primary challenges prior to study abroad and none of them mentioned this topic. Given the emphasis on fear of racism as a barrier to participation in study abroad for students of color this finding surprised me. Thus, this finding may challenge some of the advice literature and barriers research. This finding from 47 students of color who had returned from study abroad 3-18 months prior may also demonstrate that, in retrospect, fear of racism abroad was not the most important challenge related to their study abroad experience.

Two of interview participants raised the topic of race early in their interview. For them it related to their choice of destination, both wanted to go to a place where they would feel different. John, a Chinese-American studied for a semester in the Netherlands and Farryn, an African American participant studied in Sweden for a year. Because so much of the literature described fear of racism abroad as a major barrier for students of color (McClure, et al., 2010; Murray Brux \& Fry, 2010) I asked them if they had been concerned about racism abroad prior to departure. Neither of them had cited fear of racism as a major concern prior to study abroad. Instead, they had cited other factors such as academic alignment, family concerns, and finances, as their primary concerns. Their stories provide counternarratives to the barriers research in the study abroad literature. 
John indicated that he had a few passing thoughts about race and racism prior to study abroad. He said that he had wondered, "Would I be treated differently? What would happen to me? Would I get mugged because I am Asian?" He described these questions as passing thoughts. When asked if he had any negative experiences abroad due to his race he stated "No, not at all." His comments may help to explain why fear of racism abroad did not come up as a barrier to study abroad in the focus groups. The mild concerns that he had were quickly alleviated abroad, thus diminishing the relevance of his initial concerns.

Farryn, also indicated that she did not have major concerns with respect to race. At the same time, she mentioned that her friends frequently asked her about race when she told them that she was planning to study in Sweden. "They're like, 'Sweden, are there any black people in Sweden?' I'm like, 'I don't know. I guess I'll find out when I get there." Even when she came back she noticed that the question simply changed to "Were there any black people there?" Because of these questions John and Farryn began to negotiate their racial or ethnic identities even before they left the U.S. This lends support to my view of the process of study abroad as a site for identity negotiation. In reflecting on his return to San Francisco John expressed his new perspective on his ethnic identity as follows.

Because I am Asian and San Francisco, there's a, I guess the district I live in, Sunset, there is a lot of Asian people. So, you know I was really comfortable. I guess, I was really comfortable. Everything seemed like daisies. When I went 
over there to Europe I was the only Asian person. Then I discovered that it doesn't matter what nationality you are, um, it's who you are as a person.

His statement about how he gained a new perspective on his ethnic identity following his study abroad experiences was echoed in comments from many other participants. These observations reinforce my theory that the time abroad is a Third Space that allows for negotiation of intersecting identities. Farryn put it this way, "[Study abroad] has opened my eyes as far as my view of the world and people in general and especially how other people view Americans. And how I view Americans." These examples suggest that, although fear of racism abroad may not be a major concern for students who have made the commitment to study abroad, it is still something that study abroad students of color and their families and friends may think about. This view suggests that study abroad advisors should include this topic as the prepare students of color for study abroad.

Additional support for including topics related to race and racism in study abroad preparation came from the few narratives about race-related conflicts that participants described. As in Jackson's (2006) research, participants talked about being "the only one" from their racial or ethnic group at their study abroad location. They did not see this as a problem, but recognized that it influenced their experience abroad. Two stories provide representative examples of the types of racialized experiences participants had while studying in countries where they were in the minority. John, the interview participant whose thoughts about race during study abroad were presented in 
this section, also explained a racialized event in which his Sri Lankan-French roommate was discriminated against at a club.

When we went to this bar one night all of us went in. and uh, You know, him being the darker skinned one they didn't say why, but they said 'you can't come in.' Yea, So I, you know, I didn't like that. And I told everybody let's just leave, because we don't want to hang out in a place that, you know, doesn't let. I knew what it was, because he's darker skinned.

In the interview John described how clear it had been to him and his other European and American friends that they would not patronize a discrimiatory establishment. This solidarity in the face of injustice was a source of pride for John. He also described how this experience created a close bond with this group of friends.

Another participant described how he saw discrimination play out in Hong Kong for himself and his girlfriend. As an Iranian-American he tended to be perceived as a White westerner and found that he was received very warmly. He described American Born Chinese students as 'superstars' in Hong Kong who received an even warmer welcome. However, he explained that his Filipina girlfriend had negative experiences related to race and ethnicity.

She is part Filipino descent. And you know that Filipinos and the other Southeast Asians such as Indonesians. They kind of have lower social status [in Hong Kong]. Because a lot of, especially the women, they come in as domestic workers and work in the sex trade and bars and stuff like that quite a bit. She would get a lot of people staring at her and being ruder to her. I think that the White people in the society there have maintained a higher status. They are not insiders, they are still not locals, but they see them as having value. I think that they look down on some of the Southeast Asian cultures. 
This example presents another type of issue that students of color may face abroad. It has been suggested that experiencing racial and ethnic relations in a new environment can help American students to re-examine their own ethnic identities (Comp, 2008b; Day-Vines, et al., 1998; Dolby, 2004; Jackson, 2006). Some believe that these experiences can lead to greater self-awareness and to a sense of pride in their racial or ethnic identity (Comp, 2008b; Dolby, 2004; Jackson, 2006). That said, these comments reinforce the recommendations in the above literature that the topic be addressed directly in preparation sessions for study abroad so that students can reach the positive aspects of this renegotiation instead of the painful ones. As suggested in Indigo's story negotiating ethnic identity in a heritage-related country presented some different challenges.

\section{Identity and heritage study abroad}

As noted in the introduction to Indigo's focal narrative, I gave special attention to the theme of heritage-seeking study abroad because of its importance in the anecdotal advice literature and the barriers research presented in chapter two. Heritage study abroad has been described as the act of seeking out a study abroad venue based on perceived shared ethnic, religious, cultural, and/or linguistic familiarity at the host location (Comp, 2008b). Because this goal for study abroad is directly linked to ethnicity it plays a role in ethnic identity negotiation on study abroad. 
All of the participants in this study had the option of choosing to study abroad in a country, or at least region, related to their heritage. Of the 47 participants in this study, only 12 explicitly mentioned that they chose their destination in order to connect with or learn more about their family background or language. Figure 8 shows country distribution for the study population and the locations that heritage-seeking participants selected.

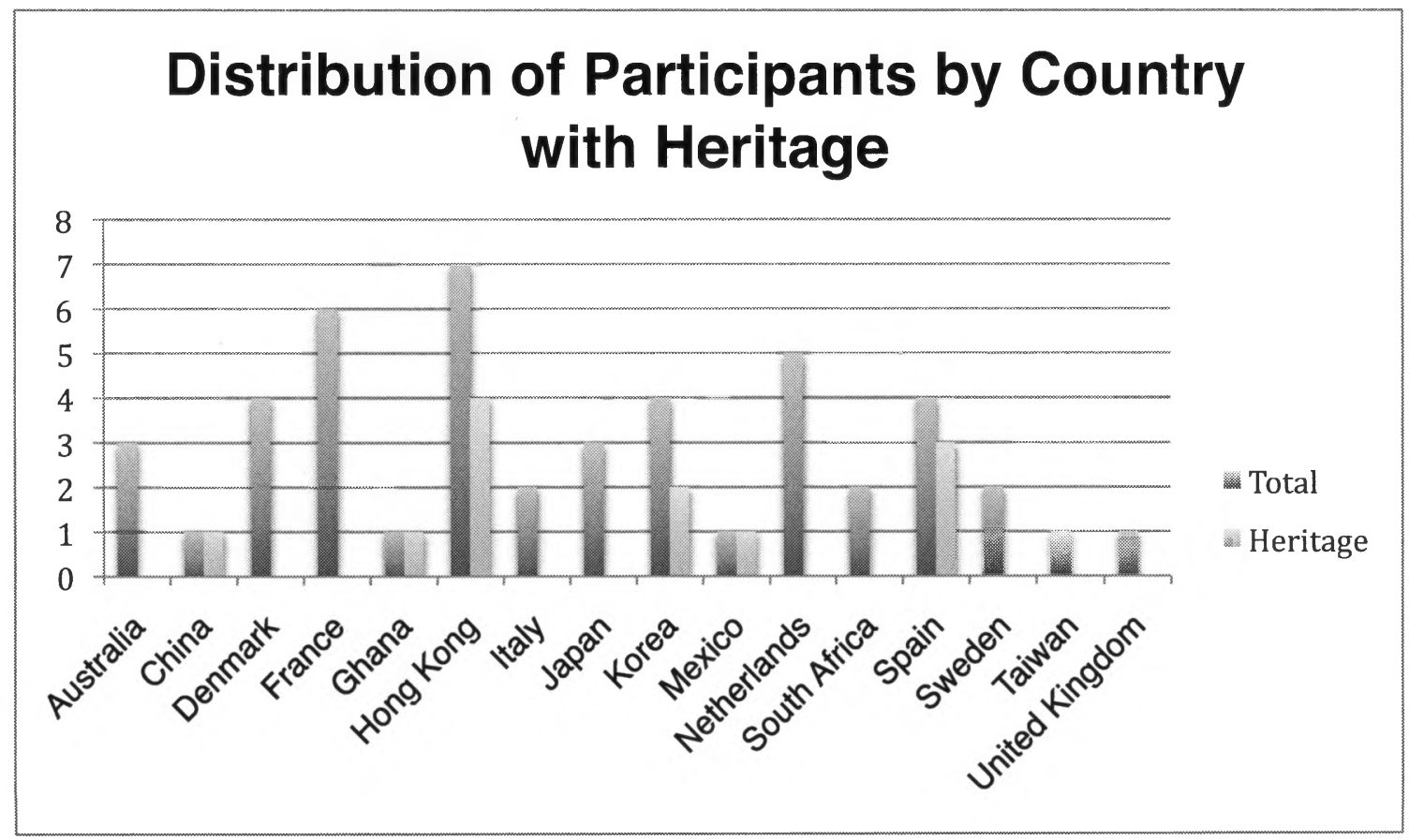

Figure 8. Chart of study participants by country with total participants in the country and heritage-seeking participants.

Although many participants chose heritage locations, these were not the top choice for any of the sub-groups in my study. Only one of the eight African American participants went to a heritage destination, four of the 15 Latino participants went to a heritage destination, and seven of the 22 Asian American participants chose a heritage 
destination. This finding aligned with Jackson's (2006) finding in her dissertation research that "the experience was more important than the location" (p. 119). These findings suggest that study abroad advisors should advise study abroad students of color by assessing their personal, academic, and professional goals before presenting heritage study abroad options.

When participants in this study selected heritage destinations their goals tended to be similar to what has been reported in the literature. This quote from one of the participants who studied for a year in Spain exemplifies the rationales of all four of the Latino participants who described exploration of linguistic or cultural heritage as one of their main goals for study abroad.

It was just really basic reasons for me. I was losing my mother tongue, Spanish, and it got to the point where I couldn't even communicate with own parents. Like, there were misunderstandings and I would throw an English word and say, "Mom, do you understand? Do you know what I'm saying?" And I wanted to really master my language, and I did that.

Thus, for her, the study abroad experience was closely connected to her identity as a Latina. It was also connected to her identity in her family and to her first language. Her statement is similar to what the other three heritage seeking Latino participants said. In addition to African American students, Latinos are the only subgroup of study abroad students of color whose experiences have been described in the literature, albeit only once, in Guerrero's 2006 dissertation. Thus, I sought compare my results against his findings. Both of our studies included 15 Latino participants. However, his 
methodology of quantifying qualitative data was a major barrier since he presented almost none of the qualitative data. Furthermore, the distribution of study abroad locations for the Latino participants in our samples was completely different. The Latino participants in my study went to 10 different countries and only four went to Spanish-speaking countries for heritage reasons. In Guerrero's sample of 15, ten went to Spanish-speaking countries, one split the year in Brazil and Mexico, and four went to non-Spanish-Speaking countries. Thus, although the number of Latino participants in our dissertation research was identical the differences in our methodologies and samples are so vast that a comparison of our findings was not possible.

The heritage-seeking participants frequently mentioned ethnic pride as a result of their experience negotiating their ethnic identity abroad. A Korean American participant who studied in Korea talked about the pride he felt while in Korea during Korean National Day. He mentioned that seeing all the people celebrating was moving. His comments underscored the sense of belonging that he felt. He also suggested that he did not always feel this same sense of belonging in the U.S. when he stated, "I don't want to appear racist, but I imagine that this is what White Americans must feel on the Fourth of July." Another participant, a Chinese American participant who studied in China found this sense of pride and belonging as she watched China prepare for the Beijing Olympics.

Also it was very touching to see the entire nation come together to celebrate the Games. There was a devastating earthquake 3 months prior to the Games, but 
everyone in the nation showed effort in rebuilding families and that area. In the end, everyone came together for the celebration. It gave me pride to be Chinese.

In addition to pride, she also experienced challenges to her identity on her second study abroad program in Korea.

In Korea, I had a few classmates who came from China. I spoke to them in fluent Chinese -- my Cantonese does not have an accent. One time a teacher asked them if there were other Chinese students, they said no, which meant that they did not consider me as Chinese. This made me feel a bit unaccepted.

This experience reminded her of the challenging relationship between her national and ethnic identity. An Asian American participant studying in Japan had similar experiences when he went out with other study abroad students. He related that waiters and shopkeepers always addressed him first in Japanese because he looked Japanese. Some of his White classmates had to respond since they spoke better Japanese than he did. These experiences highlight some of the complexity of negotiating ethnic identity abroad that participants shared.

Considerations about race and ethnicity did not always lead participants to heritage destinations. As in the section on social capital from family abroad, many participants described the importance of family connections in the host country or region in selecting their destination. These local connections guided five participants to locations that were not heritage countries and yet facilitated a connection to family. These participants included three Vietnamese Americans who studied in Taiwan, Denmark and France. One participant, who described himself as Surinamese-Chinese- 
Irish studied in the Netherlands to connect with his father's study abroad experience, extended family, and to learn the language and culture of the country that had colonized his father's native country. The fifth of these participants, an Egyptian American studied in the Netherlands because she was born in Italy and wanted to experience Europe. This location was the best fit for her major. Each of these examples suggests a similar motivation to that which inspires heritage-seeking study abroad. However, these examples present a different view of how students' heritage may guide their choice of study abroad locations. Understanding these relationships to heritage may help study abroad offices and advisors better understand the backgrounds of their students of color. Some of the anecdotal advice literature examined in chapter two presented similar recommendations by suggesting that study abroad advisors learn about the history of ethnic groups in the U.S. (Flores, 2008; Le, 2008; Lewis, 2008). This recommendation relates to CRT's emphasis on experiential knowledge (Solorzano \& Yosso, 2001), which underscores the importance of recognizing and valuing the complexity of the lived experiences of people of color. These findings related to the influence of heritage add more depth to discussions about the role of capital.

Heritage had one additional impact on location selection. Four participants intentionally selected locations that were not related to their heritage. All four of these participants described themselves as Chinese-Americans. One chose to go to France because he felt that a year in France would give him the confidence he needed to re- 
apply and study for a year in China later in his academic career. He achieved this goal and described how his initial international experience in France gave him the adaptability he needed for his year in China. He considered studying abroad in a Western country to be an easier transition because he grew up in the U.S. Two of the other participants who selected study abroad locations where they would be outsiders studied in the Netherlands. The final participant in this group, chose to study in France to experience what his immigrant parents may have felt when they arrived in the U.S. with no connections of language experience. This approach to heritage study abroad because of connections to Western culture, or to experience was it is like to be an outsider, or to understand their parent's immigration experience has not been addressed in the study abroad literature. Recognizing these possible motivations for study abroad students of color could lead to new ideas for outreach and advising practice. That said, all four of these participants mentioned that they lived in fairly homogeneous Asian American neighborhoods prior to study abroad. Thus, this finding may be due to geographic peculiarities in this study location rather than a larger phenomenon for study abroad students of color. Given that nine participants, or nearly $20 \%$, made decisions related to heritage that were not heritage-seeking decisions I recommend that future studies examine this theme.

Heritage had other impacts as well. Heritage interests led some participants to connect with their ethnicity as minorities in the host culture. This example from a 
Mexican American participant who studied in Japan brings together much of the complexity for participants who entered homogeneous societies in which they were clearly identifiable as different.

I really stuck out in Japan. The testimonials I heard before I went encouraged me to blend in. I couldn't do that in Japan where everyone else is Japanese. ... While I was there I reconnected with my heritage by taking Spanish, which I had grown up with but never really learned. Taking Spanish in Japan was a strange and interesting experience.

For her the experience of being an outsider led to a new opportunity to connect with her heritage and to consider the meaning of belonging. This idea of exploring heritage in a non-related country relates directly to Comp's hypothesis in his 2008 article U.S. Heritage-Seeking Students Discover Minority Communities in Western Europe. In that article he examined the possibilities for minority students from the U.S. to learn from and with minority populations in Western Europe. This representative example from my research suggests that this may be possible. However, the limited number of participants who addressed this in my research makes it difficult to draw any conclusions.

These findings related to the role of heritage in the study abroad process suggest a more nuanced view of heritage than has been presented in the literature. All of the examples support the importance of ethnic heritage in the study abroad process. However, these examples of participants who selected countries where extended family lives, or locations where they would be different are new to the literature. As noted above these findings support the CRT emphasis on counter narratives (Solorzano \& 
Yosso, 2001) because they highlight the role that personal history plays in the lives and choices of people of color. This framework guided my research process and may be why these different approaches emerged in my study when they had not been presented previously. As noted in the individual sections there are many possible implications for practice, all of which require recognizing individual student strengths With this recognition advisors need to listen to what motivates students, learn about their life histories, and value their experiences. , These approaches may help practitioners connect more students of color to the study abroad opportunities that will benefit them most.

\section{Negotiating American identity abroad}

Previous studies have examined the role of otherness in the study abroad experiences. For example, White students in Dolby's (2004) study became aware of their otherness abroad. She suggested that this alienation helped them examine their American identity. For the participants in the current study, it was often the recognition of sameness with other Americans that have propelled negotiation of American identity.

In this research, some participants and their families were concerned about how Americans would be received abroad. All 47 participants studied abroad at the same time, in 2008-09, during the last two years of the H.W. Bush administration. One of the interview participants, Farryn, who studied for a year in Sweden, talked about her parents' concerns about her safety as an American abroad. 
So when I first went over there, my parents were just like, you know, kind of be aware of where you are, don't necessarily walk out, walk around with your passport out, you know be conscious of your surrounding because you know, you are an American! I'm like okay, it was like in the back of my head but it wasn't like, I wasn't like scared or anything but I kind of didn't want to put it out there that I am black like yeah yeah! I'm American!

The balancing act between accepting her American identity and minimizing it for safety reasons points out the power of American identity for students abroad. Comments from others highlighted other challenges that American identity posed for participants. Indigo's comments on American identity highlight some of the complexity related to American identity negotiation that came out in this research.

Another aspect of being Black is stereotypes of Black American follow you when you are in different countries. [...] Ghanaian people would say things like Black American woman are emasculating, too strong, too street smart, aggressive, loud. American movies are watched all around the world and the negative portrays of Black people in the American media reaches everyone and affect their view of Black woman. People have negative thoughts about you before you even open your mouth [...] traveling abroad made me realize it is an international problem. Sometimes I feel like I have to relax people around me so they can be comfortable. I feel like unintentionally I end up disproving Black stereotypes.

These comments suggest that she came to recognize the challenges that stereotypes of African Americans posed in her international experience and then made a conscious decision to counter those stereotypes. In this excerpt Indigo appears to have learned to accept the property she carries. She then decided to challenge it. Furthermore, she appeared to have recognized that this understanding of her multiple identities gave her 
strength. Her perspective on the weight of her American identity related closely to the realization that participants in Dolby's (2004) study had of their identity as property. Dolby's (2004) research on national identity negotiation for U.S. and Australian students proposed an examination of American identity as property (Dolby, 2004). Interpreting American identity in this way may lead to recognition of the privilege that this identity can carry. Many of the participants in this study recognized that their American identity also carried a responsibility. In addition, many seemed surprised at their newfound privilege as Americans abroad. As Ace, one focus group participant stated.

I felt proud to be an American but there was no real distinction since everyone treated me really nice and I don't think it's because I was American. It may have been because I am Chinese and blended in with the culture because of my heritage. However, I became aware of the animosity between Hong Kong natives and Mainlanders.

Thus for her as a Chinese-American studying in Hong Kong, she had to negotiate national and ethnic identities at the same time. This negotiation of intersecting identities appears to occur due to the Third Space that is created by looking back at the U.S. from the host environment. For her, and others, this negotiation created room for both identities to be critically examined, and also allowed for both identities to co-exist. Another participant who studied in Hong Kong described a slightly different negotiation of American and ethnic identity.

But for me, it was more mental like being an $\mathrm{ABC}$, American born Chinese. I grew up in Pacifica which isn't too far, but there's a lot of White people there 
and so, for me, I feel like I'm a Twinkie, yellow on the outside, white on the inside. Going there, like first in Hong Kong, honestly, I felt really claustrophobic. I was like there's so many Asian people here. Every time I would see like, you know a tourist group with an American flag, or you know, a group of white people. I'd be like, "Oh, my people." And then I realize I look just like everybody else. So, it like - it was hard for me just mentally to adjust like, "I'm a Chinese. I am Chinese. I am Chinese. I am Chinese."

Based on her comments, this interplay between her ethnic and American identities was already present in the U.S. Entering the Third Space of study abroad made it more acute and led her to review the differences between how she saw herself and how others perceived her.

Nearly all of the participants in this study talked about discovering their American identity in the Third Space of their time abroad as an important, and sometimes challenging, part of their study abroad experience. As noted in Indigo's story, American identity is frequently perceived abroad through the lens of popular media and politics. The stories that participants told about coming to terms with their American identity alongside their racial or ethnic identity illustrated this complexity.

Privilege was an important topic in many of the groups. This connects to some of what Dolby (2004) described in her study. She found that participants learned to recognize that American ways were not always right. They also saw how others see America as a bully that often appears to dictate what is right. These findings related to American privilege suggest that students are already prepared to respond to Reilly and Senders' (2009) belief that "study abroad should deliberately address issues of 
economic injustice and disparity, and that we should push our students to analyze their own relative 'wealth' more critically"' (2009, p. 249).

Participants in this study described how the Third Space of their time abroad gave them the perspective to recognize the global implications of American privilege. Because they were looking at American privilege from the outside, their negotiation of American identity seemed to both expand this identity and also to force a critical examination of this identity. As one first generation Chinese-American participant indicated in a focus group,

I guess I - before I went over there, I guess I could say I was sort of like an ignorant American, because before that, I always felt sorry for people who didn't live in the States. You know, they're missing out on a lot of the great things here.

He acknowledged that he quickly changed his view "But then going there, I'm like, wow, you know. It's actually really nice there." Another student responded,

I mean, everything is there already and I guess my - what I thought was I didn't think other countries would be as civilized. I don't know if that's the right word. But they were - yes, pretty much the same, and if not, even - you know, more even better in some parts. Like where I was it was really nice: and the government would take care of their people.

These examples of recognizing American privilege are representative of the comments participants made about their American-centered perspective. In all cases it appeared that the Third Space of their host country made them more conscious of their quality of life in the U.S. In the excerpts above they were becoming aware of the material aspects of American identity and questioning this privilege. In the groups some participants 
explained that later in the negotiation process they noticed that they were able to see new options for their relationships with people abroad and with their American identity. Examples of this came in participants' understanding of the complexities of other parts of the world. As one participant who studied in South Africa explained how this played out with other international students.

And one thing that other international students pointed out to us is that when people would ask the kids from California where they were from, we would say California. And when they ask are there U.S. students? They would say, "We're from America" and they were kind of like, "How do you decide for yourself? Why do you do that?" And it was like, "Oh, I don't know."

This realization of the bigotry of U.S. students' expectation that others would have a strong sense of how identities in the U.S. are tied to states caused her to think about what she knew about the countries the other international students were from. She quickly realized that she did not have the nuanced view of other countries and cultures that she assumed others had about her culture when she introduced herself as from California rather than the U.S.

And then it made me kind of think more like I'm not going to be able to come here and be like all South Africans are like this and, you know, all Swedish people are like because I didn't like it when people were doing that about me. And I would kind of like, "No, they're from Ohio. They're from Minnesota. We're from California. We're different."

The Third Space of her time abroad helped her to see the meaning behind the expectations that she, and the other U.S. students, led her to challenge U.S. centered assumptions. 
So it just made me realize even though, you know, that's not true, obviously. I mean, we have some ways and everything. But I just thought, you know, like I hope that I accurately represent the differences in South Africa when I come back, the way I'm - try to like, represent the - one of the differences about being from the U.S.

The realization she describes suggests that she may be ready to challenge others to view relationships between U.S. and other countries in a more balanced way.

These few examples of confirm much of what has been presented in the literature. For students of color and White students study abroad creates a context for national identity negotiation (Dolby, 2004, 2005, 2007; Jackson, 2006; Souders, 2009; Talburt \& Stewart, 1999; Wick, Jackson, \& Flores, 2009). In order to explain why this negotiation occurs during the time abroad I propose adding the framework that the time abroad is a Third Space that creates a context for this identity negotiation free from the constraints of U.S. society.

\section{Obama's impact on American identities abroad}

Barak Obama's election as the $44^{\text {th }}$ president of the United States illustrated the shifting nature of negotiating American identity abroad. Research has documented how many study abroad students are struck by the realization that many people around the world have negative perceptions about the U.S. (e.g. Dolby, 2004). Identity is always contextual. The historic nature of Barak Obama's election as the $44^{\text {th }}$ president of the U.S. had an immediate impact on the experiences of the participants in this study. 
Farryn, an African American who studied for a year in Sweden, illustrates the nature of this historic event on how she was perceived in Sweden.

And then in my classes and things, there were a lot of people; I was surprised who were really closely following the elections and the debates and things. And so people knew that I was an American and they would ask like, "So who are you voting for and why are you feeling this way?' And so forth, and so on. And then after Obama got elected in November, like it was ... it felt like I got elected because on that day, so many people just kept coming up to me and saying congratulations, like we are so happy for you. I didn't hear anybody say anything negative, I should take that back! The only person I heard say something negative was another American!

Two of the focus groups digressed into active discussions about where they were when the election results were announced and how the people around them reacted to the news. Thus the positive reaction that many people and nations around the world had to Obama's election had a direct impact on the participants of this study. Indigo also talked about how people immediately shifted what they called her after the election.

It varies a lot in Ghana because you know I get called White girl, left girl, half cast. Jamaican I get that a lot which I am, so, but its weird how they even know because you look the same. It's just - you get called something different but then and of course the whole election then to all the Black girls they called "Obama! Obama! Come here Obama."

This immediacy of this change was a shock for many. After Indigo shared this in the focus group all of the participants shared their observations from before and after Obama. One talked about how everyone he knew hated Bush and loved Obama. Another talked about TV footage of the celebrations in the town of Obama in Japan. These small and large reactions all had an impact on this cohort of study abroad 
students that may have been different for others studying abroad at a different time. The overwhelming sense was that perceptions of the U.S. immediately shifted from negative to positive and perceptions of the participants changed at the same time. This finding reinforces power of the U.S. on the global scale and may help to explain why, in her second study, Dolby (2005) found that Australian students tended to notice their national identity while studying abroad much less than their American counterparts. These examples of the importance of Obama's election around the world suggest that advisors should prepare students not only for recognizing their American identity, but also for recognizing, and critiquing the impact that the U.S. has around the world.

\section{Negotiating a global identity}

I proposed the term global identity to bring together the sub-themes in this section on negotiating intersecting identities. Global identity has not been fully defined in the literature, but a few authors have discussed it. For example, Dolby's (2004) research concluded that study abroad led to profound learning about the self and relatively little learning about the host culture. Angulo's (2008) work provided a different view that suggested that identity negotiation was profound on study abroad because students were making room for ideas from the host culture. Neither of these studies analyzed the experiences of participants of color. Nor did they propose a framework to explain why these changes in identity were happening. The present research on study abroad students of color further defines this concept. First, this 
analysis proposes that the time abroad acted as a Third Space because participants were able to look at themselves differently than they would have in the U.S. This Third Space allowed them to critically examine their intersecting identities. By negotiating intersecting identities in this Third Space participants also appeared to recognize how their identities are contextually situated and socially mediated. Thus, this global identity allowed participants to make room for their multiple identities and recognize that identities are flexible and change based on location and current events, such as Obama's election.

After discussing how she negotiated her American identity abroad Indigo stated "My experience in Ghana just makes me feel like I can live anywhere and that anything is possible." Her comments are almost identical to what many others said in the focus groups and suggest that identity negotiation can lead to agency, as discussed in the final section of this chapter. By creating a Third Space her year in Ghana provided a rich environment for critically examining her intersecting identities. She explained in the focus group that she wrote and published her article (Goodson, 2010) to inspire others to take advantage of study abroad. When I asked her if I could cite her article in my dissertation she responded enthusiastically, because she hoped to share her perspectives with the broadest possible audience. With her, and others, the self-confidence that came from their understanding of their identities appeared to motivate them to give back to their home communities in order to share their newfound global identity. 
Agency: Confidence, Commitment, and Engagement

This section examines the role of agency in the study abroad process and the impact of the Third Space of the time studying abroad on agency. Agency, the ability to act reflexively and deliberately in response to outside circumstances, has been described as an essential tool for social change at the individual and societal level (Luckett \& Luckett, 2009). These authors also consider that agency is supported by social and cultural capital and negotiation of identity.

Similar to the themes of capital and identity participants in this study entered the study abroad process with agency. In many cases participants wrote about the inner strength that gave them the confidence to pursue study abroad in their application essays. Once abroad, participants gained agency in the Third Space of their host environment. The Third Space abroad was a new environment, free from U.S. preconceptions about race and ethnicity, that allowed participants to see themselves in new ways. For some participants the Third Space of the time abroad transformed their agency into global citizenship, a commitment to social justice, democratization, and humanization.

To provide a structure for this section I begin with a focal participant, Jackie. Her narrative illustrates many of the key themes in this sub-section. Following her narrative I explore four sub-themes that emerged from the data. These are (a) agency at 
application, (b) agency through new experiences, (c) agency as a critical lens, and (d) agency as global citizenship.

Agency: Focal participant Jackie

Jackie demonstrated agency in her study abroad application essay. For her, this agency at the time of application came from social and cultural capital that she gained through previous travel and community cultural wealth from her home environment.

I went to Italy for three weeks in January 2008. [...] I found myself learning the language and certain gestures quickly as a survival mechanism to obtain basic necessities. As a first generation Jamaican-American and child of a perpetually transitioning home environment, I've had to learn to reconcile and adapt. I am skilled and committed to making the study abroad experience a beneficial and growing time.

The agency evinced in these statements was also buoyed by her ethnic identity and life history. Later in her application essay she described how her success in overcoming poor academic performance contributed to this agency and prepared her for success during study abroad.

Being an NCAA Athlete, working two jobs, going to school, having been in a bad relationship and being new to San Francisco all affected my GPA my freshman year. Since then I have learned to better balance my academic and athletic careers with my personal life.

This agency Jackie required as she applied for study abroad reinforces the concept that students begin a process of transformation when they decide that they can access study abroad. It also reinforces the finding that students must have agency and capital in order to make the decision to study abroad. 
Jackie continued to access her agency to navigate the new systems when she arrived abroad. In the focus group she explained the competitive application process for the art school she hoped to attend abroad.

Going to the Academia di Belli Arte. Like, no one speaks English. It's an Italian institution. So, I was just like, "Oh, man." Like, oh, what did I get myself into, you know, and I took, probably about a year and a summer of Italian, and I was hustling, I was like yeah I need to get my chops up, I need to know how to speak Italian, and I was very intimidated. You know, everybody went in for the art exam. Everybody is serious, you know; let's get down to business. Yeah, and I'm like, I flew all the way over here. I have to get in to this university.

The determination she demonstrates in this quote suggests that she was able to apply the agency she brought to the study abroad process in order to navigate new systems and structures. Before and after this quote she described the advisors and teachers who helped her prepare for the exam. This additional network and knowledge facilitated her success in this new, challenging environment. The way that she shared this information in the focus group suggested that her success on the exam built confidence and had become a source of pride.

In her description of her time abroad she presented her interpretation of the Third Space that is created abroad. "I kind of just took a step back and looked at my life and considered, how do I want to live my life?" Thus, for her, the Third Space of time abroad supported development of agency in many parts of her life. It gave her a chance to re-evaluate her priorities. The supportive network abroad is another part of this Third Space. By the time she arrived in Italy the local coordinators already assumed that she 
would succeed. They then provided support, and social and cultural capital, designed to ensure that success.

In the focus group Jackie talked about how her confidence from abroad gave her the strength to have difficult conversations with her father and other family members.

It was more like a whole family thing for me, like coming out to my dad and people in my family, you know, because of how Jamaican's are homophobic and everything. After I [returned home], I don't know, everything just started to unfold. [... I realized] who was important and who, I can trust and who I can't trust, and who loves me for me.

Her realizations indicate that she may be more able to advocate for herself in difficult situations after return from study abroad. This form of agency allowed her to reveal her identity thus informing new relationships with family and friends.

Study abroad, it just - it opened me up and showed me the ways [of] being comfortable with who I am as a person and helped me be able to be open enough, for-- whoever, like my family members. Being able to open up and love and express myself to my partner and everything, and just being me and not hiding and not being afraid of anything, whether if it's in a workplace or, my personal life, or dealing with family, friends and associates or whatever. It's just you feel so much more empowered and happy, yeah. Happy.

The confidence, and happiness, that she shared with the group in this final quote appears to come from the opportunity she had to re-invent herself in the Third Space of her time abroad. My additional encounters with Jackie outside of the focus group gave me insights into what she did with this agency after study abroad. She became deeply committed to sharing her stories and to encouraging others to take advantage of study abroad and other educational opportunities. To reach a broad audience, she served as a 
bridge between the study abroad office and programs serving students of color on campus and in the community. In this capacity, she participated in many events. At these sessions she exuded passion and compassion as she shared her stories and encouraged others to give themselves the chance to study abroad. These actions appear to be outcomes of her agency from study abroad and relate to the construct of global citizenship that is presented in greater depth in the final section of this chapter.

\section{Agency at application and beyond}

As demonstrated in Jackie's narrative many of the participants entered the study abroad process with a strong sense of agency. They believed that study abroad was attainable. Participants used words like "proud," "confident," "motivated," "open minded," and "mature" to describe their readiness for study abroad in their application essays. Participants wrote about how these qualities provided the agency they needed to embark on this challenging experience and to succeed while abroad. Many participants wrote about how they developed these qualities. In doing this they showed how they came to be their own agents. As one participant wrote in her application essay:

Part of the reason I chose San Francisco State, rather than my home town of Los Angeles, is that I knew that being away from family and friends would force me to become more independent. Studying in South Africa will increase my independence and maturity to an even greater degree.

Through her comments she shows the agency she has applied to her past decisions and connects it to her choice to participate in study abroad. 
Based on the application essays participants also believed that study abroad would have a positive impact on them and on their family or community. All three of the focal participants wrote about how they hoped study abroad would increase their agency have a positive impact on the world. For Indigo, the focal participant in the identity section, she achieved some of this impact after studying abroad by having her article on her studies in Ghana published. She also participated in many events for the Black Student Union and other student groups in order to serve as a role model for students who may not have been considering study abroad. Christine, the focal participant in the capital section, wrote in her application essay that she hoped study abroad would help her reach her "full potential and become the inspirational teacher who will teach and encourage her students to strive for their dreams." This goal shows how her motivation for study abroad is not only personal. Their stories are good examples of the agency participants possessed as applicants. The stories suggest what they were able to accomplish with this agency through study abroad.

\section{Agency through new experiences}

The interplay of identity and capital in the Third Space of study abroad gave many participants confidence and agency to achieve their goals. Frequently, this interplay took place because of new experiences abroad. For another participant this new experience came in the form of mastering Spanish.

I woke up one morning. I went to class. It was second semester. I understood everything. I mean the accent was just so strange to me when I got there, 
because I'm used to Mexican Spanish, but then the Spain Spanish is so different. And when I'm like at school and I was just practicing my Spanish with the American friends going out, going to eat, being able to communicate, it was just like - I don't know - I saw angels and heard heaven. It was just awesome.

Many participants responded positively to this comment. They too recalled the moment when they were able to communicate effectively in the host language and acknowledged that it had been a major turning point. Learning another language adds cultural capital, and appeared to also facilitate the development of global networks described in the capital section of this chapter.

For others agency came from relatively mundane new experiences. For example, one interview participant who studied for a semester in the Netherlands, talked about how he learned to shop, cook, and ride a bicycle while he was abroad. Despite the common nature of these experiences when combined with all of his new experiences on study abroad he came to see himself differently, he was empowered. His description of these changes suggested that he recognized that his time abroad was a unique context. "Before that I had never cooked! I had only maybe made noodles, and maybe fried eggs but when I was there, it was kind of starting a new life over, that is what it felt like but you know short term just 6 months." The new life he describes is evidence for the theory that the time abroad is a Third Space that allows for profound changes because of the possibility for reinvention and the necessity of taking on new responsibilities. He attributed changes in his relationship with his family to the new experiences he had in the Third Space of study abroad. He explained that before he went abroad he did not 
talk with his parents much. As he said, "we didn't really talk about big issues. At the dinner table we just ate and discussed our day. And, not to be specific, just things like oh it was good at work, or at school, just small talk." His time abroad changed him and changed his relationship with his parents.

Now that I am back I have so much to tell them every time I am at the dinner table and I can ask my parents about their past! And so now that I have traveled, there were some really key words that would spark their interest and then they would comment on their experience. So, I said bicycles and my dad said, when he was in Hong Kong had a bicycle. You know I have never heard about his past, it was always my mom who shared stories, so like we are learning about each other too!

His comment highlights how his study abroad experience drew him closer to his parents' immigration experience and how it helped him to connect with his heritage. Thus, even though he studied in the Netherlands, his new perspective from international experience built a bridge between him and his parents.

These findings suggest that the new experiences on study abroad are not only important for what they represent, but that they may also contribute to agency and serve students in many ways after study abroad. Given the current culture of assessment in education (Hamilton, et al., 2007; Hulstrand, 2006) this finding could guide research into types of new experiences abroad that have the most positive impact on agency. Such research could help to differentiate outcomes from different types of programs (Engle \& Engle, 2003), or help to explain differences in outcomes from short and longterm programs. 


\section{Agency through a critical lens}

The agency participants described was often coupled with the development of a critical lens. For Jackie, this critical lens led her to examine her relationships. Indigo's experiences in Ghana also caused her to look critically at the expectations that she had for her experience in Ghana. Through this lens she was able to re-evaluate her preconceptions about Ghana and about what she would experience there.

For others, this critical lens related to an examination of differences in systems at home and abroad. This idea came out clearly in one participant's description of the perspective she gained from the comparative education class she took in Sweden.

When I was hearing other peoples education system, it kind of opened my eyes, that yeah we have our downfalls but so does everyone else and it is just, no one system has all the answers.

Others echoed her recognition that systems are different and should all be challenged or questioned. The two participants who studied in South Africa talked about many of these realizations. One of them used a critical lens to draw parallels between South Africa and the U.S.

I felt like I was living in the U.S., hearing my parents' stories or something, from the '70s or the '60s. But supposedly, it as over, like, "Oh, 1994 - Yay Nelson Mandela!" But it wasn't over. I was still feeling things. But of course, in the U.S. we also still experience racial tension and issues and not just racial, but economic issues that may be linked to racial issues.

This perspective on the U.S. relates to the Third Space of her time abroad. While abroad she was able to compare what she saw in South Africa to what she knew about the U.S. 
Through this critical lens she recognized that in the U.S. and South Africa racism, classism, and other forms of discrimination were still commonplace. In different focus groups, the 7 participants who studied in Hong Kong described "discrimination," "materialism," "prejudice," and "segregation" between the local population and people from the mainland. Rather than judge these differences they talked about the historic and political factors that created these divisions. None of them had written about these issues in their application essays. Thus, these ideas appeared to be new conclusions based on their experiences abroad. These examples of the critical lenses that participants developed abroad suggest that the Third Space of study abroad provided them with an opportunity to examine power and privilege in the world in new ways. Agency as global citizenship

The agency that participants gained from their new experiences and from development of a critical lens seemed to guide some students towards a notion of global citizenship. This term is used frequently in the study abroad literature (Dolby, 2008; Goodman, 2009; Hendershot \& Sperandio, 2009; Lewin, 2009; Reilly \& Senders, 2009; Tarrant, 2010). However, the meaning is contested. Most of the definitions consider global citizenship to be a commitment to citizenship and democratization. Based on this research I suggest adding humanization and social justice in the U.S. and abroad to this definition. I propose these changes because the participants in this study frequently returned from study abroad deeply committed to having a positive impact on the world. 
This idea was most clearly stated by one of the interview participants, a Vietnamese American health education major, who studied for a year in Taiwan.

I want to do something that contributes to different communities overseas like the poor communities. Want to reach out like I'm not like a rich or anything, but [I really want to] do something for them.

For some this interest related to volunteering to do global development work as in this example. Others joined tutoring programs in their home community. Others redoubled their commitments to family members and friends in need. Some simply wanted to share their study abroad stories with as many people as possible so that others would benefit from the opportunity that they had. In all of these cases participants credited their perspectives from study abroad as motivation for these commitments.

Not all participants described global citizenship. Some shared their views about having global options thanks to study abroad. This idea generally appeared in the form of optimism and self-confidence. One of focus group participants put it this way.

By me going abroad, I learned a lot about different cultures and plus my self. You know, I learned about other cultures as well as other things there but not more like about other things but more like about my self.

He begins by acknowledging the global identity be brought back from abroad and also recognizes the global capital that he acquired. He continued his thoughts with a sentiment that was almost identical to what Indigo shared by stating "If I can go somewhere else and survive and adapt another culture, back here is a cake, I mean, I can do almost everything." Similar self-confidence and agency led other participants to 
commit to giving back to their community. From past research, especially Jackson's (2006) dissertation research, I expected participants to want to contribute to promotion of study abroad after return. As with Jackie, many participants returned with passion and commitment. This commitment led some to become roll models for others. One participant described how she encouraged her cousin to take the leap and apply to teach in Korea for an academic year. She remembered her challenges during the year, but judged that it was worthwhile and encouraged her cousin.

So I was never really alone for an entire year. Time was my problem. But after going, I came back and immediately my cousin was like, "Oh, I'm going to teach English in South Korea like I don't know if I can go for a year." And I'm like, "Please, a year of your entire life is nothing like you're going to want to stay there for five more years if you enjoy and you will.

This perspective on the change that can occur in the Third Space of the time abroad led some to change their path and consider lives of service as discussed in the first section on agency with the examples of the three focal participants, all of whom committed to giving back after their study abroad experience.

\section{Summary and Synthesis}

When I began this study I hoped to develop a framework for understanding why underrepresentation of students of color on study abroad is an equity issue. To answer this I had to know more about what students of color gain from study abroad. The literature gave me a few ideas and guided me towards a conceptual framework. Explorations of identity in relationship to study abroad were most promising and led to 
my research question: How does the study abroad experience shape the identity and goals of college students of color? Starting with this question provided insights into the nature of study abroad for students of color and the interplay of capital, identity, and agency in the Third Space of study abroad. This Third Space allowed participants to leverage and build capital, negotiate their intersecting identities, and develop agency that guided them in their future. For most participants these increases in social and cultural capital allowed them to developed global networks, language skills, and cultural knowledge that could be considered a form of global capital. By negotiating racial, ethnic, and American identity they found more strength in all of these and made room for a new global identity. This global identity provided a framework for negotiation of intersecting identities that was flexible enough to recognize that identities change as contexts change. The agency participants developed provided them with selfconfidence and broadened their ideas about the role they could play in the world. For some this agency looked like global citizenship because it provided a critical lens and a profound commitment to making positive change at home and abroad. 
Chapter Five: Discussion and Recommendations

This chapter discusses the implications of this study on how the study abroad experience shapes the identity and goals of college students of color. It begins with an overview of findings that outlines the methodology and findings. The following section provides an interpretation of the findings related to study abroad as a process, Third Space, and the importance of racial and ethnic heritage. The section on implications examines the relevance of these findings in relationship to leadership, equity, policy, and methodology. The chapter closes with recommendations for action, further study, and reflections on the research process.

\section{Overview of Findings}

Consistently low levels of study abroad participation by students of color have fueled extensive anecdotal advice literature and a few empirical studies examining perceived barriers to access. Yet, there remains a limited body of literature that explores the study abroad experiences of students of color or examines the role that study abroad played in their identity development. The primary goal of this study was to add narratives of study abroad of students of color to the literature. These narratives provided a lens to critically reexamine the existing study abroad literature that I categorized as anecdotal advice literature and barriers research in my literature review. Documenting student experiences allowed me to investigate the role of identity in their 
study abroad process. Their perspectives allowed me to reexamine the intersections of race, ethnicity, and other social locations as students negotiated a global identity through their study abroad experiences.

This longitudinal qualitative study began with in-depth interviews with four participants, followed by and five focus groups with 4-11 participants in each group. I also analyzed the application essays for all participants to provide a pre-post view of the participants. The 47 participants (Appendix A) all participated in cross-cultural immersion study abroad programs (Engle \& Engle, 2003) of at least one semester in length in 2008-09. As described in chapter 3 the participants were atypical study abroad students. All were students of color, $64 \%$ were first generation college students, and $45 \%$ received Pell Grants, a common indicator of low socioeconomic status.

This research asked the question: How does the study abroad experience shape the identity and goals of college students of color? The findings fell in two areas. The first set of findings are related to the nature of study abroad the second set describe areas of growth for participants. This research suggested a new understanding of study abroad as a process that begins when students determine that they want to participate and take action to apply. This process includes the steps of application, preparation, time abroad, and return. The time abroad acts as a Third Space where students can critically evaluate their abilities, identities, and goals. Participants experienced change on study abroad in three main areas, capital, identity, and agency. These changes led 
some students to develop global citizenship, a commitment to citizenship, democratization, humanization, and social justice in the U.S. and abroad.

These findings appear to support Dolby's (2004) assertion that "study abroad is not simply a private good or individual experience" (p. 173). Instead, study abroad appears to have implications for practice of citizenship, democratization, humanization, and social justice. These outcomes could have a positive impact on the world. With one exception (Reilly \& Senders, 2009), none of the study abroad literature suggests that the field is preparing students to meet these goals through study abroad. Viewing study abroad as a transformative process that begins at application presents opportunities to design systems that foster these outcomes. Focusing the process of study abroad on these goals could increase the likelihood of students developing global citizenship, a commitment to citizenship, democratization, humanization, and social justice in the U.S. and abroad. In order for study abroad to produce engaged citizens, committed to democracy and humanization I propose a CRT-based pedagogy for study abroad. This pedagogy could follow students through the process of study abroad and facilitate their critical examination of their intersecting identities. This process could include opportunities for students to leverage their community cultural wealth at home and abroad and facilitate critical examination of the structures that privilege dominant forms of social and cultural capital in the U.S. and abroad. Such an approach could make it more likely that study abroad students critically reexamine their intersecting identities, 
develop social and cultural capital, learn to value community wealth, and develop agency to make positive change in the world.

This study challenges current rhetoric used to promote study abroad. This rhetoric focuses on "survival in the global economy" (Reilly \& Senders, 2009, p. 251). Such rhetoric is founded on the idea that education's primary function is to develop human capital for participation in the workforce. None of the participants in this study cited that reason as their primary goal for study abroad. Thus, this argument may be, not only a repetition of ideas that reproduce inequity, but also ineffective with the audience it is targeted to reach. The findings presented here and in chapter four suggest that students may respond better to rhetoric about developing a global identity and gaining knowledge, skills, awareness, and networks that they can leverage to make the world a better place for themselves and humanity. Promoting study abroad based on these goals would reconnect study abroad to the core goals of international educational exchange of promoting global understanding as discussed in Reilly and Sender's (2009) article presenting their conceptualization of critical study abroad.

\section{Interpretation of Findings}

The findings present two new constructs that have implications for practice, leadership, and policy and reframe the importance of race, ethnicity, and heritage. First, the research suggested that study abroad began when participants first became interested and continued well beyond their return to the U.S. This framework of study 
abroad as a process that begins when students decide to pursue it, rather than as an event that takes place between two plane trips, provides a new framework for examining the role of study abroad in higher education. Second, the data demonstrated how the study abroad experience provided the participants with an opportunity to step outside of their usual frame of reference and examine who they are and what they want to accomplish in life. This Third Space (Bhabha, 2004) allowed them to negotiate many aspects of their identity through interaction with the host culture and other students Given the salience of race in U.S. society (Ladson-Billings \& Tate, 1995; Solorzano \& Yosso, 2001) this experience of stepping outside of U.S. societal expectations may have been different for these students than their White counterparts. In addition, the data highlighted the complex role that racial and ethnic heritage played in the study abroad experiences of these students of color. This role went beyond common notions of heritage seeking study abroad as outlined by Comp (2008b) and others. As noted in chapter four, heritage played a major role in program selection for 21 of the 47 participants in this study, but its role was much more complex than has been posited in the anecdotal advice literature or barriers research literature.

\section{Study abroad as a process}

This research suggests that study abroad is a transformative process that begins when students decide that it is possible and apply. My review of application essays suggested that for most of them the transformation of study abroad began when they 
first heard it was possible and the focus groups held 12-18 months after return from abroad confirmed that the transformation continued over a year after they came home. The interactions of capital, identity, and agency described in chapter four help to define student experiences throughout the study abroad process. Application essays indicated that participants needed social and cultural capital to access study abroad and begin their process of identity negotiation. While abroad, students created global networks that formed a global capital made up of these networks and language and culture knowledge. Negotiating ethnic, racial, American, and other identities provided an opportunity for students to critically negotiate their intersecting identities to form a global identity. Together this global capital and global identity supported development of agency that for some participants led to global citizenship.

Furthermore, this research supported the idea that study abroad had a long-term transformative effect on students, but also created a need to continue to access a global network. The enthusiasm of participants in the focus groups supports this assertion. For example, the participants in one of the long-term returnee groups decided to stay together and get a drink so that they could continue their conversations. As a group they also asked me to distribute contact information. This led me to realize that, even 12-18 months after study abroad participants had many re-entry needs. These needs were more than the typical career advice, re-entry shock, and international opportunity program 
that is common to re-entry events. This finding could be used to guide programming for study abroad returnees that is available well after students return to the U.S.

\section{Third Space while abroad}

Students frequently describe study abroad as a life-changing experience. The results of this study suggest that this impact is due to the fact that the time abroad is a Third Space where students to connect with the host culture and with other international students in ways that might not be possible in the U.S. Participants in this study described how their time abroad allowed them to leverage and build social and cultural capital. They also described complex negotiation of intersecting identities that included racial, ethnic, and national identities. Finally, many participants described their commitment to making positive change in the world. These changes appeared to be due to the Third Space of the host environment.

\section{Importance of racial and ethnic heritage}

Race and ethnicity played an important role in the study abroad process for the participants in this study. This finding confirmed the CRT tenet that race and racism are central to understanding how U.S. society functions (Delgado Bernal, 2002; LadsonBillings \& Tate, 1995; Yosso, 2005). It also suggested that race continues to be salient when students of color leave the U.S. context. That said, for the participants in this study race played roles that were different from what has been anticipated in the literature. 
The barriers research literature and anecdotal advice literature in chapter two present fear of racism abroad as a barrier to study abroad for students of color. None of the participants in this study mentioned this fear as a barrier to study abroad. However, many discussed the important role that race and/or ethnicity played in the study abroad process. Some described how family and friends asked questions about race prior to study abroad. Others described racial relationships and inequitable structures in their host country. The importance of race throughout the process led me to recommend that study abroad offices include issues about race and racism as they prepare students for study abroad.

Ethnic heritage also played an important role in the study abroad process for participants in this study. This finding has additional importance due to the prevalence of the suggestion that students of color tend not to study abroad because of a lack of heritage seeking destinations (Comp, 2008a; LeMay Burr, 2005; Martinez, Ranjeet, \& Marx, 2009; Obst, Bhandari, \& Witherell, 2007; Picard, Bernardino, \& Ehigator, 2009; Raby, 2008). Those sources suggest that students of color chose study abroad based on perceived shared ethnic, religious, cultural, and/or linguistic familiarity at the host location (Comp, 2008b). Of the 47 participants in this research only 12 selected their destination for heritage-seeking reasons. However, an additional nine participants chose destinations, based on their heritage, that were not directly related. Five participants chose to study in locations where extended family lived. Although these locations did 
not reflect the participants' heritage, they provided an opportunity to connect with family that had been spread around the world. The other four students who cited heritage as a guiding factor in location choice sought an environment where they would feel different. These findings suggest that the impact of ethnic heritage on the study abroad process is more complex than has been reported. These findings support the CRT emphasis on counter narratives (Solorzano \& Yosso, 2001) because these stories highlight the complex roles that personal history can play in the experiences of people of color.

Limitations

Conducting this research at my institution with the students I advise introduced limitations to this study. These limitations were also strengths. The institutional context made it possible to conduct a qualitative study on a large number of students all of whom participated in a single type of study abroad program, cross-cultural immersion, for a semester or year. Because the institution focuses solely on semester and year-long study abroad at host universities around the world I was able to look at a single type (Engle \& Engle, 2003) of study abroad for a broad variety of students and locations. This context's large numbers of study abroad students of color from a broad variety of racial and ethnic groups led to larger numbers and a broader perspective than has been reported in any of the existing literature. My connection to the participants also 
facilitated conversation in the interviews and focus groups that may not have been possible for an outsider.

My relationship to the participants is also a limitation because it biases my research. Despite efforts to manage bias in the focus group instrument, critical colleagues, and the research assistants described in chapter 3 I did not expect to capture many negative experiences or challenges to the study abroad experience. My bias would have been a major concern if I had been assessing the efficacy of study abroad. Since the goal of this was instead to identify a broad range of experiences and share student voices this bias presented an acceptable limitation.

\section{Implications}

By documenting the experiences of students of color throughout the study abroad process this study has provided data that in some cases support, and in others challenge the commonly cited reasons for increasing study abroad for students of color. As noted in chapter two most of these reasons are rooted in ideologies that suggest that the goals of education relate only to increasing competitiveness in the job market. In contrast, international educators, of which study abroad professionals are a subset, frequently, tend to cite broader goals for education that relate to increased understanding, stability, and security in the world (Reilly \& Senders, 2009).

The suggestion from this research that the study abroad process creates a Third Space that increases the social and cultural capital that students bring to the process and 
gives them an opportunity to negotiate intersecting identities presents powerful opportunities for pedagogy. Social and cultural capital are essential assets that provide access to power and opportunity (Bourdieu, 1985). The suggestion that study abroad can help students learn to effectively leverage their social and cultural capital while adding to both implies that that participation in study abroad could provide them with the tools to reduce inequity in the U.S. The ways that participants critically negotiated their intersecting identities of race, ethnicity, and nationality provided an opportunity for them to develop affirming counter narratives. Such narratives can serve to challenge the dominant structures that reproduce inequity (Solorzano \& Yosso, 2001). These results suggest that study abroad can have powerful impacts on individuals that may result in positive change for society when students return and act as global citizens committed to citizenship, democratization, humanization, and social justice in the U.S. and abroad. Some participants in this research appeared to be developing global citizenship. If this is a desired outcome for study abroad, then many changes, or new commitments will need to be made.

Implications for leadership

Concerns about underrepresentation of students of color on study abroad over the last few decades have not resulted in major changes in participation rates (Chow \& Bhandari, 2010). This research suggests that addressing this problem may require leadership to reexamine the goals for study abroad. By introducing the idea of study 
abroad as a transformative process that begins when students decide there is more room for influencing this transformation. The importance in this research of capital, identity, and agency throughout the process suggest that leaders could increase study abroad participation by students of color by developing systems that allow these students to better leverage their social and cultural capital (Bourdieu, 1985) and their community cultural wealth (Yosso, 2005).

In addition, recognizing that the transformation from study abroad starts at this earlier stage allows leaders to develop learning outcomes related to each stage in the learning process. This would provide additional areas that could be measured as institutions work towards comprehensive internationalization (Hudzik, 2011).

In order to change participation rates this research also suggests that international education leaders will need to take a critical stance on underrepresentation of students of color in study abroad as outcomes of structural inequities in society. Such an approach may help the field move beyond its assessment of underrepresentation as marketing problems or student deficiencies.

\section{Educational equity issues}

Participation in study abroad has not been considered an equity issue; instead, it has been described as a problem of statistical underrepresentation. None of the literature on study abroad used the term equity, which is part of the reason why equality of access has been the primary focus of diversity efforts. This research suggests a different 
approach that emphasizes equity throughout the study abroad process, from access to outcomes. Reconsidering the goals of study abroad and designing a pedagogy that guides all students toward global citizenship could also begin to address equity in study abroad.

\section{Study abroad policy issues}

If study abroad is seen as such an essential component of education then institutions will need to look carefully at the barriers that they have created in the design of policies to facilitate student participation. As discussed in chapter 2, the existing literature has not yet effectively shown that study abroad has a positive impact in areas such as language acquisition, intercultural sensitivity, academic knowledge, maturity independence, and more. This research adds detail on changes in capital, identity, and agency as results of study abroad. It seems that economic and political arguments for increasing study abroad participation and diversity are the most effective rationales for policy makers whereas this study suggests that self-discovery and transformation are the most salient for students. This presents a challenge to all those who hope to continue to fund these activities. A middle ground that considers the potential of study abroad to develop global capital, global identity, and global citizenship could garner attention.

\section{Methodological advancement}

Defining critical research colleagues and practicing this form of research collaboration enhanced all aspects of my research process. As critical colleagues we 
worked together in order to broaden our perspectives, challenge our frameworks, and confront our bias. Moreover, as none of my critical colleagues work in study abroad or international education, their perspectives forced me to clarify things I took for granted. They also recognized the importance of some themes that I had overlooked. Since both are researching issues related to students of color in higher education participating in their process added perspective on my participants. I have not seen this type of interdisciplinary research team in study abroad research and I believe that it can offer a balance between outside research and insider research.

\section{Recommendations for Action}

Based on this research I recommend that international educators directly address capital, identity, and race throughout the study abroad process for students from all backgrounds. These constructs can provide strength or introduce challenges. This research suggested that the study abroad process often leads to profound examination of identity in a fairly short period of time. These issues are complex and challenging. A carefully designed curriculum that helps students navigate the study abroad process could facilitate this negotiation of identity, build capital, and move students closer to global citizenship. Such a curriculum could begin the process of critical identity negotiation at the application stage as happened for many of the participants in this study. In addition, I recommend that programming throughout the study abroad process focus on providing students with opportunities to build upon their social and cultural 
capital that facilitate negotiation of intersecting identities. Integrating this curriculum as students enter the study abroad process would provide a context for addressing some of the challenges that participants in this study faced in the Third Space of the host environment.

To incorporate these recommendations, study abroad professionals will need to think differently about the role of study abroad in their students' lives. They will also need to learn more about their students' backgrounds and life experiences as a small portion of the of the anecdotal advice literature has suggested (Flores, 2008; Le, 2008; Lewis, 2008). This research suggested that students required many forms of social and cultural capital in order to access study abroad. Part of the reason for this is the tendency of these forms of capital to be most easily accessed by dominant groups in society (Bourdieu, 1985). To better support students of color, practitioners could design systems that ascribe value to the community cultural wealth that students of color carry (Yosso, 2005). For example, changes to application essays could present more room for students of color to leverage their community cultural wealth. Following these recommendations may require the design of a curriculum and pedagogy around the entire study abroad process. Such an approach could lead to benefits for students who engage with any part of the study abroad process, including the earliest information sessions or inquiries. In this way even students who choose not to study abroad could gain some of the knowledge, skills, and awareness that participants explore more fully. 
This approach would connect all aspects of a study abroad office's work to comprehensive internationalization efforts (Hudzik, 2011).

\section{Dissemination of findings}

In order to have an immediate impact on practice I will begin by sharing my research with my colleagues in the Office of International programs (OIP). Sharing my findings with the OIP will allow me to discuss opportunities for influencing practices for the institution that supported this study. In addition to providing insights into our students' experiences, my research provides a lens through which we can examine our role in their development. Bringing my results back to the OIP is one small way that I can give back to my colleagues who supported my research and invite them to consider the possible implications.

I have identified a few opportunities to share my findings with the campus at large. One of these was the SF State level of the CSU Student Research Competition. Competing in this forum gave me practice presenting and exposed colleagues at SF State who are on the panel or in attendance to my work. Another is through a presentation as part of International Education Week in November 2011. For that presentation I plan to invite some of the participants to join the session and share their narratives. My topic will fit well within the context of this campus-wide event and will give staff, faculty, and administrators from across the campus an opportunity to learn more about the experiences of study abroad students of color. 
I have been asked to present my findings and facilitate a discussion at the California State University International Programs Coordinators' Conference in September 2011. I have presented in this venue before and recognize it as an effective way to introduce new ideas to study abroad advisors from throughout the 23-campus system. These campuses have a similar demographic profile to SF State and have access to the same study abroad opportunities making the findings fairly easily transferrable.

Regional and national conferences for international education and study abroad professionals are essential venues for influencing practice. As I was conducting my research I proposed three sessions related to this research all of which were accepted. Thus, I will share aspects of my research as a co-presenter of Equity in education abroad: How can practical knowledge and theoretical frameworks help increase access and enhance outcomes for students of color? at the Forum on Education Abroad Conference in Boston in April, 2011. I will co-present two additional sessions Achieving equity: Beyond diversity and underrepresentation in education abroad and Minority students and the goal of equity: Reimagining international education leadership at NAFSA: Association of International Educators' Annual Conference in Vancouver, Canada in May 2011. As the titles suggest the first session is designed to engage study abroad advisors and the second examines leadership in international education more broadly. As a regular presenter at NAFSA's Region XII (CA, HI, NV) conference I intend to propose a session modeled on the three themes I explored in my 
findings for their annual conference in October 2011. I have also been collaborating with the Diversity Abroad/Diversity Network to design daylong capacity building workshops that will help campuses design systems and structures to overcome persistent underrepresentation of students of color on study abroad. I look forward to adding what I have learned through this research to our ongoing collaboration.

I have opportunities to share my findings internationally as well. In February 2011 I was invited to conduct a week of workshops on comprehensive internationalization and study abroad in Hong Kong. Those workshops gave me an opportunity to discuss some of the implications of the complex transformation that our students of color undergo while abroad with a host university overseas. I will also make a variety of presentations in India as a Fulbright-Nehru scholar in March 2011. I look forward to discussing how identity negotiation may play out differently for students from our two countries.

In addition to the sessions and workshops I will seek opportunities to publish my findings. To reach a practitioner audience I will respond to calls for papers from IIE Networker and International Educator. These practitioner magazines reach members of the two largest member organizations for international educators. I have also been asked to write profile of SF State's equity initiatives for Diversity Network's Best Practices Series. This will give me a chance to contextualize my findings within the institutional practices that support high rates of participation by students of color. 
Finally, I hope to influence scholarship by sending manuscripts to peer reviewed journals. Frontiers: The interdisciplinary journal of study abroad is the only journal dedicated solely to research on study abroad and presents an essential outlet for this research. Their editors may be most interested in my findings related to heritage study abroad. Other aspects of this research, specifically my findings about the nature of study abroad as a process, may be better suited for the Journal of studies in international education. This publication reaches an international scholarly audience. The increased interest in study abroad from student development theorists and recent publication of articles related to study abroad in the National Association of Student Affairs Professional's Journal suggest that this could be a promising venue for a manuscript focusing on my findings related to identity negotiation and student development.

To reach broader audiences I will seek opportunities in qualitative research journals such as Qualitative Research Journal, Comparative Education Review or the International Journal of Qualitative Studies in Education. Finally, the American Educational Research Journal or Harvard Educational Review may be interested in my research because of my focus on identity negotiation, Third Space, and CRT.

\section{Recommendations for Further Study}

Research on other types of study abroad is essential. As Engle and Engle's (2003) taxonomy points out there are many forms of study abroad and each is a distinct educational experience and may result in distinct learning outcomes. For this study 
examining a single type of study abroad strengthened the transferability of results to other semester and yearlong cross-cultural immersion programs. It is likely that the experiences reported in this study were related to the type of program. Given the increased prominence of faculty led programs, service learning programs, and programs that are not based in U.S. or international institutions of higher (Chow \& Bhandari, 2010) similar research on the experiences of students of color on those study abroad program types would be beneficial.

Research on how the engagement documented here relates to support for the institution or for study abroad in general through donations, volunteer service, or other resources else would help support study abroad initiatives and provide further definition for the construct of global citizenship.

Research across different institutional types and or locations in the U.S. may yield additional insights into the experiences of study abroad students of color. As detailed in the methods section of chapter three, the site of this study has a profound commitment to study abroad and to issues of equity and social justice. The context of this study is also a highly diverse institution in a highly diverse region. Similar research at different institutions and in different areas would help distinguish the effect of institutional context of this study from the overall findings.

To build on the idea of study abroad as a process it may be beneficial to conduct similar research at each stage of the study abroad process from initial inquiry through 
return. This study focused on students who had returned from study abroad with a prepost element from the application essays and the timing of the two focus groups.

Following students through the process of study abroad from application to return may help to define the factors that supported capital development and led to negotiation of identity. Such research could lead to additional recommendations for practice at those stages.

Given the complex intersectional nature of identity additional research on a broader range of social locations is essential. Such research could emphasize intersections of race, class, gender, ability, sexuality, age, family educational history, family immigration history, and other factors. Now that this study has begun to theorize on the nature of study abroad for students of color research including White students would make it possible to understand which of the themes described in this study are relevant to those students.

\section{Reflections on the Research Process}

As a working professional conducting research in my field I was keenly aware of how this process was changing my views, perceptions and approaches to my work. I have been engaged in the work of expanding study abroad opportunity for all students, but had not had a chance to talk to students and learn what it meant to them. Returnees always stop by to say thank you and "it changed my life." Conducting this study gave me more detail that informed my outreach and advising with students and also led me to 
have different conversations with faculty, staff, and other professionals. While conducting the research I began to integrate new ideas into my practice. For example, the overwhelmingly positive response to my focus groups contributed to our office's creation of a series of workshops for other study abroad returnees designed to give them a forum for this type of open-ended exchange and help them build a community after study abroad. The importance of mentors in providing social capital guided our development of a peer mentor program that provides applicants with access to study abroad returnees.

Feedback from participants suggested that I created a research process that served an educational function. One striking element about this research was the appreciation that participants expressed for being included in the process, for having their voices heard, and for being introduced to a group of other students who shared a similar experience. In addition, at the end of each group students were reluctant to leave. They continued conversations in small groups, came to me for advice on international opportunities, or exchanged contact information. Supporting student learning was one of my research goals, but is also something that I could have encouraged even more by offering structures for ongoing dialog, sharing articles or other materials on adjusting back to life in the U.S., or connecting them with resources to help them integrate their international experience in their resumes and cover letters. 
The enthusiastic response from study abroad returnees caught me off guard. If I conduct similar research in the future I would prepare to give another option to people who cannot attend focus groups or interviews. An online survey, quick email response, or other format would have given me very beneficial additional data. It would be easy to write this type of instrument into the research protocol. Adding a provision in the protocol for email consent and a few open-ended questions would have made it easy to quickly follow up with interested participants who could not travel to the focus group and thus gain additional perspectives.

It was essential to follow up regularly with participants and to be prepared to make last-minute adjustments. For each group one person did not show up and at least one extra came, and one person arrived was very late. Fortunately, with the help of my research assistants, I was prepared to accommodate all of these scenarios. This allowed me to include as many participants into the research process.

This research suggests that research on study abroad returnees can generate a lot of enthusiasm and has potential to be beneficial to the participants. This good will could be used to obtain high response rates. In order to value the generosity of these willing participants, I believe that it is essential to consider what the participants gain through their involvement in the research. For this reason I recommend designing research that benefits the participants while gathering the information that the researcher needs. 


\section{Conclusion}

The results of this research help define the unique aspects of the study abroad experience for students of color. They suggest that study abroad is a transformative process beginning when students believe that is it possible and take steps to apply. In addition, the results suggest that the time abroad creates a Third Space in which students can leverage their community cultural wealth in order to negotiate a global identity and develop agency for global citizenship. The student narratives in this study lent support to arguments that study abroad can promote citizenship, democratization and humanization for participants and their host communities. These results could help international educators in the U.S. and abroad more effectively support study abroad students of color throughout the study abroad process.

I began this research by questioning the value of study abroad. The participants confirmed its value and affirmed my belief that underrepresentation of students of color is an equity issue that must be addressed throughout the study abroad process. At each step of the research I saw how study abroad created opportunities for personal growth. In application essays participants shared their enthusiasm for an experience that, they believed, would be life changing. They also described their strengths, challenges, hopes, and fears thus connecting study abroad to all aspects of their lives. The interviews and focus groups gave me insights into the breadth and depth of the changes that participants experienced. In the focus groups participants were confident, self-assured, 
enthusiastic, happy, and hopeful. Many were committed to giving back, to sharing their stories with others, and to choosing careers where they could make a difference in the lives of others. Hearing students say, "My experience abroad just makes me feel like I can live anywhere and that anything is possible," confirmed my belief in the powerful, positive impact that study abroad can have and renewed my commitment to increasing access and outcomes for study abroad students of color and to sharing practices with others. 


\section{References}

Adams, T., \& de Wit, H. (2010). Editorial: Special issue on study abroad. Journal of Studies in International Education, 14(5), 431-432.

Akom, A. A. (2003). Reexaming resistance as oppositional behavior: The Nation of Islam and the creation of a Black achievement ideology. Sociology of Education, 76(4), 305-325.

American Council on Education. (2002). Beyond September 11: A comprehensive national policy on international education. Washington, DC: Author.

American Council on Education, Art and Science Group, \& the College Board. (2008). College-bound students' interests in study abroad and other international learning activities: A special edition of Student Poll ${ }^{\mathrm{TM}}$. Washington, DC: Author.

Andriano, B. (2010). Study abroad participation and engagement practices of firstgeneration undergraduate students. Unpublished doctoral dissertation, The George Washington University, Washington DC.

Angrosino, M. V. (2008). Recontextualizing observation: Ethnography, pedagogy, and the prospects for a progressive political agenda. In N. K. Denzin \& Y. S. Lincoln (Eds.), Collecting and interpreting qualitative materials (pp. 161-184). Thousand Oaks, CA: Sage.

Angulo, S. (2008). Identity change in students who study abroad. Unpublished doctoral dissertation, The University of Texas at Austin.

Anonymous. (2009). From the editor. Peer Review, 11(4), 3.

Anzaldúa, G. (2007). Borderlands: The new mestiza $=$ La frontera (3rd ed.). San Francisco: Aunt Lute Books.

Apple, M. W. (1990). Ideology and curriculum (2nd ed.). New York: Routledge.

ASHE-ERIC. (2002a). Multiple identities: Acknowledging the interrelationship among roles. ASHE-ERIC Higher Education Report, 29(6), 67-78.

ASHE-ERIC. (2002b). Theoretical frameworks of diverse identity development theories: A view through a different lens. Higher Education Report, 29(6), 3366.

ASHE-ERIC. (2002c). Theoretical frameworks of identity development theory: Foundational theories. ASHE-ERIC Higher Education Report, 29(6), 9.

Association of American Colleges and Universities. (2007). College learning for the new global century: A report from the national leadership council for liberal education and America's promise. Washington DC: Association of American Colleges and Universities.

Australian Government, \& Australia Education International. (2009). Database of Research on International Education. Retrieved December 13, 2009: 
http://www.aei.gov.au/AEI/PublicationsAndResearch/ResearchDatabase/Default htm

Ayers, D. F. (2005). Neoliberal ideology in community college mission statements: A critical discourse analysis. Review of Higher Education, 28(4), 527-549.

Bernal, D. D. (2002). Critical race theory, Latino critical theory, and critical racedgendered epistemologies: Recognizing students of color as holders and creators of knowledge. Qualitative Inquiry, 8(1), 105.

Bhabha, H. K. (2004). The location of culture. London ; New York: Routledge.

Bhandari, R., \& Chow, P. (2007). Open doors 2007: Report on international educational exchange. New York: Institute of International Education.

Bhandari, R., \& Chow, P. (2008). Open doors 2008: Report on international educational exchange. New York: Institute of International Education.

Bhandari, R., \& Chow, P. (2009). Open doors 2009: Report on international educational exchange. New York: Institute of International Education.

Biles, J., \& Lindley, T. (2009). Globalization, geography, and the liberation of overseas study. The Journal of Geography, 108(3), 148.

Biles, J. J., \& Lindley, T. (2009). Globalization, geography, and the liberation of overseas study. The Journal of Geography, 108(3), 148-154.

Blumenthal, P., \& Gutierrez, R. (2009). Meeting America's global education challenge: Expanding study abroad capacity at U.S. colleges and universities. New York: Institute of International Education.

Blumenthal, P., \& Laughlin, S. (2009). Meeting America's global education challenge: Promoting study abroad in science and technology fields. New York: Institute of International Education.

Bogdan, R. C., \& Biklen, S. K. (2008). Qualitative research for education: An introduction to theories and methods (5 ed.). Boston: Allyn and Bacon.

Bolen, M. (2007). Introduction. In M. Bolen (Ed.), A guide to outcomes assessment in education abroad (pp. 1-7). Carlisle, PA: The Forum on Education Abroad.

Bond, D. G. (1988). Values Clarification and International Education: The Yonsei Experience. Paper presented at the Annual Meeting of the International Studies Association. Retrieved from http://0search.ebscohost.com.opac.sfsu.edu/login.aspx?direct=true\&AuthType=ip.cooki e.url.uid\&db=eric\&AN=ED305273\&site=ehost-live

Bourdieu, P. (1985). The social space and the genesis of groups. Theory and Society, 14(6), 723-744.

Bourdieu, P. (1986). The forms of capital (R. Nice, Trans.). In J. Richardson (Ed.), Handbook of theory and research for the sociology of education (pp. 241-258). New York: Greenwood Press.

Bourdieu, P., \& Wacquant, L. (1999). On the cunning of imperialist reason. Theory, Culture \& Society, 16(1), 41-58. 
Bryman, A. (2007). Effective leadership in higher education: A literature review. Studies in Higher Education, 32(6), 693-710.

Caton, K., \& Santos, C. A. (2009). Images of the other: Selling study abroad in a postcolonial world. Journal of Travel Research, 48(2), 191-204.

Center for Global Education. (2009). Center for Global Education at LMU Study Abroad Research On-Line Retrieved December 13, 2009, from http://www.globaled.us/ro

Chickering, A., \& Braskamp, L. (2009). Developing a global perspective for personal and social responsibility. Peer Review, 11(4), 27-31.

Chow, P., \& Bhandari, R. (2010). Open doors 2010 report on international educational exchange. New York: Institute of International Education.

Coleman, J. S. (1988). Social capital in the creation of human capital. The American Journal of Sociology, 94, S95-S120.

Commission on the Abraham Lincoln Study Abroad Fellowship Program. (2005). Global competence and national needs: One million Americans studying abroad. Washington DC: Author.

Committee For Economic Development. (2006). Education for global leadership: The importance of international studies and foreign language education for U.S. economic and national security. Washington, DC: Author.

Comp, D. (2008a). Research and literature on U.S. students abroad: A bibliography with abstracts 2001 to 2006. Unpublished manuscript.

Comp, D. (2008b). Research and literature on underrepresentation in education abroad: An annotated bibliography. Unpublished manuscript.

Comp, D. (2008c). U.S. heritage-seeking students discover minority communities in Western Europe. Journal of Studies in International Education, 12(1), 29-37.

Comp, D., Gladding, S., Rhodes, G., Stephenson, S., \& Vande Berg, M. (2007). Literature and resources for education abroad outcomes assessment. In M. Bolen (Ed.), A guide to outcomes assessment in education abroad (pp. 97 - 136). Carlisle, PA: The Forum on Education Abroad.

Creswell, J. W., \& Plano Clark, V. L. (2007). Designing and conducting mixed methods research. Thousand Oaks, CA: Sage.

Day-Vines, N., Barker, J. M., \& Exum, H. A. (1998). Impact of diasporic travel on ethnic identity development of African American college students. College Student Journal, 32(3), 463.

Delpit, L. (1995). Other people's children: Cultural conflict in the classroom. New York: The New Press.

Denzin, N. K., \& Lincoln, Y. S. (2008). Collecting and interpreting qualitative materials (3 ed.). Los Angeles: Sage Publications.

Dolby, N. (2004). Encountering an American self: Study abroad and national identity. Comparative Education Review, 48(2), 150-173. 
Dolby, N. (2005). Globalisation, identity, and nation: Australian and American undergraduates abroad. Australian Educational Researcher, 32(1), 101-118.

Dolby, N. (2007). Reflections on nation: American undergraduates and education abroad. Journal of Studies in International Education, 11(2), 141-156.

Duncan-Andrade, J. M. R. (2004). Your best friend or your worst enemy: Youth popular culture, pedagogy, and curriculum in urban classrooms. Review of Education, Pedagogy \& Cultural Studies, 26(4), 313-337.

Duncan-Andrade, J. M. R., \& Morrell, E. (2008). The art of critical pedagogy: Possibilities for moving from theory to practice in urban schools. New York: Peter Lang.

Engle, L., \& Engle, J. (2003). Study abroad levels: Toward a classification of program types. Frontiers: The Interdisciplinary Journal of Study Abroad, 9, 1-20.

Espinoza, O. (2007). Solving the equity-equality conceptual dilemma: a new model for analysis of the educational process. Educational Research, 49(4), 343-363.

Flores, M. (2008). Increasing study abroad opportunities and academic sucess for Latino students. Los Angeles: Project for Learning Abroad, Training, and Outreach.

Flores, M., Lewis, S., \& Le, E. (2009, May). Students of color on study abroad. Paper presented at the NAFSA: Association of International Educators' Annual Conference.

Fontana, A., \& Frey, J. H. (2008). The interview: From neutral stance to political involvement. In N. K. Denzin \& Y. S. Lincoln (Eds.), Collecting and interpreting qualitative materials (pp. 115-160). Thousand Oaks, CA: Sage.

Fraenkel, J. R., \& Wallen, N. E. (2009). How to design and evaluate research in education (7th ed.). New York, NY: McGraw-Hill.

Freire, P. (2009). Pedagogy of the oppressed (M. B. Macedo, Trans. 30th anniversary ed.). New York: Continuum.

Fulkerson, G. M., \& Thompson, G. H. (2008). The evolution of a contested concept: A meta-analysis of social capital definitions and trends (1988-2006). Sociological Inquiry, 78(4), 536-557.

Giroux, H. (1997). Pedagogy and the politics of hope: Theory, culture, and schooling : a critical reader. Boulder, Colo.: Westview Press.

Giroux, H. (2010). Rethinking education as the practice of freedom: Paulo Freire and the promise of critical pedagogy. Truthout. Retrieved from http://www.truthout.org/10309_Giroux_Freire

González, N., \& Moll, L. C. (2002). Cruzando el puente: Building bridges to funds of knowledge. Educational Policy, 16(4), 623.

Goodson, S. I. (2010). Ko bra: Go and come. Africana Studies Journal, 11, 59-65.

Gradstein, M., Justman, M., \& Meier, V. (2005). The political economy of education: Implications for growth and inequality. Cambridge, Mass.: MIT Press. 
Grenfell, M. (2009). Applying Bourdieu's field theory: The case of social capital and education. Education, Knowledge \& Economy, 3(1), 17-34.

Guerrero, E., Jr. (2006). The road less traveled: Latino students and the impact of studying abroad. Unpublished doctoral dissertation, University of California, Los Angeles.

Gutierrez, K. D., Baquedano-Lopez, P., \& Tejeda, C. (1999). Rethinking diversity: Hybridity and hybrid language practices in the third space. Mind, Culture \& Activity, 6(4), 286.

Gutierrez, R., Bhandari, R., \& Obst, D. (2007). Meeting America's global education challenge: Exploring host country capacity for increasing U.S. study abroad. New York: Institute of International Education.

Gutierrez, R., Hawthorne, A., Kirk, M., \& Powers, C. (2009). Meeting America's global education challenge: Expanding U.S. study abroad in the Arab world: Challenges and Opportunities. New York: Institute of International Education.

Hamilton, L. S., Stecher, B. M., Marsh, J. A., McCombs, J. S., Robyn, A., Russell, J., et al. (2007). Standards-based accountability under no child left behind: Experiences of teachers and administrators in three states. Santa Monica CA: RAND Corporation.

Helms, J. E. (1993). Black and white racial identity: Theory, research, and practice. Westport, CT: Praeger Paperback.

Hoffa, W. (2007). A history of US study abroad: Beginnings to 1965. Carlisle, PA: Frontiers Journal Inc.

Hoffa, W., Pearson, J., Martin, P. C., \& NAFSA: Association of International Educators. (2005). NAFSA's guide to education abroad for advisers and administrators (3rd ed.). Washington, D.C.: NAFSA, Association of International Educators.

Horvat, E. M., Weininger, E. B., \& Lareau, A. (2003). From social ties to social capital: Class differences in the relations between schools and parent networks. American Educational Research Journal, 40(2), 319-351.

Hudzik, J. K. (2011). Comprehensive Internationalization: From Concept to Action. Washington, D.C.: NAFSA: Association of International Educators, Washington.

Hulstrand, J. (2006). Beyond anecdote: Education Abroad comes of age. International Educator, 15(1), 52-55.

IES Abroad. (2009). Increasing the participation of underrepresented students in study abroad programs: Recommendations for university presidents, corporate leaders, and study abroad professionals. Chicago, IL: Author.

Institute for International Education. (2008). Gilman advisor newsletter: Summer 2008. Retrieved July 10, 2008, 2008, from 
http://www.iie.org/programs/gilman/newsletter/advisor_newsletters/advisorsum mer08.html

Iverson, S. V. (2007). Camouflaging power and privilege: A critical race analysis of university diversity policies. Educational Administration Quarterly, 43(5), 586611.

Jackson, M. J. (2005). Breaking the barriers to overseas study for students of color and minorities. IIE Networker(Fall), 16-18.

Jackson, M. J. (2006). Traveling shoes: Study abroad experiences of African American students participating in California State University international programs. Unpublished doctoral dissertation, University of San Francisco, San Francisco, CA.

Janes, D. (2008). Beyond the tourist gaze? Cultural learning on an American "semester abroad" programme in London. Journal of Research in International Education, 7(1), 21-35.

Kamberelis, G., \& Dimitriadis, G. (2008). Focus groups: Strategic articulations of pedagogy, politics, and inquiry. In N. K. Denzin \& Y. S. Lincoln (Eds.), Collecting and interpreting qualitative materials (pp. 375-402). Thousand Oaks, CA: Sage.

Kasravi, J. (2009). Factors influencing the decision to study abroad for students of color: Moving beyond the barriers. Unpublished doctoral dissertation, University of Minnesota, Minneapolis, MN.

Kauffmann, N. L., \& Kuh, G. D. (1984). The impact of study abroad on personal development of college students. Paper presented at the Convention of the American Educational Research Association, New Orleans.

Koniordos, S. M. (2008). Social capital contested. International Review of Sociology, 18(2), 317-337.

Kozol, J. (1992). Savage inequalities: Children in America's schools (1st Harper Perennial ed.). New York: HarperPerennial.

Kuh, G. (2008). Why integration and engagement are essential to effective educational practice in the twenty-first century. Peer Review, 10(4), 27.

Ladson-Billings, G., \& Donner, J. (2005). The moral activist role of critical race theory scholarship. In N. K. Denzin \& Y. S. Lincoln (Eds.), The SAGE Handbook of Qualitative Research (3 ed.). Thousand Oaks, CA: Sage Publications, Inc.

Ladson-Billings, G., \& Tate, W. F. (1995). Toward a critical race theory of education. Teachers College Record, 97(1), 47.

Landau, J., \& Moore, D. C. (2001). Towards reconciliation in the motherland: Race, class, nationality, gender, and the complexities of American student presence at the University of Ghana, Legon. Frontiers: The Interdisciplinary Journal of Study Abroad(7), 25-59. 
Le, E. (2008). Study abroad advising for Asian American students. Los Angeles: Project for Learning Abroad, Training, and Outreach.

Lee, S. J. (1996). Asian Americans: The absent minority, the silenced minority, and the model minority Unraveling the "model minority" stereotype: Listening to Asian American youth (pp. 1-17). New York: Teachers College Press.

LeMay Burr, P. (2005). Building study abroad acceptance among Hispanic students: The value of talking to the hispanic family. IIE Networker(Fall), 36-38.

Lew, J. (2007). A structural analysis of success and failure of Asian Americans: A case of Korean Americans in urban schools. Teachers College Record, 109(2), 369390.

Lewin, R. (2009). The handbook of practice and research in study abroad: Higher education and the quest for global citizenship. New York, NY: Routledge; Association of American Colleges and Universities.

Lewis, S. (2008). Study abroad advising for African-American students. Los Angeles: Project for Learning Abroad, Training, and Outreach.

Males, L., Otten, S., \& Herbel-Eisenmann, B. (2010). Challenges of critical colleagueship: Examining and reflecting on mathematics teacher study group interactions. Journal of Mathematics Teacher Education, 13(6), 459-471.

Martinez, M. D., Ranjeet, B., \& Marx, H. (2009). Creating study abroad opportunities for first-generation college students. In R. Lewin (Ed.), The handbook of practice and research in study abroad: Higher education and the quest for global citizenship (pp. 527-542). New York: Routledge.

McClure, K. R., Szelenyi, K., Niehaus, E., Anderson, A. A., \& Reed, J. (2010). "We just don't have the possibility yet": U.S. Latina/o narratives on study abroad. Journal of Student Affairs Research and Practice, 47(3), 367-386.

Moje, E. B., Ciechanowski, K. M., Kramer, K., Ellis, L., Carrillo, R., \& Collazo, T. (2004). Working toward third space in content area literacy: An examination of everyday funds of knowledge and Discourse. Reading Research Quarterly, 39(1), 38-70.

Moll, L. C., \& Diaz, S. (1987). Change as the goal of educational research. Anthropology \& Education Quarterly, 18(4), 300-311.

Moll, L. C., \& et al. (1992). Funds of knowledge for teaching: Using a qualitative approach to connect homes and classrooms. Theory into Practice, 31(1), 132141.

Moran, C. D. (2003). Conceptualizing Identity Development: Unmasking the Assumptions within Inventories Measuring Identity Development. NASPA Journal (National Association of Student Personnel Administrators, Inc.), 40(3), 43-55. 
Morgan, R. M., Mwegelo, D. T., \& Turner, L. N. (2002). Black women in the African diaspora seeking their cultural heritage through studying abroad. NASPA Journal, 39(4), 333-353.

Murray Brux, J., \& Fry, B. (2009). Multicultural students in study abroad: Their interests, their issues, and their constraints. Journal of Studies in International Education, 1-20.

Murray Brux, J., \& Fry, B. (2010). Multicultural students in study abroad: Their interests, their issues, and their constraints. Journal of Studies in International Education, 14(5), 508-527.

National Center for Education Statistics. (2004). Digest of Education Statistics, 2003. NCES 2004-025. Retrieved from http://nces.ed.gov/pubsearch/pubsinfo.asp?pubid=2005025

National Center for Education Statistics. (2009). Digest of Education Statistics, 2008. NCES 2009-020. Retrieved from http://nces.ed.gov/Pubsearch/pubsinfo.asp?pubid $=2009020$

National Center for Education Statistics. (2010). Digest of Education Statistics, 2010. NCES 2010-020. Retrieved from http://nces.ed.gov/programs/digest/d09/

Norton, I. (2008a). Changing the face of study abroad. Chronicle of Higher Education, 55(5), B12-B15.

Norton, I. (2008b). How 5 colleges are diversifying study abroad. Chronicle of Higher Education, 55(5), B16-B17.

Obst, D., Bhandari, R., \& Witherell, S. (2007). Meeting America's global education challenge: Current trends in U.S. study abroad and the impact of strategic diversity initiatives. New York: Institute of International Education.

Orfield, G., Lee, C., \& Harvard Civil Rights Project, C. M. A. (2005). Why segregation matters: Poverty and educational inequality: Civil Rights Project at Harvard University (The).

Pandit, K. (2009). Geographers and the work of internationalization. Journal of Geography, 108(3), 91-91.

Phinney, J. S. (1992). The multigroup ethnic identity measure: A new scale for use with diverse groups. Journal of Adolescent Research, 7(2), 156-176.

Phinney, J. S., \& Ong, A. D. (2007). Conceptualization and measurement of ethnic identity: Current status and future directions. Journal of Counseling Psychology, 54(3), 271-281.

Picard, E., Bernardino, F., \& Ehigator, K. (2009). Golbal citizenship for all: Low minority participation in study abroad - Seeking strategies for sucess. In R. Lewin (Ed.), The handbook of practice and research in study abroad: Higher education and the quest for global citizenship (pp. 321-345). New York: Routledge. 
Raby, R. L. (2008). Meeting America's global education challenge: Expanding education abroad at U.S. community colleges. New York: Institute of International Education.

Reilly, D., \& Senders, S. (2009). Becoming the change we want to see: Critical study abroad for a tumultuous world. Frontiers: The Interdisciplinary Journal of Study Abroad, 18, 241-267.

Richardson, L., \& St. Pierre, E. A. (2008). Writing: A method of inquiry. In N. K. Denzin \& Y. S. Lincoln (Eds.), Collecting and interpreting qualitative materials (3 ed., pp. 473-499). Los Angeles: Sage Publications.

Rumbaut, R. G. (2005). Sites of belonging: Acculturation, discrimination, and ethnic identity among children of immigrants Discovering successful pathways in children's development: Mixed methods in the study of childhood and family life (pp. 111-163). Chicago: University of Chicago Press.

Salisbury, M., Paulsen, M., \& Pascarella, E. (2010). To see the world or stay at home: Applying an integrated student choice model to explore the gender gap in the intent to study abroad. Research in Higher Education, 51(7), 615-640.

Salisbury, M., Paulsen, M., \& Pascarella, E. (2011). Why do all the study abroad students look alike? Applying an integrated student choice model to explore differences in the factors that influence White and minority students' intent to study abroad. Research in Higher Education, 52(2), 123-150.

Salisbury, M., Umbach, P., Paulsen, M., \& Pascarella, E. (2009). Going global: Understanding the choice process of the intent to study abroad. Research in Higher Education, 50(2), 119-143.

San Francisco State University. (2010). Fall 2010 undergraduate student profile. Retrieved March 2, 2010, from http://www.sfsu.edu/ ubp/pdfs/student/campprof10.pdf

Schachter, E. P. (2005). Context and identity formation: A theoretical analysis and a case study. Journal of Adolescent Research, 20(3), 375-395.

Schroeder, K., Wood, C., Galiardi, S., \& Koehn, J. (2009). First, do no harm: Ideas for mitigating negative community impacts of short-term study abroad. The Journal of Geography, 108(3), 141.

Solorzano, D. G., \& Yosso, T. J. (2001). Critical race and LatCrit theory and method: Counter-storytelling. International Journal of Qualitative Studies in Education (QSE), 14(4), 471-495.

Souders, B. (2009). Now that I'm home, who am I? National identity negotiation among U.S. study abroad students. Unpublished doctoral dissertation, University of Maryland, Baltimore County, United States, Maryland.

Stallman, E. (2009). Intercultural competence and racial awareness in study abroad. Unpublished doctoral dissertation, University of Minnesota, Minneapolis, MN. 
Stanton-Salazar, R. D. (1997). A social capital framework for understanding the socialization of racial minority children and. Harvard Educational Review, 67(1), 1 .

Stanton-Salazar, R. D., \& Dornbusch, S. M. (1995). Social capital and the reproduction of inequality: Information networks among Mexican-origin high school students. Sociology of Education, 68(2), 116-135.

Steinberg, M. (2007). The place of outcomes assessment in higher education today and the implications for education abroad. In M. Bolen (Ed.), A guide to outcomes assessment in education abroad (pp. 7-22). Carlisle, PA: The Forum on Education Abroad.

Stewart, D. W., \& Shamdasani, P. N. (1990). Focus groups: Theory and Practice. Newbury Park, CA: Sage.

Stroud, A. H. (2010). Who plans (not) to study abroad? An examination of U.S. student intent. Journal of Studies in International Education, 14(5), 491-507.

Sutton, R. C., Miller, A. N., \& Rubin, D. L. (2007). Research design in assessing learning outcomes of education abroad programs. In M. Bolen (Ed.), A guide to outcomes assessment in education abroad (pp. 23-59). Carlisle, PA: The Forum on Education Abroad.

Talburt, S., \& Stewart, M. A. (1999). What's the subject of study abroad?: Race, gender, and "living culture". The Modern Language Journal, 83(2), 163-175.

Tarrant, M. A. (2010). A conceptual framework for exploring the role of studies abroad in nurturing global citizenship. Journal of Studies in International Education, 14(5), 433-451.

Tatum, B. D. (1992). Talking about race, learning about racism: The application of racial identity development theory in the classroom. Harvard Educational Review, 62(1), 1.

Tatum, B. D. (1997). "Why are all the Black kids sitting together in the cafeteria?" and other conversations about race (1st ed.). New York: BasicBooks.

Tillman, M. (2010). Diversity in international education hands-on workshop: Summary Report. Washington, D.C.: American Institute for Foreign Study.

Torres, V., Jones, S. R., \& Renn, K. A. (2009). Identity development theories in student affairs: Origins, current status, and new approaches. Journal of College Student Development, 50(6), 577-596.

Van der Meid. (2003). Asian Americans: Factors influencing the decision to study abroad. Frontiers: The Interdisciplinary Journal of Study Abroad, 32(3), 71 110.

Van der Meid, J. S. (2003). Asian Americans: Factors influencing the decision to study abroad. Frontiers: The Interdisciplinary Journal of Study Abroad, 9, 71-110.

Vande Berg, M. (2004). Introduction. Frontiers: The Interdisciplinary Journal of Study Abroad, $X($ Fall), xii-xxii. 
Veeck, G., \& Biles, J. J. (2009). Geography, geographers, and study abroad. Journal of Geography, 108(3), 92-93.

Weaver, H. D. (1989). Research on U.S. Students abroad: A bibliography with abstracts: Council on International Educational Exchange, New York NY, California Univ, Santa Barbara, National Association for Foreign Student Affairs, Washington DC, Institute of International Education, New York NY.

Wick, D. (2009). Social capital and ethnic identity in study abroad. Unpublished manuscript, San Francisco State University.

Wick, D., Jackson, M. J., \& Flores, M. (2009, October). Study abroad and the process of identity: Sharing student voices. Paper presented at the Ethnic Studies: 40 Years Later Race, Resistance, Relevance.

Yosso, T. J. (2005). Whose culture has capital? A critical race theory discussion of community cultural wealth. Race Ethnicity and Education, 8(1), 69-91.

Young, D. (2008). Persistence at a liberal arts university and participation in a studyabroad program. Frontiers: The Interdisciplinary Journal of Study Abroad, XV, 93-110.

Young, J. (2009). Antevasin: The impact of globalization on self identity. Unpublished doctoral dissertation, Alliant International University, San Diego, CA. 
APPENDIX A: Participant Demographics with Study Locations

\begin{tabular}{|c|c|c|c|c|c|c|c|c|c|}
\hline 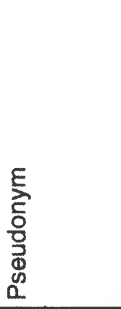 & 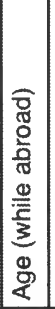 & 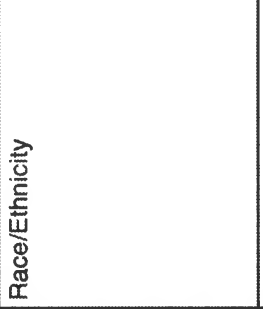 & 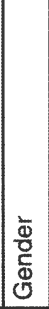 & 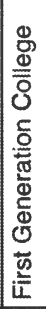 & 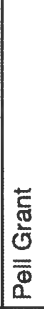 & 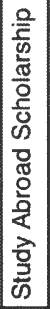 & $\begin{array}{l}\frac{2}{5} \\
\text { D } \\
\text { ठ }\end{array}$ & 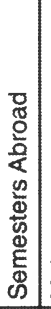 & $\frac{\frac{1}{0}}{\frac{0}{2}}$ \\
\hline Ace & 31 & Chinese American & $F$ & $Y$ & $Y$ & $Y$ & Hong Kong & 11 & Marketing \\
\hline $\mathrm{Al}$ & 23 & Chinese American & $M$ & $\mathrm{Y}$ & $Y$ & $\mathrm{~N}$ & Japan & 2. & Japanese, Finance \\
\hline Andrea & 20 & Sri Lankan American & $F$ & $Y$ & $\mathrm{~N}$ & $\mathrm{~N}$ & Denmark & 11 & International Business \\
\hline Ant & 26 & Chinese American & $\mathrm{M}$ & $\mathrm{Y}$ & $\mathrm{N}$ & $\mathrm{N}$ & France & 21 & French, International Business \\
\hline Ben & 22 & Chinese American & $\mathrm{M}$ & $\mathrm{N}$ & $Y$ & $Y$ & Korea & 2 & Civil Engineering \\
\hline Carl & 22 & Chinese American & $M$ & $\mathrm{Y}$ & $\mathrm{Y}$ & $Y$ & China & 4. & Cinema \\
\hline Carrie & 21 & Chinese American & $\mathrm{F}$ & $\mathrm{Y}$ & $N$ & $Y$ & Korea & 31 & Biology, Chemistry \\
\hline Cass & 22 & Mexican American & $\mathrm{F}$ & $\mathrm{Y}$ & $N$ & $\mathbf{Y}$ & Japan & 2. & Japanese, Psychology \\
\hline Christine & 22 & Vietnamese American & $F$ & $Y$ & $Y$ & $\mathrm{~N}$ & France & 21 & Liberal Studies \\
\hline Cindy & 19 & African American & $F$ & $\mathrm{~N}$ & $Y$ & $\mathrm{~N}$ & South Africa & 2 & Child Adolescent Development \\
\hline Ed & 22 & Chinese American & $M$ & $Y$ & $Y$ & $\mathrm{~N}$ & Netherlands & $2 \mid$ & Management \\
\hline Eli & 20 & Latino & $F$ & $Y$ & $Y$ & $\mathrm{~N}$ & Italy & 2 & Criminal Justice, History, Microbiology \\
\hline Fabio & 19 & Mexican American & $M$ & $Y$ & $\mathrm{~N}$ & $\mathrm{~N}$ & France & 2 & French, European Studies \\
\hline Farryn & 26 & African American & $F$ & $Y$ & $\mathrm{~N}$ & $\mathrm{~N}$ & Sweden & 2 & Liberal Studies \\
\hline Frank & 21 & Chinese American & $\mathrm{M}$ & $\mathrm{Y}$ & $\mathrm{N}$ & $\mathrm{N}$ & Hong Kong & 1 & Marketing \\
\hline Gabriela & 22 & Mexican American & $F$ & $\mathrm{Y}$ & $Y$ & $\mathrm{~N}$ & Sweden & 2 & Communication Studies, Broadcast \\
\hline Hady & 25 & Iranian American & $M$ & $\mathrm{~N}$ & $Y$ & $\mathrm{Y}$ & Hong Kong & 1 & Environmental Science \\
\hline Indigo & 22 & African American & $F$ & $Y$ & $Y$ & $\mathrm{Y}$ & Ghana & 2 & Africana Studies \\
\hline Jackie & 21 & African American & $\mathrm{F}$ & $\mathrm{Y}$ & $Y$ & $\mathrm{Y}$ & Italy & 2 & Studio Art \\
\hline Jan & 22 & Mexican American & $F$ & $\mathbf{N}$ & $\mathrm{N}$ & $\mathrm{N}$ & Spain & 2 & Spanish, Communication Studies \\
\hline Jason & 23 & Chinese American & $M$ & $\mathrm{Y}$ & $Y$ & $\mathrm{~N}$ & France & 1 & MBA \\
\hline Jessee & 22 & Asian American & $M$ & $N$ & $\mathrm{~N}$ & $\mathrm{~N}$ & Australia & 1 & Communication Studies, Sociology \\
\hline $\mathrm{Jim}$ & 22 & Korean American & $M$ & $\mathrm{~N}$ & $\mathrm{~N}$ & $\mathrm{Y}$ & Korea & 1 & American Studies \\
\hline JJ & 37 & Latino & $M$ & $Y$ & $Y$ & $\mathrm{Y}$ & Denmark & 1 & International Relations \\
\hline John & 24 & Chinese American & $M$ & $Y$ & $\mathrm{~N}$ & $\mathrm{Y}$ & Netherlands & 1 & Accounting \\
\hline Joseph & 28 & Cuban American & $M$ & $N$ & $\mathrm{~N}$ & $\mathrm{~N}$ & Denmark & 1 & Philosophy \\
\hline Karina & 19 & Chinese American & $F$ & $N$ & $\mathrm{~N}$ & $\mathrm{~N}$ & Hong Kong & 3 & International Business \\
\hline Kort & 23 & Vietnamese American & $M$ & $N$ & $\mathrm{~N}$ & $\mathbf{N}$ & Denmark & 1. & Journalism \\
\hline Margaret & 21 & Mexican American & $\mathrm{F}$ & $N$ & $N$ & $\mathrm{~N}$ & Mexico & 2 & Health Ed., Spanish, Holistic Health \\
\hline Mary & 24 & Egyptian American & $F$ & $Y$ & $N$ & $\mathrm{Y}$ & Netherlands & 1 & Marketing, International Business \\
\hline Mary J & 21 & African American & $F$ & $\mathrm{Y}$ & $Y$ & $Y$ & Korea & 2 & International Business \\
\hline Mia & 26 & Mexican American & $F$ & $Y$ & $N$ & $\mathrm{~N}$ & Spain & 2 & Spanish \\
\hline Morgan & 20 & Mexican American & $F$ & $\mathrm{~N}$ & $\mathrm{~N}$ & $\mathrm{~N}$ & Spain & 2 & Spanish, Journalism \\
\hline Paula & 35 & Mexican American & $F$ & $Y$ & $N$ & $\mathrm{~N}$ & Spain & 2 & Art History \\
\hline Phuong & 22 & Vietnamese American & $F$ & $Y$ & $Y$ & $Y$ & Taiwan & 2 & Health Education \\
\hline Ravi & 25 & South Asian Indian & $M$ & $N$ & $N$ & $\mathrm{~N}$ & France & 1 & MBA \\
\hline Rod & 23 & Bolivian American & $M$ & $N$ & $N$ & $Y$ & Japan & 2 & Japanese \\
\hline Rusty & 38 & African American & $M$ & $Y$ & $Y$ & $\mathrm{~N}$ & Australia & 4 & Industrial Design \\
\hline Rusty W & 20 & Philipino American & $\mathrm{F}$ & $\mathrm{N}$ & $Y$ & $\mathrm{~N}$ & France & 2 & Drama \\
\hline Sam & 21 & Latino & $F$ & $\mathrm{~N}$ & $N$ & $\mathrm{~N}$ & Australia & 1 & Sociology \\
\hline Sam & 20 & Chinese American & $M$ & $Y$ & $Y$ & $\mathrm{~N}$ & Hong Kong & 2 & Management \\
\hline Sara & 20 & Latino & $F$ & $\mathrm{Y}$ & $Y$ & $\mathrm{~N}$ & UK & 2 & Psychology \\
\hline Tim & 21 & Vietnamese American & $M$ & $Y$ & $Y$ & $Y$ & Hong Kong & 2 & Finance \\
\hline Unicorn & 20 & African American & $F$ & $Y$ & $\mathrm{~N}$ & $Y$ & South Africa & 2 & Sociology \\
\hline Winnie & 20 & Chinese American & $F$ & $Y$ & $\mathrm{~N}$ & $\mathrm{~N}$ & Hong Kong & 1 & Administration, Marketing \\
\hline Xisha & 21 & Chinese American & $\mathrm{F}$ & $\mathrm{N}$ & $\mathrm{N}$ & $N$ & Netherlands & 2 & Marketing, Decision Science \\
\hline Zakjes & 22 & Surinamese American & $M$ & $\mathrm{~N}$ & $\mathrm{~N}$ & $\mathrm{Y}$ & Netherlands & 1 & Administration \\
\hline
\end{tabular}




\section{APPENDIX B: Interview Question Bank}

1. When and where did you study abroad?

2. How long have you been back in the U.S.?

3. What issues have come up since you came home?

4. How do you feel you have changed since you returned to the U.S.?

5. What impact did your study abroad experience have on your relationships with friends or family?

6. Who has been most interested in hearing about your experiences?

7. What have they wanted to know?

8. Thinking back, what made you decide to study abroad?

9. What challenges did you face as you considered study abroad? (financial, academic, family, social...)

10 . What helped you overcome these challenges?

11. What were your expectations about study abroad?

12. How did your experience meet your expectations?

13. What are some of your best memories from study abroad?

14. What challenges did you face while studying abroad?

15 . What did you learn about your host country and region?

16. What did you discover about yourself?

17. How did study abroad influence your views on other people, countries, or cultures?

18. How has study abroad affected you academically?

19. What influence has study abroad had on your future plans?

20. How has your study abroad experience shaped how you see yourself?

21 . What role did your American identity play in your study abroad experience?

22 . What role did ethnicity play in your study abroad experience?

23. How have you experienced adjusting back to life in the U.S.?

24 . Would you recommend study abroad? Why? Why Not?

25. So that we can hear all of your ideas please take a few minutes to write some ideas for us about how to address the following question:

a. Do you think that efforts should be made to help more students of color, low-income students, students who struggle academically, first generation college students, and students with disabilities study abroad? If you answer 'yes' then what should be done? What suggestions do you have for reaching out to underrepresented students?

26. What else would you like to add to my topic that I have not asked?

27. Do you have any questions for me? 


\section{APPENDIX C: Focus Group Question Bank}

1. Please introduce yourself and share your major and your study abroad location, year, and duration.

2. What made you decide to study abroad? How did you select your location?

3. What challenges did you face as you considered study abroad? (financial, academic, family, social...)

4. What helped you overcome these challenges?

5. Before you left, what were your expectations about study abroad?

6. When you first arrived abroad, how well did your experience abroad meet your expectations?

7. What are some of your best memories from study abroad?

8. What challenges did you face while studying abroad?

9. How did study abroad influence your views on other people, countries, or cultures?

a. How have your experiences from abroad impacted your life since you returned to the U.S.?

10. What role did your American identity play in your study abroad experience?

11 . What role did race and/or ethnicity play in your study abroad experience?

a. What impact did race and/or ethnicity have on where you decided to study?

12. How have you experienced adjusting back to life in the U.S.?

a. How have family and friends responded to your stories from study abroad?

b. How have professors or other students responded?

c. How have employers or co-workers responded?

13. What influence has study abroad had on your future plans?

14 . Would you recommend study abroad? Why? Why Not?

15. As preparation for the last two questions I would like for you to take a few minutes to consider and write some ideas about the main questions in my research. This will give each of you a chance to focus your thoughts before we discuss as a group.

a. How did your study abroad experience shape how you see yourself in the U.S.? (As related to race/ethnicity, age, gender, or characteristics?)

b. What impact did your study abroad experience have on your goals?

16. What would you like to share from what you wrote?

17. What else would you like to add to my topic that I have not asked?

18. Do you have any questions for me/us? 


\title{
APPENDIX D: Interview Consent Form (Page 1)
}

\author{
San Francisco State University \\ Informed Consent to Participate in a Research Study \\ Interviews for a Study on Identity Negotiation through Study Abroad
}

\begin{abstract}
A. PURPOSE AND BACKGROUND
The purpose of this research study is to learn more about the experiences that San Francisco State University (SF State) students have on study abroad programs. The researcher is specifically considering the experiences of students from diverse backgrounds.
\end{abstract}

The researcher, David Wick, is a doctoral candidate at SF State conducting research for his dissertation.

You are being asked to participate in this study because you participated in a semester or yearlong SF State study abroad program, are a student of color, and help to represent the breadth of the programs and students who participate in these programs.

\section{B. PROCEDURES}

If you agree to participate in this research study, the following will occur:

- You will be interviewed for approximately sixty minutes one to two times.

- The interviews will be digitally recorded to ensure accuracy.

- The interview will take place in the researcher's office at a time convenient for you or at a time and location convenient to you.

- The researcher may contact you later to clarify your interview answers for approximately fifteen minutes.

- You will allow the researcher to review the Statement of Purpose from your study abroad application.

- The total time commitment will be no more than 3 hours (includes reading the consent form).

\section{RISKS}

There is a risk of loss of privacy. However, no names or identities will be used in any published reports of the research. Only the researcher will have access to the research data. There is some chance that insiders could infer the identity of participants since the name of the university (SFSU) may be used if the study is published. Any names or identifying information of individual participants will be changed or omitted in the study.

There is a slight risk of discomfort or anxiety due to the nature of the questions asked; however, the participant can answer only those questions he/she chooses to answer, and can stop participation in the research at any time.

\section{CONFIDENTIALITY}

The research data will be kept in a secure location and/or password protected program, and only the researcher will have access to the data. All identifying information will be removed and the data will be kept in a locked cabinet or office. All data will be stored for one year following the completion of the study then destroyed.

\section{E. DIRECT BENEFITS}

There will be no direct benefits to the participant.

\section{F. Costs}

There will be no cost to you for participating in this research. 


\section{APPENDIX D: Interview Consent Form (Page 2)}

Research Title: Interviews for a Study on Identity Negotiation through Study Abroad Researcher's Name: David Wick, Ed.D. Candidate, SFSU

\section{G. COMPENSATION}

There will be no compensation for participating in this research.

\section{H. ALTERNATIVES}

The alternative is not to participate in the research.

\section{OUESTIONS}

You have spoken with David Wick about this study and have had your questions answered. If you have any further questions about the study, you may contact the researcher by email at dwick@sfsu.edu and 415-269-2758 or you may contact the researcher's advisor, Professor Barbara Henderson at barbarah@asfsu.edu or 415-338-1319.

Questions about your rights as a study participant, or comments or complaints about the study, may also be addressed to the Office for the Protection of Human Subjects at 415: 338 1093 or protocol@sfsu.edu.

\section{J. CONSENT}

You have been given a copy of this consent form to keep.

PARTICIPATION IN THIS RESEARCH IS VOLUNTARY. You are free to decline to participate in this research study, or to withdraw your participation at any point, without penalty. Your decision whether or not to participate in this research study will have no influence on your present or future status at San Francisco State University.

Signature Research Participant
Date:

Signature

Researcher
Date:

(Page 2 of 2) 


\title{
APPENDIX E: Focus Group Consent Form (Page 1)
}

\author{
San Francisco State University \\ Informed Consent to Participate in a Research Study
}

Focus Groups for a Study on Identity Negotiation through Study Abroad

\section{A. PURPOSE AND BACKGROUND}

The purpose of this research study is to learn more about the experiences that San Francisco State University (SF State) students have on study abroad programs. The researcher is specifically considering the experiences of students from diverse backgrounds.

The researcher, David Wick, is a doctoral candidate at SF State conducting research for his dissertation.

You are being asked to participate in this study because you participated in a semester or yearlong SF State study abroad program, are a student of color, and help to represent the breadth of the programs and students who participate in these programs.

\section{B. PROCEDURES}

If you agree to participate in this research study, the following will occur:

- You will be asked to complete a confidential demographics questionnaire when you arrive at the focus group. The estimated time for completing the questionnaire is 5 minutes.

- You will spend approximately 90 minutes in the focus group.

- The focus group will be digitally recorded to ensure accuracy.

- The focus group will take place at SF State in the Office of International Programs.

- The researcher may contact you later by e-mail to clarify your focus group comments.

- You will allow the researcher to review the Statement of Purpose from your study abroad application.

- The total time commitment will be no more than 2 hours (includes reading the consent form and completing the questionnaire).

\section{RISKS}

There is a risk of loss of privacy. However, no names or identities will be used in any published reports of the research. Only the researcher will have access to the research data. There is some chance that insiders could infer the identity of participants since the name of the university (SFSU) may be used if the study is published. Any names or identifying information of individual participants will be changed or omitted in the study.

Also, because the focus groups include discussion of personal opinions, extra measures will be taken to protect each participant's privacy. The researcher will begin the focus group by asking the participants to agree to the importance of keeping information discussed in the focus group confidential. He will then ask each participant to verbally agree to keep everything discussed in the room confidential, and will remind them at the end of the group not to discuss the material outside.

There is a slight risk of discomfort or anxiety due to the nature of the questions asked; however, the participant can answer only those questions he/she chooses to answer, and can stop participation in the research at any time.

\section{CONFIDENTIALITY}

The research data will be kept in a secure location and/or password protected program, and only the researcher will have access to the data. All identifying information will be removed and the data will be kept in a locked cabinet or office. All data will be stored for one year following the completion of the study then destroyed. 
APPENDIX E: Focus Group Consent Form (Page 2)

Research Title: Focus Groups for a Study on Identity Negotiation through Study Abroad Researcher's Name: David Wick, Ed.D. Candidate, San Francisco State University

\section{E. DIRECT BENEFITS}

There will be no direct benefits to the participant.

\section{F. COSTS}

There will be no cost to you for participating in this research.

\section{G. COMPENSATION}

There will be no compensation for participating in this research.

\section{H. ALTERNATIVES}

The alternative is not to participate in the research.

\section{OUESTIONS}

You have spoken with David Wick about this study and have had your questions answered. If you have any further questions about the study, you may contact the researcher by email at dwick@a sfsu.edu and 415-269-2758 or you may contact the researcher's advisor, Professor Barbara Henderson at barbarahasfou.edu or 415-338-1319.

Questions about your rights as a study participant, or comments or complaints about the study, may also be addressed to the Office for the Protection of Human Subjects at 415:338-1093 or protocolosfsu.edu.

\section{J. GROUP CONFIDENTIALITY}

This form is intended to protect the confidentiality of what members of this discussion group say during the course of this study, Focus Groups for a Study on Identity Negotiation through Study Abroad. Please read the following statement. When you sign your name at the bottom of this page you are indicating that you agree to comply.

I promise that I will not communicate or talk about information discussed during the course of these focus groups with anyone outside of $m y$ fellow focus group members and the facilitators.

\section{K. CONSENT}

You have been given a copy of this consent form to keep.

PARTICIPATION IN THIS RESEARCH IS VOLUNTARY. You are free to decline to participate in this research study, or to withdraw your participation at any point, without penalty. Your decision whether or not to participate in this research study will have no influence on your present or future status at San Francisco State University.

Signature Research Participant

Date:

Signature Researcher

Date: 
APPENDIX F: Demographic Questionnaire

STUDY ABROAD OUTCOMES DEMOGRAPHIC SURVEY

OATA FROM ALL PARTYCIPATING STUDENTS ARE AGGREGATED FOR COMPARATIVE STUDIES GY VARIOUS CHARACTERISTICS. YOU MAY SKIP ANY QUESTION YOU DO NOT WISH TO ANSWER.

\section{Study ABRoAd Location(s)}

INSTITUTION

COUNTRY

2. STUDY AEROAD TERM(S)

FALL, SPRING,

OR YEAR

YEAR

3. EDUCATIONAL DETAILS

\begin{tabular}{|c|c|c|c|}
\hline MAJOR & & $\begin{array}{l}\text { SECOND MANOR } \\
\text { ANDOOR MINORS }\end{array}$ & \\
\hline $\begin{array}{l}\text { CLASS STATUS } \\
\text { WHILE ON } \\
\text { STUDY AEROAD }\end{array}$ & $\begin{array}{l}\text { SOPHOMORE } \\
\text { JUNIOR } \\
\text { SENIOR }\end{array}$ & GPA (ESTIMATE) & \\
\hline $\begin{array}{l}\text { ACADEMIC GOAL } \\
\text { SOR STUDY } \\
\text { AGROAD }\end{array}$ & $\begin{array}{l}\text { MAJOR } \\
\text { MINOR }\end{array}$ & $\begin{array}{l}\text { GENERAL ED } \\
\text { ENRICHMENT }\end{array}$ & OTHER \\
\hline
\end{tabular}

4. STUDENT CHARACTERISTICS

\begin{tabular}{l}
\hline GENDER \\
BIRTH YEAM \\
ETHNICITY/RACE \\
\hline LANGUAGE(S) \\
SPOKEN AT HOME \\
COUNTRY OF \\
BIRTH \\
\hline IF BORN OUTSIDE \\
US, AGE AT \\
ARRIYAL
\end{tabular}

\section{FINANCIAL BACKGROUND}

\begin{tabular}{|c|c|c|c|}
\hline FINANCIAL AID & $\begin{array}{l}\text { YES } \\
\text { No }\end{array}$ & EOP & $\begin{array}{l}\text { YES } \\
\text { No }\end{array}$ \\
\hline PELL GRANT & $\begin{array}{l}\text { YES } \\
\text { No } \\
\end{array}$ & PROJECT CONNECT & $\begin{array}{l}\text { YES } \\
\text { No }\end{array}$ \\
\hline $\begin{array}{l}\text { SCHOLARSHIPS } \\
\text { (REGULAR OR } \\
\text { STUDY ABROAD) }\end{array}$ & & TRIO/SSS & $\begin{array}{l}\text { YES } \\
\text { No }\end{array}$ \\
\hline
\end{tabular}

6. Parental Education level

MOTHER'S HIGHEST LEVEL OF

EDUCATION COMPLETED

O GramMar schoOL

High School or equivalent

8 VOCATIONAL/TECHNICAL SCHOOL (2

8 YeAR)

SOME COLLEGE

BACHELOR'S DEGREE

8 Master's Degree

DOCTORAL DEGRE

PRofessional deGREe (MD, JD, ETC.

DON'T KNOW
FATHER'S HIGHEST LEYEL OF

EDUCATION COMPLETED

G GRAMMAR SCHOOL

HIGH SCHOOL OR EquiValent

VOCATIONAL/TECHNICAL SCHOOL (2

$O$ YEAR)

BACHELOA'S DEGREE

8 MASTER'S DEGREE

DOCTORAL DEGREE

$\bigcirc$ PROFESSIONAL DEGREE (MD, JD, ETC.)

DON"T KNOW 